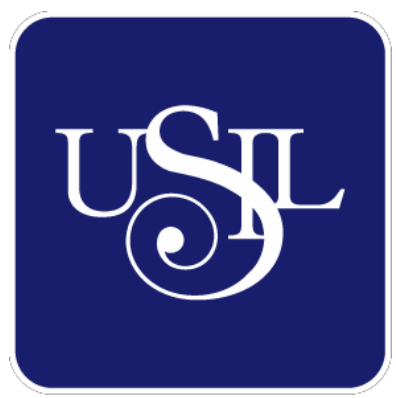

UNIVERSIDAD

SAN IGNACIO

DE LOYOLA

FACULTAD DE CIENCIAS EMPRESARIALES

Carrera de International Business

\title{
PARQUE AUTOMOTOR Y MEDIOS DE TRANSPORTE ALTERNATIVOS EN LIMA METROPOLITANA, 2010 AL 2018
}

Tesis para optar el Título Profesional de Licenciado en International Business

\author{
CLARITA BRENDA MARTINEZ ESQUÉN \\ (0000-0002-4736-1730)
}

Asesor:

Mag. Jesús Robles Lara

(0000-0003-3122-1335)

Lima - Perú

2020 


\section{Índice}

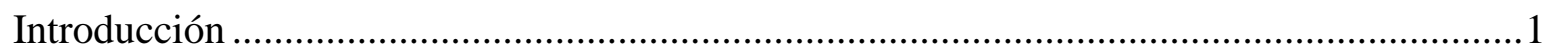

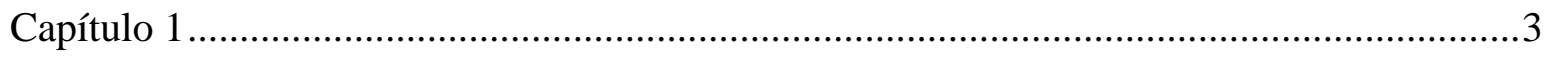

1.1. Problema de Investigación .............................................................................

1.1.1. Planteamiento del Problema..........................................................................

1.1.2. Formulación del Problema. ...........................................................................

1.1.3. Justificación de la Investigación. ..............................................................6

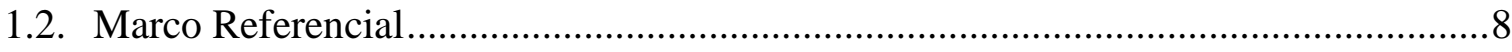

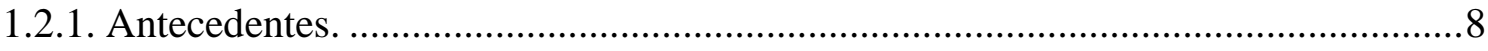

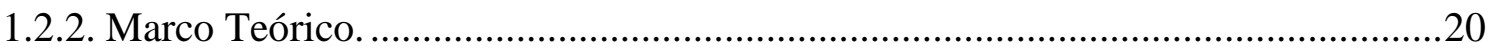

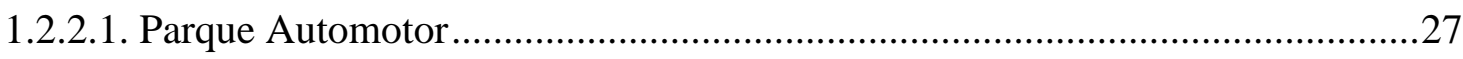

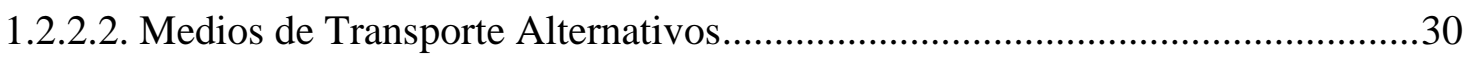

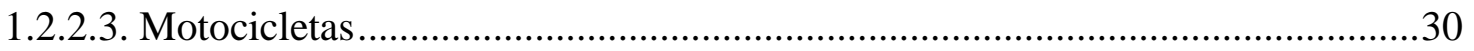

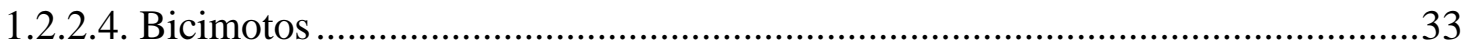

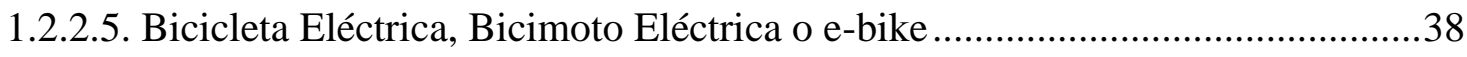

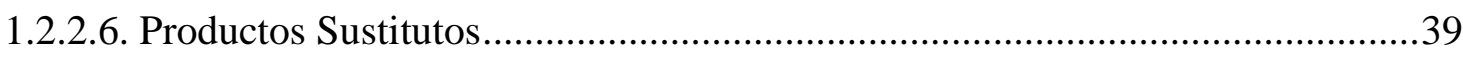

1.2.2.7. Elasticidad Ingreso de la Demanda...................................................41

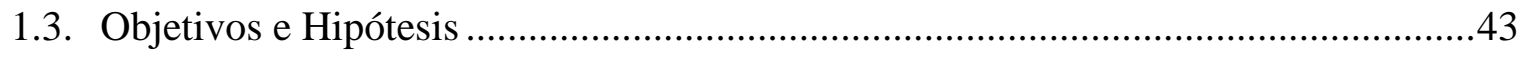

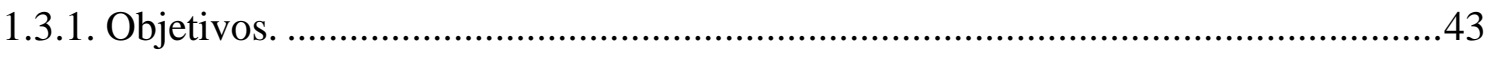

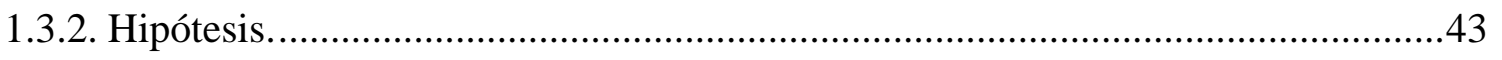


Capítulo 2

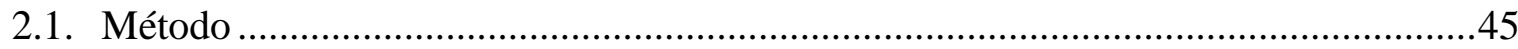

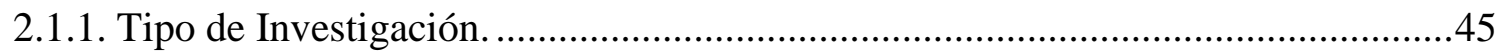

2.1.2. Diseño de Investigación. ..............................................................................45

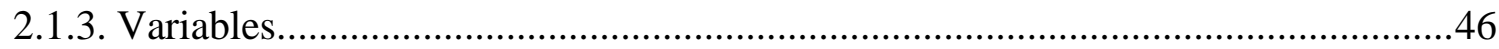

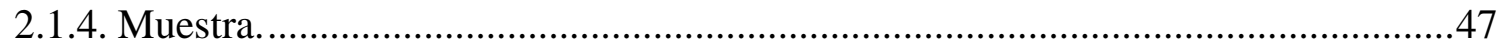

2.1.5. Instrumentos de Investigación.........................................................................49

2.1.6. Procedimientos de Recolección de Datos. .......................................................49

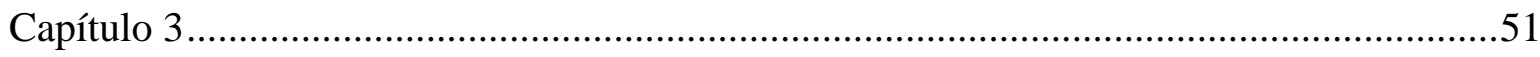

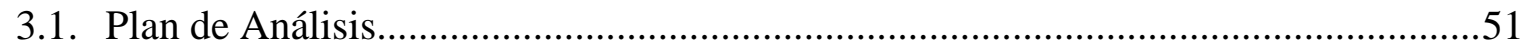

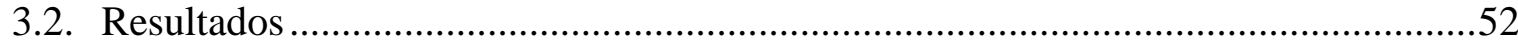

3.2.1. Presentación de Resultados. ............................................................................52

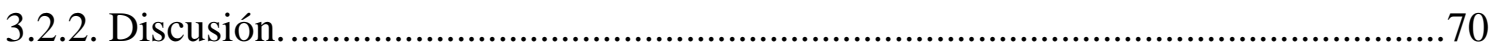

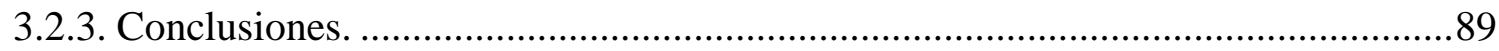

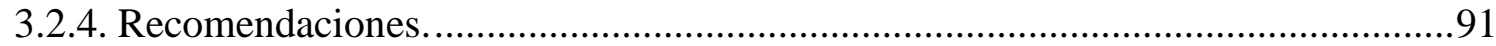

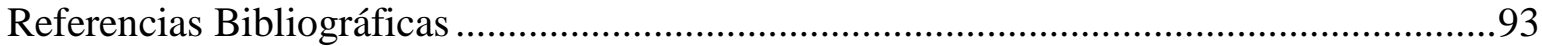

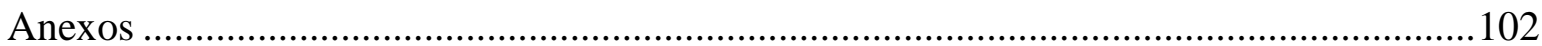




\section{Índice de Tablas}

Tabla 1. Elasticidad Ingreso de Automóviles en Perú .................................................................... 42

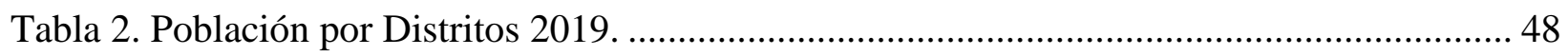

Tabla 3. Valoración de Atributos (En Porcentajes) ......................................................................... 57

Tabla 4. Insatisfacción hacía los Medios de Transporte Públicos ................................................ 59

Tabla 5. Importaciones por Tipo de Vehículo (En Miles de Unidades) ......................................... 71

Tabla 6. ¿Ha considerado sustituir su tipo de movilización actual a un medio de transporte

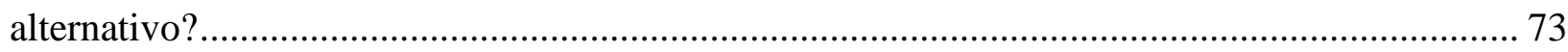

Tabla 7. ¿Qué factores lo incentivan a sustituir su medio de transporte por uno alternativo? ..... 74

Tabla 8. ¿Cuánto gasta en transporte mensualmente? Sea en transporte público, taxi o en su propio vehículo (combustible más otros gastos en su vehículo).................................................... 77

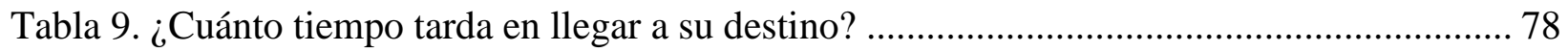

Tabla 10. Evolución de Ventas de Automóviles y Motocicletas (En Miles de Unidades) ............ 79

Tabla 11. Evolución del Uso de Tipo de Transporte (En Porcentajes)......................................... 80 Tabla 12. ¿Considera que alguno de los medios de transporte alternativo sería una solución para

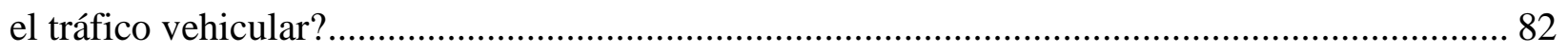

Tabla 13. ¿Considera a las regulaciones necesarias o innecesarias para la congestión vehicular?

Tabla 14. ¿Considera que las regulaciones van concordes o por encima de lo necesario de

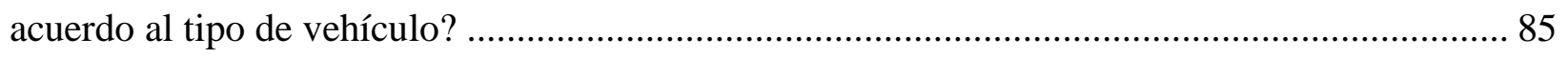

Tabla 15. Ventas de Automóviles vs. Importaciones de Vehículos Alternativos........................... 87 


\section{Índice de Figuras}

Figura 1. Evolución de los Medios de Transporte Alternativos (En Miles) .................................. 52

Figura 2. Evolución de las Importaciones de Bicimotos y Vehículos Eléctricos (En Miles)....... 53

Figura 3. Motivo de Movilización (En Porcentajes)................................................................... 54

Figura 4. Distribución de Motivos de Movilización (En Porcentajes) ............................................ 55

Figura 5. Frecuencia de Movilización (En Porcentajes) ………………………………............. 55

Figura 6. Tiempo de Recorrido (En Porcentajes) …………....................................................... 56

Figura 7. Niveles de Importancia de los Atributos de Transporte (En Porcentajes)...................... 58

Figura 8. Niveles de Insatisfacción de acuerdo a los Aspectos de Movilización (En Porcentajes)

Figura 9. Nivel de Satisfacción con el Transporte Público....................................................................... 60

Figura 10. Gasto Promedio Semanal en Transporte (En Porcentajes) ........................................... 61

Figura 11. Proporción de Conocimiento de los Medios de Transporte Alternativos en la

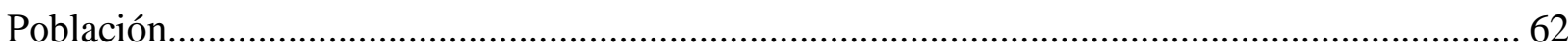

Figura 12. Proporción de la Consideración sobre Sustituir el Medio de Transporte Actual por un

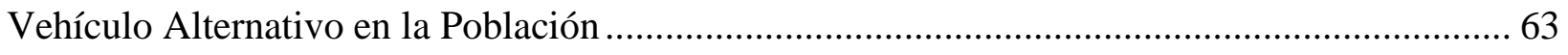

Figura 13. Incentivos para Sustituir El Medio de Transporte Actual por uno Alternativo (En

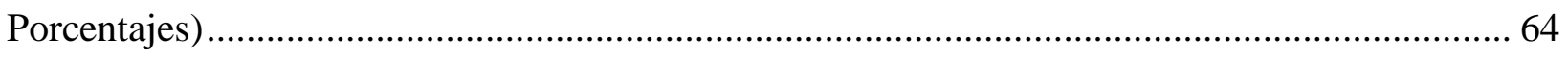

Figura 14. Detractores para la Sustitución de un Medio de Transporte Tradicional a un

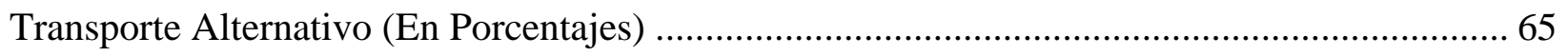

Figura 15. Niveles de Conformidad en Cuanto a la Propuesta de Medios de Transporte Alternativos como Sustitutos de los Medios Transporte Convencionales ...................................... 66 
Figura 16. Proporción de las Consideraciones de la Población sobre las Soluciones que El Estado Propone para los Problemas del Tráfico Vehicular (En Porcentajes) ....................................... 66

Figura 17. Proporción de la Conformidad con la Necesidad de las Nuevas Medidas Restrictivas

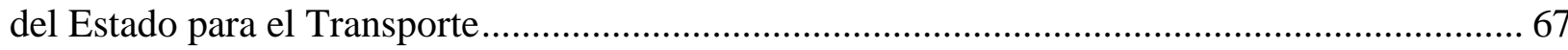

Figura 18. Proporción de la Consideración sobre el Nivel de Concordancia y Necesidades hacía las Nuevas Medidas Restrictivas del Estado para el Transporte........................................... 68

Figura 19. Opinión de los Encuestados en cuanto a las Restricciones Vehiculares .................... 69

Figura 20. Comportamiento de las Importaciones por Tipo de Vehículo (En Miles de Unidades)

Figura 21. Evolución de las Importaciones de Kits de Bicimotos......................................... 72

Figura 22. Uso de Tipos de Vehículos como Medios de Transporte (En Miles)........................ 80 


\section{Título}

Parque Automotor y Medios de Transporte Alternativos en Lima Metropolitana,

2010 al 2018 


\section{Dedicatoria}

Quiero dedicar este trabajo a mi padre, por hacerme saber que puedo lograr todo lo que me propongo. A mi abuela, por enseñarme fortaleza y a mi madre, por ser mi soporte. Les debo todo. 


\section{Agradecimiento}

Todo mi agradecimiento va a mis padres y abuela por siempre tratar de darme lo mejor y procurar mi bienestar. Valoro mucho cada cosa que me han dado y enseñado con mucho amor. Espero que este sea un logro más para que se sientan orgullosos. Todo lo que tengo, es gracias a ustedes. 


\section{Resumen}

El presente trabajo de investigación titulado "Parque Automotor y Medios de Transporte Alternativos en Lima Metropolitana, 2010 al 2018” es desarrollado con el objetivo de demostrar si existe una relación entre el parque automotor y la cantidad de vehículos alternativos en Lima. Hoy en día, como todos sabemos, el problema del tráfico es uno de los más importantes en el Perú, el cual lamentablemente sigue empeorando. La aparición y evolución de los diferentes medios alternativos de transporte como la motocicleta, bicimotos, scooters, bicicletas eléctricas y otros, ha hecho que comiencen a ser usados de manera masiva, ya no solo para trasladarse al trabajo, a los centros de estudios u otro sino también para realizar repartos o delivery. Es aquí, donde nos preguntamos si estos medios de transporte pueden sustituir al automóvil convencional y lograr disipar los problemas de la congestión vehicular en Lima. Se utilizarán investigaciones relacionadas directa e indirectamente al tema, así como modelos aplicados en otros continentes para validar el trabajo de investigación. Se desarrollará una investigación cuantitativa correlacional-causal de diseño no experimental-transversal, tomando como muestra a 308 personas dentro de tres distritos de Lima con mayor afluencia de estos vehículos alternativos. Se utilizará una encuesta para obtener datos aplicados a nuestra población. Una vez concluido el trabajo, se espera demostrar que existe una relación inversa entre el parque automotor y la cantidad de medios de transporte alternativos.

Palabras Clave: Parque Automotor, Vehículo Alternativo, Medio de Transporte Alternativo; Congestión Vehicular 


\section{Introducción}

Unas de las aspiraciones más grandes de los jóvenes conforme van entrando a la vida laboral e independizándose, es la adquisición de un vehículo propio; ya sea una motocicleta, un auto o camioneta. Sin embargo, el problema empieza cuando nos damos cuenta de la realidad del transporte peruano junto a sus grandes falencias; la congestión vehicular a causa del incremento del parque automotor, malas prácticas de conducción y vehículos muy antiguos nos hace perder mucho tiempo para movilizarnos de un lugar a otro, encareciendo los gastos de mantención de un vehículo y exponiéndonos en mayor medida a sufrir robos en los atascos vehiculares. Por esta razón, a parte de las motocicletas comenzaron a surgir diferentes alternativas de movilización, de poca inversión y que sean eficientes; como las bicimotos, scooters eléctricos, patines eléctricos, bicicletas con pedaleo asistido, entre otras. Las bicimotos son vehículos híbridos entre bicicletas y motos, debido a que cuentan con un motor mecánico o eléctrico. Bajo este esquema, las bicimotos mecánicas se han popularizado no solo en Perú, si no en muchos países de Latinoamérica y las bicicletas eléctricas ya se encuentran plenamente introducidas en países de Europa al igual que los scooters y patines eléctricos. Todos estos vehículos de dos ruedas pueden ser ensamblados en Perú; pero no pueden ser fabricados aquí, ya que no se cuenta con los equipos o materiales necesarios para la construcción de motores, por lo que, todos estos son importados desde China, USA o Europa aumentando las importaciones y manteniendo en movimiento la economía.

El principal objetivo de esta investigación es determinar el tipo de relación entre el parque automotor y los medios de transporte alternativos en Lima; incluyendo a la motocicleta, bicimotos y vehículos eléctricos varios, analizando su comportamiento desde el año 2010 hasta el 2018. En el capítulo uno de la investigación, se define de una manera más profunda la problemática del parque automotor incluyendo variables como la contaminación ambiental, congestión vehicular, 
seguridad y la antigüedad de vehículos, se explica por qué esto afecta al ciudadano peruano y como esta relación podría hacer mejorar nuestro sistema vial. Se desarrollan teorías y conceptos pertenecientes al tema para comprender de una manera más clara el contexto.

En el capítulo dos, se determina el método de esta investigación; siendo correlacional-causal entre variables, se define su diseño y desarrolla la disgregación de la muestra. Se menciona brevemente los instrumentos de investigación y cuáles fueron los procedimientos de recolección de datos en campo, detallado forma, lugar y comportamiento.

En el capítulo tres, se da a conocer los resultados de la investigación previa junto a un análisis y desarrollo de cada respuesta en detalle obtenidos por medio de los instrumentos de investigación; en este caso una encuesta. Además, se desarrolla un debate entre la data obtenida de otras fuentes y los resultados de estos.

Finalmente, se extraen las conclusiones de la investigación esperando demostrar la hipótesis de relación entre las variables mencionadas y se proponen recomendaciones para la problemática principal. 


\section{Capítulo 1}

\subsection{Problema de Investigación}

\subsubsection{Planteamiento del Problema.}

Es sabido que, en los últimos años han aparecido nuevos tipos de vehículos, los cuales pueden ser híbridos, completamente eléctricos, más pequeños, pero sobre todo muy innovadores. Alguno de estos nuevos vehículos o medios de transporte son las bicicletas con motor a gasolina o eléctrico; conocidos como "bicimotos", bicicletas eléctricas, scooters y patines eléctricos.

Esto ha implicado un cambio para los usuarios que no tenían la capacidad adquisitiva suficiente para poder comprar un auto o una motocicleta, ya que, según Andina; Agencia Internacional de Noticias (2017), tan solo el 30\% de autos vendidos nuevos fueron comprados por medio de financiamiento, aunque el $69 \%$ de peruanos tendría intenciones de financiarse, $22 \%$ tomaría un préstamo personal y $9 \%$ lo haría por medio de leasing. Por otro lado, Perú 21 (2018) nos dice que el $79 \%$ de los consumidores peruanos estarían dispuestos a financiarse con bancos y solo el $21 \%$ pagaría al contado. A pesar de esto; los bancos y financieras pueden ser muy exhaustivos con las evaluaciones crediticias antes de otorgar un préstamo y generalmente, estos usuarios son jóvenes, que no tienen un respaldo o garante para poder ser aprobados con facilidad, lo que termina haciendo que los rechacen y desistan de la compra del vehículo esperado. Otra razón, es la congestión vehicular en Lima como consecuencia del incremento del parque automotor, en donde Lima se posiciona con 807529 vehículos en la categoría de autos, ascendiendo a un total de 1752919 vehículos combinando todas las categorías. Además, muchos peruanos no se atreven a manejar una motocicleta; a pesar de que 
esta ofrezca una ventaja sobre el automóvil de ser más económica y rápida, pero también más peligrosa, o a usar bicicleta, por la falta de infraestructura en las vías en las calles y por largas distancia entre casa y trabajo de los usuarios volviendo el trayecto muy cansado. Según Lima Cómo Vamos (2018), el 68.9\% de la población se transporta a su centro de labores y/o estudio por medio de transporte colectivo; $18 \%$ en transporte privado o individual y $13.1 \%$ en transporte no motorizado.

Finalmente, otra razón de acojo de estos vehículos son los nuevos extranjeros que han llegado con poca inversión de dinero, pero con muchas ganas de trabajar, este último ejemplo se materializa en la aparición de nuevos conceptos de delivery por medio de aplicaciones, como UberEats, Glovo o Rappi que aceptan cualquier tipo de vehículo de dos ruedas para realizar los servicios, y también en la oportunidad de negocio del servicio de alquiler de scooters para tramos de 2 a $3 \mathrm{~km}$ como Grinn o Movo, volviendo a estos vehículos una muy buena opción.

Hace unos 5 años tal vez pasaban desapercibidos, pero hoy en día con el aumento de la demanda ha llevado hasta incluso que el Ministerio de Transportes y Comunicaciones (MTC) se pronuncie mediante el Decreto Legislativo No $019-2018-\mathrm{MTC}$ en cuanto a restricciones y regulaciones de uso.

Ante esto, nos comenzamos a preguntar ¿de dónde provienen estos vehículos? Y, ¿en qué momento llegaron tantos? Ya que podemos encontrarlos en diferentes modelos, precios y calidades. Lo que supone que se pueden comprar en tiendas formales y otras que no lo son tanto. Lo cierto es que, si bien algunos componentes como los marcos, repuestos y accesorios se pueden fabricar y comercializar directamente en Perú, los motores a gasolina o eléctricos, son todos importados desde un solo origen; China, a diferencia de las bicicletas ya 
completamente ensambladas, patines o scooters eléctricos que también pueden venir desde Estados Unidos o Europa e incluso de reconocidas marcas como Toyota, Hyundai y otros.

Lo que nos lleva a inferir, que nuestras importaciones de motores y estos medios de transporte de dos ruedas han ido creciendo exponencialmente debido a una muy buena aceptación en el mercado y aumento de demanda, al ser aparentemente una solución ante el tedioso tráfico y que va por debajo del presupuesto de $\mathrm{S} / 50$ soles semanales promedio en gastos en transporte del limeño (RPP, 2017). Consecuentemente, se esperaría que el parque automotor debería haber disminuido en los últimos años, al tener como referencia al consumidor limeño que prefiere un mayor beneficio y menor costo al mismo tiempo, reemplazando la compra de un vehículo de cuatro ruedas nuevo o usado, por la adquisición de una motocicleta, bicimoto a gasolina o eléctrica, scooter, patín eléctrico u otros que le daría mayor eficiencia, ya que el usuario de un auto gasta en promedio más de S/ 238 semanales (Marketwin, 2017). Mientras que, con una motocicleta, se gastaría S/ 40, una bicimoto a gasolina gastaría tan solo S/ 15 semanales y con los vehículos eléctricos simplemente se necesitarían cargas, sin tener que lidiar con horas de atasco en el tráfico por un recorrido de $200 \mathrm{~km}$ semanales lo que equivale a una distancia entre Barranco-Cercado de Lima ida y vuelta diario.

\subsubsection{Formulación del Problema.}

\section{Problema General.}

¿Existe una relación entre el parque automotor y los medios de transporte alternativos dentro de Lima desde el 2010 hasta $2018 ?$ 


\section{Problemas Específicos.}

- ¿Cuál es la relación entre el parque automotor y la cantidad de vehículos alternativos?

- ¿Qué factores influyen en la relación entre el parque automotor y la cantidad de vehículos alternativos?

- ¿Qué elementos influyen en la cantidad de vehículos alternativos?

- ¿Existe una relación entre los problemas del parque automotor y su crecimiento?

- ¿Los vehículos alternativos son una solución ante los problemas del parque automotor?

\subsubsection{Justificación de la Investigación.}

Según La República (2018), el peruano pierde más de 60 horas mensualmente en el tráfico, esto se ve traducido en uno de los principales problemas del país, ocupándonos en el tercer puesto en el ranking de las ciudades con mayor tráfico vehicular a nivel mundial llevando al limeño a gastar 57\% adicional de su tiempo en el tráfico (Gestión, 2018), por lo que el gobierno se ha planteado diferentes soluciones para poder contrarrestarlo, por ejemplo; una reevaluación de las sanciones a los conductores imprudentes, intento de compromiso nacional que se aplica a cada ciudadano para seguir correctamente las normas de tránsito, organización de nuevos medios de transporte publico creados por la Municipalidad de Lima, como el servicio de Tren Eléctrico, Metropolitano y Corredor Azul, aunque es sabido que el transporte público por medio de concesionarios en Lima es de bajo agrado entre la población por estándares de calidad y seguridad, y no ha podido ser regulado al punto de lograr un cambio 
trascendental por lo que ocupa los porcentajes más bajos de uso. Según Lima Cómo Vamos (2018) a pesar de que el transporte público por medio de buses, cústers y/o combis siguen siendo los más usados, son los que cuentan con la calificación más baja de satisfacción entre todos los medios de transporte con un 35.1\% de calificación dentro de la categoría "Malo/Muy Malo" en cuanto a cústers y/o combis y con un $24.5 \%$ en buses. Además, se ha implementado la construcción de nuevos accesos a avenidas principales para disipar la acumulación de vehículos, caso: ampliación de la Costa Verde, el By-Pass en la Carretera de Evitamiento con el Av. Derby, Línea Amarilla, entre otros más.

A pesar de aquellas propuestas, ninguna ha resultado efectivamente, pues el parque automotor ha ido incrementándose desde un 12.3\% de Junio del 2015 a Julio del 2016 (Gestión, 2016) llegando a un crecimiento de $17.3 \%$ en el presente año. Esto debido a la insatisfacción con los otros medios de transporte, y el rechazo de la población limeña hacía ellos.

Mediante este estudio se podrá entender si es que realmente los ciudadanos de Lima están reemplazando sus automóviles convencionales por vehículos alternativos de dos ruedas en su transporte diario para ir al trabajo o centro de estudios. Conoceremos si el parque automotor ha disminuido por efecto de sustitución de un nuevo producto o si permanece constante en el mercado, hallando así una relación directa o indirecta entre ambas variables de estudio. Además, esto nos llevará a entender el perfil del consumidor peruano al momento de optar por su medio de transporte, qué factores son importantes, ¿realmente son primordiales el tráfico y gasto mensual de transporte para tomar una decisión? O, ¿la vanidad de tener un vehículo propio sobrepasa esto a pesar de las desventajas? Por otro lado, identificaremos si el perfil del consumidor de un vehículo alternativo de dos ruedas es muy diferente al de un vehículo de 
cuatro ruedas, lo que ayudará a las empresas de estos productos a formar una mejor estrategia de comercialización al entender las necesidades de su cliente potencial desde otro ángulo.

Finalmente, se podrá determinar si el conductor peruano es consciente de la congestión vehicular que hay en Lima y si está dispuesto a contribuir con su cambio y mejora, para poder esquematizar una solución viable que comience desde los ciudadanos y no solo sea atribuida a la gestión pública. Es importante contribuir y llegar a los ciudadanos, para hacer que concienticen sobre este tema y sean parte del cambio que toda la comunidad busca.

\subsection{Marco Referencial}

\subsubsection{Antecedentes.}

- Infantas, F. \& Mendoza, M. (2017) Estudio de pre-factibilidad para la instalación de guna planta ensambladora de bicimotos en Lima Metropolitana. Cuyo objetivo ha sido determinar la viabilidad técnica y económica para la instalación de una planta de bicimotos eléctricas en la ciudad de Lima, que contribuya al desarrollo económico social y del medio ambiente del país. Según data, las importaciones de bicimotos eléctricas fueron aumentando desde el 2002 hasta el 2014 en un 532\% con una demanda dentro de los distritos de nivel socioeconómico A y B dentro del rango de edad de 20 a 40 años de 124000 ciudadanos aproximadamente. Además, se alegó a que el principal detractor de uso de bicicletas era la falta de ciclovías y ciclo paraderos. Al finalizar el estudio, se concluye la rentabilidad del negocio debido a la alta demanda potencial y beneficios del producto como, por ejemplo, la economía y contribución al medio ambiente. Este estudio nos demuestra la potencial oportunidad de negocio para la comercialización de bicimotos que podría actuar como sustituto de los vehículos convencionales de cuatro ruedas, 
infiriendo a una relación indirecta en cuando a cantidad de importaciones realizadas en ambos productos.

- Rivera, J. (2015). El Uso de la Bicicleta como Alternativa de Transporte Sostenible e Inclusivo para Lima Metropolitana Recomendaciones desde un Enfoque de Movilidad. Con el objetivo general de conocer la relación entre el Marco Legal en el Perú y el uso de la bicicleta como medio alternativo urbano sostenible para recuperar el espacio público de Lima Metropolitana. Se aplicó una combinación de métodos sintético analíticos para determinar los factores que volverían a la bicicleta un medio de transporte más atractivo para los ciudadanos. Se llegó a la conclusión de que se necesitan cambios y persistencia en los planes regionales y municipales junto con el apoyo de organizaciones y la ciudadanía. Por otro lado, se habla de la recuperación del espacio vial aludiendo a menos congestión vehicular, mayor tranquilidad y seguridad al estar en las vías si es que se utiliza bicicletas o vehículos no motorizados en gran cantidad. Esta investigación nos hace referencia al cambio ocurrido en Barcelona en donde se comenzó a optar por vehículos menores para una mejora, incurriendo a una relación indirecta entre autos y vehículos híbridos.

- Fernández, J. (2018) Análisis del crecimiento económico en el Perú y su relación con las importaciones de autos asiáticos en el periodo 2010 al 2015. Cuyo objetivo general fue determinar las relaciones que existieron entre el crecimiento económico en el Perú y la importación de autos en el periodo 2010 al 2015, mediante una metodología de investigación descriptiva cuasi experimental con una muestra de 20 empresas peruanas del rubro automotriz. Se pudo llegar a la conclusión de que, debido al crecimiento económico 
de los últimos años, las importaciones de vehículos chinos crecieron ya que eran una opción más económica en contraste con los vehículos americanos, a su vez se implementaron nuevos modelos de combustible como el GLP y GNV siguiendo el círculo de movimiento en la economía. Así, este estudio nos muestra que el nivel de ingresos tiene una relación directa con la elección de tipo de vehículo que escoge el ciudadano, sin embargo, optan por una opción más económica e incluyen componentes que abaraten su mantenimiento como es la conversión de combustible dual para obtener un mayor ahorro.

\section{- Méndez, J. (2017) Parque automotor y contaminación ambiental en el Centro}

Histórico de Lima. Con el objetivo de realizar un estudio antropológico de la contaminación ambiental que se genera por medio del parque automotor estudiando la zona más emblemática de Lima. Se concluyó que, para la modificación de la calidad y contaminación ambiental, es necesario realizar restructuraciones por medio de planes firmes, proyectos y programas que regulen la antigüedad de los autos que conforman el parque automotor, mejora en la calidad de combustible, incentivar al ordenamiento de rutas, aumento de la inspección en cuanto a cumplimiento y regulación de las empresas informales para su desaparición. Esta investigación nos demuestra que como medida para solucionar la calidad del aire es necesario encontrar una alternativa más ecoeficiente para el transporte de los ciudadanos, con motores menos contaminantes, estando los automóviles en una posición negativa ya que, aunque haya gran cantidad de ellos, no están teniendo un impacto positivo en la sociedad. Por esta razón, a modo de solución están las importaciones de vehículos alternativos que son menos contaminantes e influenciarían en 
la disminución del actual parque automotor en Lima, no solo por un tema de congestionamiento, sino también por salud.

\section{- Corrales, A. (2016) Congestión Vehicular en Medellín: Una Posible Solución desde}

la Economía. Con el objetivo de encontrar propuestas sostenibles mediante un enfoque económico para el problema del tráfico colombiano. Se encontró la relación entre el nivel de ingresos y la elección de tipo de medio de transporte, en donde indica que una persona con un estrato alto de ingresos suele optar por un transporte privado y uno de estrato bajo de ingresos optará por usar el transporte público. Además, se propone trabas económicas como la inclusión de peajes para incentivar el desuso de vehículos privados y disminuir su cantidad. Por otro lado, se propone una mejora de infraestructuras viales para que otros medios sustitutos como el uso de bicicleta, sea propagado junto a la iniciativa de usar medios de fuente eléctrica o solar. Este estudio nos permite reafirmar, que la relación entre los vehículos alternativos y menos contaminantes podría ser indirecta con el uso de vehículos de cuatro ruedas, ya que presenta ventajas para el medio ambiente y económicas a la vez que disminuye la congestión vehicular. También nos demuestra la necesidad de que el gobierno aplique mejoras en las disposiciones de transporte para que las personas puedan considerar otros vehículos como una buena opción de movilización.

- Morales, B. (2014) Modelo de Masificación de Vehículos Eléctricos en Bogotá D.C. Cuyo objetivo era desarrollar un modelo de factibilidad para la comercialización de vehículos eléctricos en Colombia. Se realizaron diferentes estudios en campo junto a un análisis del parque automotor, consumo de energía y demanda potencial para estimar la 
rentabilidad del proyecto. En base a esto, se determinó que los vehículos eléctricos presentaban mayores ventajas que los vehículos convencionales en cuanto al medio ambiente, salud pública, calidad de vida, consumo de combustible y congestión vehicular. A su vez, se descubrió que debido nuevos a proyectos masivos de movilización, se podría dar el escenario más pesimista para la utilización de vehículos eléctricos de 174 mil (4.76\% el parque automotor) a 80 mil unidades (2.7\% del parque automotor). Este estudio nos permite hallar una relación indirecta entre el parque automotor y la demanda de vehículos eléctricos, ya que cuando las medidas políticas para impulsar el uso del transporte convencional mediante la mejora de infraestructuras, normas o disminución de restricciones aumentan, la demanda de los vehículos alternativos disminuye.

- Haworth, N. \& Nielson, A. (2007) Motor scooters and mopeds: A growing attraction for young people. Estudia la cantidad de accidentes y severidad de estos, para los scooters motorizados y bicimotos, ya que hay muy poca data sobre este tema, al ser un vehículo nuevo y muy usado por los jóvenes. Este estudio se llevó acabo en Queesland, Australia recolectando información del 2001 al 2005 en donde hubo un crecimiento del $64.4 \%$ de scooters y "mopeds" convirtiéndose en el vehículo mayoritario de dos ruedas en circulación, esto debido a que hubo mucha mercadotécnica dirigida para jóvenes para propulsar su difusión por medio de las ventajas de reducir las tarifas de parqueo, reducción de gastos de combustible, flexibilidad, facilidad de adquisición y menor ratio de accidentes a comparación de otros vehículos, como la motocicleta o automóvil. Por estos motivos, se incentivó el uso de los vehículos alternativos y disminuyeron los viajes por medio de automóviles convencionales. Probando así, la relación indirecta entre estos dos tipos de 
medio de transporte y la importancia de políticas no restrictivas, pero influyente del Estado para los ciudadanos.

- Blackman, A. (2012) The increased popularity of mopeds and motor scooters: Exploring usage patterns and safety outcomes. Buscó entender la diferencia entre los patrones de uso de un scooter o "mopeds"; que equivalen a un vehículo similar a una bicimoto eléctrica o mecánica. Además, buscó determinar los factores de seguridad diferenciales entre un scooter y un “moped”. El estudio se llevó acabo en Queesland, Australia ya que estos vehículos eran muy populares y de rápido crecimiento en esta zona en particular, mediante la observación y análisis estadístico de la información de accidentes. Se pudo observar que, en 2005, en países de América del Norte y Europa, la venta de estos vehículos era mayor que de las motocicletas mismas. Por otro lado, en el 2008, hubo un crecimiento en la venta y registro de motocicletas que llevo a la disminución de la cantidad de scooters y "mopeds" circulando, demostrando una relación inversa. Además, en Australia hubo un aumento del $50 \%$ en la venta de mopeds durante el periodo de 2004 al 2009 en promedio, en donde el mayor crecimiento se situó en Queesland con un $150 \%$, esto debido a que no se necesitaba una licencia de motocicleta para conducir, solo la de auto, mientras que el vehículo tenía tan solo un $13 \%$ de crecimiento siendo el menor de todos los medios de transporte estudiados. Este estudio nos prueba la importancia de las políticas de seguridad concorde a la situación para implantar un sistema de transporte sostenible. 
- Rodríguez, D., Santana, M., \& Pardo, C. (2015). La motocicleta en América Latina: caracterización de su uso e impactos en la movilidad en cinco ciudades de la región. Realizo este estudio para entender las causas y consecuencias del incremento de motocicletas junto a su impacto en las políticas de transporte públicas. Nos comenta que existen múltiples razones por las que las motocicletas se han vuelto tan populares y nos muestra referencias de otros países donde su crecimiento se ha visto incrementado, como por ejemplo Argentina en donde el parque de motocicletas creció un 78\% del 2008 al 2011, mientras que el parque automotor tan solo un $16 \%$ en el mismo periodo. Según estudios en Asia, Europa y América Latina, el incremento del uso de las motocicletas se debe a la congestión vehicular y su eficiencia contra esta, involucrando una reducción del tiempo de viaje y mayor flexibilidad frente a las necesidades del usuario a comparación del transporte público. Además, el mal servicio y atributos del último mencionado han jugado a favor del aumento de las motocicletas circulantes. Otro causante es el uso de motocicletas como medio de transporte público en donde son usadas como "mototaxis"; los cuales son más económicos que un taxi y más cómodos que el transporte público. Otro dato interesante es el recolectado de Chang \& Wu (2008) donde a pesar de contar con un buen sistema de transporte público en Taipéi; China, se posee en promedio 1,17 motocicletas por hogar a comparación del 0,19 de automóviles con un 32,3\% de uso en la población; siendo el mayor medio de transporte usado, esto debido a la facilidad de tramos cortos e intermitentes paradas que se puede hacer sin problema junto a la economía de mantención. Este estudio nos demuestra la practicidad y cómo se han tenido que adaptar los países con sobrepoblación y graves problemas de congestión vehicular a vehículos 
alternativos como la motocicleta y bicicleta, demostrando practicidad sobre los automóviles.

- Velandia, P. (2014) Criterios metodológicos para involucrar el factor moto en los estudios de tránsito en Bogotá. Busca definir el factor moto bajo los parámetros que influyen en el tránsito, a partir de un modelo basado en la relación velocidad - espacio, y propone relaciones que comparan la motocicleta con el automóvil. En donde, nos dice que la motocicleta es un medio de transporte inclusivo, de fácil adquisición, y que fortalece la formación de la cultura vial en el conductor. Además, nos comenta que, normar este tipo de conducción podría mejorar el desplazamiento vial en la ciudad. El uso de motocicletas podría disminuir la contaminación ambiental por medio de una baja en las emisiones junto con la congestión vial, debido a la relación espacio y funcionalidad de las motocicletas. Sumado a esto, nos habla de que al existir un nuevo medio de transporte que ofrece ventajas comparativas y competitivas, este debería ser regulado, pero permitiendo su funcionalidad, y no impidiendo trabas políticas que afecten al usuario y la eficiencia de transporte que este aporte, ya que lo que se busca es un medio de transporte sostenible y desarrollado pues no hay que solo enfocarse en los automóviles convencionales, sino que hay que considerar a todos los actores involucrados. Esto nos confirma que, las motocicletas tendrían ventajas sobre el automóvil y que si otros medios de transporte alternativos aparecieran deberían ser regulados sin afectar al ciudadano; si no velar por su bienestar e incluso más, si gira en entorno a una mejora en un problema tan persistente como lo es la congestión vehicular. 
- Moreno, A. (2011) Análisis de alternativas de movilidad urbana sostenible en la zona metropolitana de San Luis de Potosí: El caso de la Bicicleta. Tiene como objetivo analizar la bicicleta como un medio de transporte alternativo y el impacto que podría tener de implantarse en mayor medida ya que se considera como un medio de transporte sostenible para el sector urbano. En principio, nos habla sobre los subjetivos de los factores de elección para transportarse en bicicleta, como marca de la misma, aceptación social, inseguridad, entre otros. Como factores negativos se encuentra principalmente el clima y las pendientes que se podrían encontrar en las rutas; ya que se genera un mayor esfuerzo físico del esperado. Sin embargo, en el estudio realizado, se define por medio de su experimento "tiempo puerta a puerta" que desplazarse en bicicleta es igual de eficiente e incluso tiene más ventajas que utilizar automóvil, donde se recorre un mismo trayecto con la misma rapidez de tiempo. A partir de esto, si se propusieran algunas soluciones ante las desventajas de transporte en bicicleta como lo es implantar un mayor número de ciclovías y otras políticas de manejo, este sería un excelente transporte, lo cual ha sido comprobado por otros países más desarrollados como por ejemplo Francia, aunque no hay que dejar de recalcar que la realidad entre Europa y América Latina, es bastante grande en cuando a congestión vehicular y cultura vial.

- Thomson, I. (1997) ¿Por qué las inversiones en el transporte público no reducen la congestión de tránsito urbano? Analiza los motivos de por qué a pesar de existir inversiones para mejorar el sistema de transporte público, la congestión vehicular no disminuye, es un estudio realizado en América Latina. En primer lugar, se habla del desarrollo y mejoras de trenes y transporte subterráneo, los cuales no han tenido gran 
impacto en la reducción de la congestión vehicular. Debido a que, las personas que sustituyen su vehículo particular por el transporte público; son muy pocas, además, este pequeño número que deja espacios vacíos en los estacionamientos anteriormente usados se llenaría rápidamente ya que no hay la suficiente oferta de estacionamientos para la demanda de automóviles circulantes, y, por último, al haber un espacio de tiempo vacío en las calles, este se redistribuirá hasta llenarse nuevamente de conductores. Ciertamente, los dueños de vehículos particulares no dejarían la conveniencia y flexibilidad que le den los automóviles a pesar de poder ahorrar con el transporte público, esto a causa de la autonomía e independencia que les da un vehículo propio. Aquí, podemos probar que, las mejoras en el transporte público no sustituirían o lo harían de manera insignificante el uso de automóviles, ya que el conductor lo que busca es comodidad, seguridad y eficiencia.

- Villalobos, J. (2016) La Bicicleta como Medio para La Disminución de Contaminación Ambiental, Accidentes de Trabajo y Enfermedades Laborales en Las Organizaciones. Busca probar la sostenibilidad de la bicicleta como medio de transporte y propone soluciones. Se realizaron estudios con días sin automóviles en Bogotá, Colombia; donde se pudo observar la gran disminución de la contaminación ambiental desde el primer día. Además, se presenta a la bicicleta como un medio de transporte sostenible en el tiempo, que puede favorecer a la salud física y mental de trabajadores que pasan su jornada laboral sin mucha actividad física, ahorrando tiempos de desplazamiento, contribuyendo al ahorro económico y salvando espacio público. Por otro lado, dos de los grandes detractores del uso de la bicicleta son la inseguridad física y vial, por falta de cultura vial en donde predominan los vehículos motorizados de gran tamaño. Debido a 
esto, han aparecido diferentes empresas y programas para promover la movilidad sostenible como "Mejor Bici", "SIBUC (Sistema de Bicicletas de Uso Compartido)", "Semana Nacional de la Movilidad Sostenible” y otros más. Esta última impartida por el Ministerio de Medio Ambiente, el Ministerio de Salud y Coldeportes. Definitivamente, es una realidad a la que toda América Latina se está adaptando.

- Yannis, G., Golias, J. \& Spyropoulou, I. (2007) Mobility Patterns of Motorcycle and Moped Riders in Greece. Por medio del estudio, se investigó las características y patrones de uso de los diferentes tipos de vehículos, como la bicicleta, motocicleta, bicimotos y automóviles. Debido a que, en Grecia, el uso de vehículos alternativos de dos ruedas habría incrementado exponencialmente desplazando a los automóviles. Se encontró una gran diferencia entre las tasas de propiedad de vehículo y tasas de uso de vehículo. Además, para encontrar los patrones de movilidad se tomó en consideración el kilometraje anual recorrido en promedio, tamaño de motor del vehículo, tipo de viaje y el ambiente de viaje (carreteras, calles y/u otros). El estudio demostró que las características de los usuarios; como edad, género y experiencia eran más influyentes sobre el tipo de vehículo. Por otro lado, se definió que el tipo de vehículo es relevante si solo consideramos el ambiente de viaje lo que concluye en que las motocicletas, bicicletas y bicimotos son más usadas y preferidas que los automóviles para viajes particulares y urbanos como ir al centro de estudios y/o trabajo. 
- Hsu, T., Tsai, C. \& Lin, Y. (2007) Comparative Analysis of Household Car and Motorcycle Ownership Characteristics. Investigaron las características principales de la propiedad de automóviles y motocicletas en tres ciudades principales de Taiwán por medio de encuestas y el modelo de regresión Poisson. Se encontró que las características de propiedad de la motocicleta y automóviles son bastante diferentes en las tres ciudades. Además, que existe una relación inversa entre los niveles de propiedad de automóviles, motocicletas y uso de transporte público. Como consecuencia, a mayor número de motocicletas, se usará menos el transporte por automóviles privados y también menos uso del transporte público. Se determinaron como factores importantes de influencia al nivel de ingresos, suministro y calidad de transporte público, lo cual proyecta una perspectiva en el futuro sobre el desarrollo de las motocicletas y otros tipos de vehículo.

- Pongthanaisawanab, J. \& Sorapipatanaab, C. (2010) Relationship between level of economic development and motorcycle and car ownerships and their impacts on fuel consumption and greenhouse gas emission in Thailand. En principio, busca estudiar los efectos en el medio ambiente debido al aumento del parque automotor por medio de la relación del ingreso económico con la propiedad de automóviles y motocicletas en Tailandia, ya que consideran relevante estudiar el futuro de una política de transporte sostenible. Se pudo demostrar que, en otros países con rápido crecimiento como Tailandia, las motocicletas predominan sobre los automóviles. Sin embargo, se prueba que existe una relación directa con el ingreso económico y una relación indirecta entre automóviles y motocicletas, en donde, mientras el poder adquisitivo aumenta; el número de vehículos privados lo hace al mismo tiempo, ya sea automóvil o motocicleta, pero una vez que se 
estabiliza el nivel de ingreso; las personas migran de una motocicleta a un automóvil por efectos de prestigio, conveniencia, seguridad y comodidad. Por otro lado, esto equivaldría a una mayor contaminación y sobrepoblación de automóviles, creciendo 2.4 veces proyectándose al año 2050. Por lo que, se sugiere implantar políticas de mejora en el transporte público y, así evitar la migración a un automóvil y ofrecer mejoras tecnológicas para las motocicletas para prevalecer su aumento en vez de automóviles. Así, se puede probar que, en otros países con mayor población, es preferido el uso de vehículos alternativos por las consecuencias dañinas como la contaminación y congestión vehicular.

En conclusión, se puede determinar, que existen diferentes fuentes de información que examinan los problemas del parque automotor junto con su conceptualización, además, se han realizado estudios para la viabilidad de vehículos sustitutos a los convencionales, debido a la problemática de la congestión vehicular y contaminación ambiental, para disminuir impactos y ganar mayor eficiencia en cuanto a tiempo y dinero. Siendo uno de ellos, las bicicletas y sus adaptaciones motorizadas, que las vuelven más prácticas e involucran menos desgaste físico. Es probado también, que no siempre las inversiones en transporte publico incentivan al uso de estas, sino que, el ciudadano busca políticas de trasporte que lo protejan y que no lo perjudiquen para adquirir un transporte cómodo, autónomo y eficiente.

\subsubsection{Marco Teórico.}

- Cohen, K. (2020) en su estudio "Human Behavior and New Mobility Trends in the United States, Europe, and China"; analizó las nuevas tendencias de transporte como micromobility, carsharing, ride-hailing o ride-sharing, y cómo estas pueden ser adoptadas por los ciudadanos, así como su impacto en la movilidad sostenible. Se 
concluye que, los factores decisivos para una sustitución en el medio de transporte se componen de una combinación de aspectos y percepciones racionales y emocionales; incluyendo al costo, tiempo, comodidad y seguridad junto a la conveniencia, identidad y aspectos ambientales, donde la compra de un automóvil se basa en mantener un status quo y no en su eficiencia. La micromovilidad; que consiste en el alquiler de medios alternativos de transporte para tramos cortos como la bicimoto, bicicleta, scooter o patín eléctrico ha demostrado ser uno de los medios más usados para el reemplazo del automóvil en los lugares analizados. En USA, un país donde el comportamiento del consumidor ha estado principalmente asociado al uso del vehículo propio, del 2006 al 2012 hubo una disminución en la cantidad de vehículos por persona de un 5-6\%, en donde los usuarios de vehículos alternativos se encontraban $40 \%$ más predispuestos a abandonar totalmente sus vehículos. Cambios demográficos, tecnológicos, económicos y de actitud están redefiniendo la forma en la que se movilizan los estadounidenses. Además, se generó una disminución de 1.67 autos por familia a comparación de 1.88 de los que no usan transporte alternativo; y un 30\% se encontraba dispuesto a abandonar sus vehículos por las actuales desventajas de transportarse en automóvil con un 70\% de aceptación para transportes alternativos. Europa no es tan dependiente de los vehículos propios como lo es Estados Unidos, donde por cada 1000 personas existe 766 vehículos, a diferencia de Europa donde dicha cantidad asciende a 507 mientras que en China alcanza a solo 74 vehículos (McGuckin, 2018); esto relacionado también al tamaño de territorio que posee cada uno de estos lugares versus la cantidad de habitantes; por lo que, para encontrar un balance en Sudamérica se debería reducir el parque automotor. La movilidad compartida (Shared Mobility) está siendo cada vez más popular en Estados Unidos especialmente 
entre los jóvenes, sectores más educados de ingreso medio y alto, y millenials. Inclusive, este concepto se ha desarrollado en la Movilidad como Sevicio (Mobility as a Service o MaaS) el cual es la integración en una plataforma de métodos de transporte privados y públicos que permite planear, reservar y pagar estos previamente para obtener un sistema de viaje conectado. De esta forma, se permite al usuario no hacerse propietario de dichos vehículos; pero si comprar su funcionalidad; lo que es el transporte como servicio. Los distintos niveles de desarrollo de MaaS permitirían ubicar los diversos métodos de transporte en la ciudad, hasta contratar paquetes completos por membresías mensuales y/o anuales, para finalmente aplicar políticas e incentivos para promoverlo.

- Lee, M., Chow, J., Yoon, G. \& He, B. (2019) "Forecasting e-scooter competition with direct and access trips by mode and distance in New York City". Explica el modelo de micromovilidad para aplicar un modelo multifactorial no-linear y así, descubrir el número de viajes por medios de transporte alternativos en Portland, Manhattan. Dicha investigación tuvo resultados de viajes de 12 minutos en promedio de duración con una valorización en ventas de casi 67 millones de USD. El tiempo promedio de viaje en Citi Bikes dentro de 1.5 millas es 5 minutos, lo que es más rápido que tomar un taxi, y mucho más económico. Además, el uso de scooters podría no ser usado para viajes completos de un punto a otro, pero sí como transporte de conexión hacía otros, por ejemplo, ir hasta la parada de buses. El modelo de sustitución de los scooters eléctricos se divide en "sustitución competitiva" que son los viajes directos y "sustitución complementaria" que son viajes de conexión. Se concluyó que, al implementar un programa de scooters, e-bikes o bicimotos bajo el modelo de micromovilidad se reemplazaría en un $1 \%$ al viaje por 
medio de taxis, y la sustitución complementaría tendría un mayor porcentaje de acuerdo a la distancia; es decir mientras más largo el trayecto, es menos probable que usen un medio de transporte alternativo y viceversa. Sumado a esto, el $48 \%$ de los visitantes en Portland, prefirieron el transporte alternativo que rentar autos, taxis o transporte público.

- Van, H., Fuji, S. \& Schmöcker, J. (2009) en su estudio "Upgrading from motorbikes to cars: Simulation of current and future traffic conditions in Ho Chi Minh City"; analizó en una ciudad de Vietnam, los efectos en las condiciones de transporte, así como la existencia de sustitución de motocicletas por automóviles. Se pudo comprobar que, si el 30 a $40 \%$ de motociclistas migraran al uso de un automóvil como medio de transporte, habría efectos negativos considerables, los vehículos bajarían su velocidad de viaje a un 5 a 7 $\mathrm{km} / \mathrm{h}$ y las motocicletas a un $10.9 \mathrm{~km} / \mathrm{h}$ lo que los haría transportarse a la velocidad de un peatón. Por otro lado, se tendría que, como mínimo inducir al $40 \%$ de la población de dejar de usar automóvil y sustituirlo por el uso de transporte público o motocicleta, para que la velocidad de viaje se duplique y tenga un efecto positivo, de $6.7 \mathrm{~km} / \mathrm{h}$ a $16.1 \mathrm{~km} / \mathrm{h}$ en buses y $20.9 \mathrm{~km} / \mathrm{h}$ en viajes en motocicletas. Se concluyó que, es importante administrar la demanda de transporte junto a la calidad y políticas de ésta, como por ejemplo; controlar la cantidad de autos en circulación para que el transporte se vuelva sostenible y, educar al ciudadano para que opte por medios más eficientes con la comunidad; tales como transportes que puedan llevar mayor cantidad de pasajeros por viaje; como los buses o, ser de menor tamaño para evitar producir tráfico como las motocicletas y vehículos alternativos de transporte. El estudio sugiere que gestionar la 
demanda de viajes, es decir, restringir el uso del automóvil y promover el uso del autobús son fundamentales para garantizar la movilidad de la ciudad.

- Tuan, V. (2011) en su estudio "Dynamic Interactions between Private Passenger Car and Motorcycle Ownership in Asia: A Cross-country Analysis" quiso encontrar la relación entre el número de motocicletas por cada 1000 habitantes (MCO) versus el número de automóviles (CAO) en las distintas economías de Asia, su efecto en la sociedad y, cómo podría afectar a las políticas de transporte en el futuro. Si bien, el auto y la motocicleta tienen ventajas y desventajas; cada uno se posiciona como el vehículo conveniente debido al tipo de actividad que se quiera realizar. Se pudo descubrir que, el MCO estaba relacionado directamente con los niveles de ingreso, pero con un punto de inflexión, como por ejemplo en Japón, en donde a partir de un ingreso de \$20 000 la adquisición de motocicletas ya no se veía influenciada. Por otro lado, los países en desarrollo están más predispuestos a tener niveles más altos de $\mathrm{CAO}$, a comparación de los países ya desarrollados, por lo que, se concluye que la cantidad de motocicletas en relación a la cantidad de automóviles podría aumentar conforme la economía va mejorando. Finalmente, se plantean distintos escenarios en donde una familia puede tener múltiples vehículos combinando motocicletas y automóviles. Se indica que, para una movilidad sostenible habría que replicar el modelo de Taiwán, en donde cada familia puede tener solo un auto y múltiples motocicletas y bicicletas, además las familias están más propensas a la compra de un primer vehículo; pero los factores que los llevan a comprar otro medio de transporte van más allá del status quo (Meurs, 1992), por lo que es muy poco probable que una familia compre más de un automóvil demostrando una relación 
inversa entre motocicletas y autos. De esta forma, el transporte público no se volvería obsoleto y el tráfico se mantendría en niveles adecuados. Para esto, es necesario implementar políticas que restrinjan el tener más de un vehículo por familia, aplicar impuestos, proponer medios de transporte alternativos y, mejorar la calidad del transporte público.

- Hiselius, L. (2014) "Could the increased use of e-bikes (pedelecs) in Sweden contribute to a more sustainable transport system?". Busca entender el comportamiento y uso de las personas que se transportan en e-bikes por medio de una encuesta en Suecia, debido a que hay muy poca data sobre esto, pero se habla mucho de las ventajas en el medio ambiente y transporte de este medio alternativo ocupando el $20 \%$ de las ventas de bicicletas. El $67 \%$ de los encuestados sustituyó su automóvil por un e-bike y un 16\% sustituyó los viajes de transporte público, en su mayoría; hombres con licencia de conducir y acceso a un automóvil; esto debido a que los hace ser más consientes acerca de las desventajas del transporte de cuatro ruedas. Además, la distancia de viajes en automóvil se reemplazó en un $72 \%$ y en transporte público en 18\%. Existen dos tipos de usuarios; los mayores de 65 años a los que se les dificulta el uso de una bicicleta normal y los jóvenes, que encuentran un recorrido con menos tiempo y mayor posibilidad de carga en la e-bike mediante la implementación de un tráiler en ella. Algo que demandan las personas para que la sustitución se lleve a cabo es la mejora de infraestructura en las vías para no tener problemas en su viaje. 
- Ng, W., Schipper, L. \& Cheng, Y. (2010) discutió en su estudio "China Motorization Trends: New Directions for Crowded Cities" las consecuencias del crecimiento de los vehículos motorizados en China, bajo dos grandes problemáticas: el consumo de combustible y la infraestructura urbana. Propone tres soluciones para impulsar el uso de la energía como combustible; "Road Ahead", "Oil Saved" e "Integrated Transport"; siendo el último el más usado debido a que se basa en el transporte mediante bicicletas y bicimotos de baja velocidad y de gran eficiencia, para así, evitar las consecuencias del tráfico en ciudades contaminadas y muy habitadas. En el transporte integrado, se busca distintas alternativas para promover el uso de bicicletas, scooters, e-bikes y bicimotos y a su vez, desincentivar el uso de vehículos particulares que ocupan mucho espacio y causan congestión vehicular. Se plantea como una de las mejores alternativas a la creación de políticas de transporte y su aplicación, no solo en infraestructura, sino también en accesibilidad conectando al usuario final y los centros de trabajo de manera sencilla. Para promoverlo es necesario la inclusión de impuestos, desarrollo de vías y priorización de vehículos alternativos de transporte, además, traería beneficios sostenibles con el medio ambiente.

- Birgit, H., Berntsen, S., Velde, S., Fyhri, A., Deforche, B., Andersen, L.\& Bere, E. (2019) "From cars to bikes - The effect of an intervention providing access to different bike types: A randomized controlled trial" Es un estudio experimental realizado a 36 padres aleatorios llevando a sus niños al kindergarden en Noruega, donde se les proponía alternativas de viaje en bicicleta, para saber si influyó en su modalidad de transporte y conducta. En Noruega, el 75\% de los hogares poseen por lo menos una bicicleta, pero 
solo el 5\% se transporta en ella. Se concluyó que al ofrecer diferentes alternativas de transporte en bicicletas como bicimotos, scooter y e-bikes causó un aumento en el uso de bicicletas, disminución en uso de automóviles y aumento del uso de bicicleta, incluso en temporada de invierno. De todas las alternativas, las bicicletas eléctricas tuvieron mayor aceptación debido a la facilidad de uso y poco esfuerzo que conlleva. Además, que los padres transporten a sus hijos en bicicletas implica una enseñanza sobre el medio de transporte a los niños; para así crear una nueva cultura de movilización sostenible y promover el transporte activo a largo plazo.

\subsubsection{Parque Automotor}

Se entiende por parque automotor a la contabilización total de vehículos con motor que existen dentro de un espacio delimitado. De acuerdo al MTC, a partir del 2004 los vehículos menores; como las mototaxis y motocicletas son también parte del parque automotor.

Según INEI (Instituto Nacional de Estadística e Informática), la medición utilizada para contabilizar el parque automotor se hace por medio del "Flujo Vehicular por Unidades de Peaje"; el que registra movimientos de entrada y salida vehicular nacional de transportes de carga y también ligeros. INEI junto a PROVIAS realizan distintos boletines de información anualmente que nos permiten tener una vista de la afluencia vehicular que ayudan con el planeamiento de transporte y vistas del comportamiento económico.

En enero del 2018, el Índice de Flujo Vehicular tuvo un crecimiento promedio de 4.1\% con respecto al año 2017, donde 3.9\% correspondían al crecimiento en vehículos pesados, $3.1 \%$ en vehículos pesados de carga (de 3 a 7 ejes) y $4.2 \%$ en vehículos ligeros. 
Se entiende por vehículos ligeros a los automóviles, station wagon, camionetas pick up, rural y de panel, por otro lado, los vehículos pesados comprenden; microbuses, buses y ómnibuses, finalmente por vehículos de carga pesada, a los camiones. Los remolques y semiremolques también son parte del parque automotor a pesar de no estar motorizados, ya que conforman una parte vital para los tráileres de carga.

Sumado a esto, la contabilización del parque automotor se puede reafirmar con el registro anual total de vehículos por medio de la Superintendencia Nacional de Registros Públicos (SUNARP) e importaciones de vehículos por medio de la plataforma de SUNAT.

El parque automotor se divide entre los vehículos nuevos y usados, siendo un $99.1 \%$ de los vehículos importados pertenecientes al parque automotor nuevos al 2013. En contraste a esta información, al 2010 el 23\% de vehículos circulando eran usados, aunque esta tendencia se rompió con la restricción de importar vehículos usados con timón al lado derecho, haciendo que la cantidad disminuya abismalmente junto a una tendencia de los consumidores de cambiar el vehículo cada 4 o 5 años.

Al 2009, el 56.9\% de los vehículos del parque automotor tenían una antigüedad de entre 1 a 7 años, volviéndose al 2013 un 75.8\% del total, aludiendo a una tendencia a la modernización de vehículos. Aunque esta tendencia no se replica en los vehículos de carga pesada, ya que, en el 2013 según MTC, 46.5\% de los vehículos tenían una antigüedad entre 1 a 5 años, pero el 26.9\% eran vehículos con más de 20 años de antigüedad. Sumado a esto, la Asociación Automotriz del Perú nos dice que el parque automotor tiene 13 años de antigüedad promedio al 2018. 
Según la Cámara de Comercio de Lima, a febrero 2018 el 66\% de los autos pertenecientes al parque automotor se encontraban entre Lima y Callao y sus importaciones han ido disminuyendo desde el 2012 en un promedio del 6\% hasta el 2016 llegando a 168522 unidades.

Los problemas del parque automotor se reducen a dos grandes componentes: la congestión vehicular; causado por el número de unidades existentes junto a una falta de ordenamiento en el sistema de semaforización y la contaminación ambiental causada por la antigüedad de los vehículos y la calidad del combustible (Posada, 2018). De acuerdo con un estudio realizado por la ONG Luz Ámbar, tan solo 380 de las 1200 intersecciones semaforizadas tienen fibra óptica y son gestionadas por la Municipalidad de Lima, la diferencia funciona sin coordinación distrital o bajo algún régimen de ordenamiento. Además, al 2016 se encontraban circulando por Lima Metropolitana un total de 1752919 vehículos. Algunas medidas propuestas por la cámara de comercio comprenden entre la impulsión para renovar el parque automotor por medio del "bono chatarrero" para dar un incentivo de compra a un nuevo auto reemplazando a aquellos vehículos con más de 20 años de antigüedad y una mejor política de ordenamiento en las calles por medio de las autoridades correspondientes.

Aunque la congestión vehicular sea un problema del día a día para los ciudadanos limeños, este no es el principal detractor de nuestra vida; si no lo es la consecuencia, la contaminación del aire. Según el Organismo de Evaluación y Fiscalización Ambiental (OEFA) en Lima, el $72 \%$ de las municipalidades no se encargan de supervisar o manejar la contaminación de sus jurisdicciones.

Otro detractor de la contaminación ambiental es la baja calidad del combustible, debido a que algunos combustibles como el diésel 2 y ciertas gasolinas, contienen azufre que evoca en 
dióxido de azufre al momento de la combustión, volviéndose altamente toxico para el ambiente y las personas. Lo recomendable según la Organización Mundial de la Salud (OMS) es 350 partes por millón (ppm) y se busca reducir a 50 ppm, sin embargo, en Perú, el combustible llega a tener 9700 ppm.

\subsubsection{Medios de Transporte Alternativos}

Los medios de transporte alternativos son aquellos diferentes a los más utilizados que conocemos actualmente como lo son los automóviles, taxis, buses o trenes. Los medios de transporte alternativos generalmente son eco amigables, ya que emiten menos o nulas emisiones de $\mathrm{CO} 2$ y tienen una mayor eficiencia que los convencionales por su relación precio-consumo. Entre estos tenemos a las motocicletas, bicimotos, bicicletas, scooters, patines, e-bikes y otros (Alternativas Económicas, 2014). Se han ido desarrollando con nuevas tecnologías innovadoras y tienen rápida expansión debido a que ocupan menos espacio y son económicos (Céspedes, E., Pérez, A. \& Ruano, A., 2014).

\subsubsection{Motocicletas}

Una motocicleta es un vehículo motorizado de dos ruedas, el cual tiene un motor mecánico para propulsar su funcionamiento y es comúnmente llamada "moto". Varían normalmente de dos a cinco velocidades y existen diversos tipos de acuerdo a la utilización de esta; por ejemplo, motocicletas de carreras, pisteras, deportivas, chopper, cross, entre otros.

En su versión convencional, por medio del motor y chasis, una moto puede llevar hasta dos personas, pero se han desarrollado nuevos modelos donde es posible viajar hasta tres personas y con una carga adicional. Volviéndolas más flexibles en cuanto a transporte. En cuanto al 
motor, es muy importante mencionar el cilindraje, existen algunos modelos desde 50cc, pero es atípico el uso de estas en transporte; si no que es más recreativo, las más usadas van desde $100 \mathrm{cc}, 125 \mathrm{cc}$ y $500 \mathrm{cc}$, aunque existen algunas con mayor cilindrada hasta el máximo que es 2 294cc. A pesar de ser parte del parque automotor en la data manejada por la SUNAT; están claramente diferenciadas

Actualmente, la motocicleta es considerada un medio de transporte alternativo ya que es más fácil de adquirir debido a su costo menor a comparación de los automóviles. Además, es más flexible para maniobrar, transportarse por las calles y de mejor acceso en cuanto a estacionamientos (Catedra, 2012). Sumado a esto, incluye menos costos conexos de mantenimiento, por lo que lo vuelve una opción más económica de transporte y privada a comparación del transporte público. Por otro lado, existen variaciones en el uso de la motocicleta, como la "mototaxi" que se utiliza para transportar pasajeros en distancias cortas y también el uso de estas para hacer trabajo de delivery.

Uno de los sesgos más relevantes en cuanto a las motocicletas; es el riesgo de sufrir accidentes; ya que debido a las velocidades que se puede alcanzar y la exposición del conductor sobre el vehículo a comparación de otros medios de transporte es bastante significativa; sobre todo en América Latina, donde existe falta de cultura vial, informalidad para adquirir una licencia de conducir y un mal estado de las vías. Sin embargo, el mayor número de accidentes se da entre vehículos grandes como automóviles, camiones y/o combis con un $76.8 \%$ del total de accidentes a nivel nacional, mientras que las motocicletas tienen un 23.2\% (INEI, 2019). En contraparte, en Lima, el porcentaje de accidentes por motocicletas es mayor, ya que el cuerpo de bomberos reporta que casi un tercio de los accidentes viales involucran a este tipo de vehículo (El Comercio, 2019). 
En el Perú, las motocicletas están categorizadas bajo cinco niveles, que definen el tipo de restricciones y documentación necesaria para circular por las calles.

Clasificaciones de vehículos motorizados menores (MTC, 2020):

- L1: Con un motor de baja potencia menores a $50 \mathrm{cc}$, que no excedan $l o s 50 \mathrm{~km} / \mathrm{h}$ y de dos ruedas. Necesitan de impulso de pedaleo para el arranque o subidas. En esta categoría se encuentran las bicimotos, bicicletas eléctricas, patines y scooter eléctricos de baja potencia. En principio, era necesario la licencia de categoría II-A para conducir, pero tras las recientes clasificaciones se migró a la II-B, sin embargo; aún no se aplica esta norma.

- L2: Con motor de baja potencia menores a $50 \mathrm{cc}$, que no excedan los $50 \mathrm{kmh} / \mathrm{h}$ de tres ruedas. En esta categoría se encuentran las trimotos. Es necesario la licencia de categoría II-B para poder conducir este vehículo si es para transporte particular, sin embargo, será necesaria una licencia II-C si se usa para transportar pasajeros.

- L3: Con motor de mayor potencia a los $50 \mathrm{cc}$ y con una velocidad mayor a los 50cc, es indistinto su tamaño o peso. En esta categoría se encuentra la mayoría de las motocicletas en el mercado. Es necesario la licencia de categoría II-B para poder conducir este vehículo.

- L4: Con motor una potencia mayor a $\operatorname{los} 50 \mathrm{cc}$ y una velocidad superior a $\operatorname{los} 50 \mathrm{~km} / \mathrm{h}$ con tres ruedas asimétricas a su eje longitudinal y con aditamento a un lado para transportar una persona adicional y equipaje extra. En esta categoría se encuentran las motocicletas con "sidecar". Es necesario la licencia de categoría II-B para poder conducir este vehículo. 
- L5: Con diferentes configuraciones y potencias de motor, abiertos o cerrados, pero de tres ruedas, similar en la parte delantera a una motocicleta con solo una rueda, pero con una extensión de chasis en la parte posterior con dos ruedas posteriores. Se utilizan para el transporte de pasajeros. En esta categoría se encuentran las "mototaxis". Es necesario la licencia de categoría II-C para poder conducir este vehículo.

Por otro lado, tenemos a las "cuatrimotos" o "ATVs", pero estás no se encuentran dentro de ninguna categoría mencionada anteriormente, aunque son usadas para fines recreativos a las afueras de Lima, a pesar de esto Luz Ámbar (2013) recomienda su categorización para un manejo más responsable.

A parte de la licencia de conducir apropiada de acuerdo a la motocicleta, es necesario contar con un Seguro Obligatorio Contra Accidentes (SOAT) y tarjeta de propiedad del vehículo.

\subsubsection{Bicimotos}

Las bicimotos son un producto relativamente nuevo en el mercado nacional, ya que nacieron recién hace aproximadamente una década (Quispe, 2019) y aún no están totalmente regulados (MTC, 2018) por lo que existe muy poca data de la contabilización de las bicimotos existentes en el mercado peruano, estadística o estudios. Sin embargo, si existen proyectos de factibilidad que nos enseñan la demanda creciente que este sector muestra, comportamiento del consumidor y el parque de bicimotos es calculado en base a las importaciones por subpartida arancelaria.

Según Mendoza (2017) Una bicimoto surge de la adaptación de un motor a gasolina o motor eléctrico en una bicicleta tradicional, sin que esta haya sido preparada para esto, con la 
finalidad de asistir en su movilización, resultando así, una combinación nueva, innovadora y muy eficiente. Una bicimoto es considerada un vehículo híbrido, ya que combina dos métodos de movilización: pedaleo de bicicleta y el motor mecánico o eléctrico.

Hasta el año pasado, los conductores de bicimotos no necesitaban SOAT, brevete o placa. Sin embargo, debido a su masificación en las calles limeñas, el MTC en Enero 2019 publicó un decreto donde reclasificaba los vehículos, incluyendo a las bicimotos dentro de la categoría L1, en donde se pedía que circularan con brevete II-B, tarjeta de propiedad, certificado de inspección técnica, placa y SOAT, aunque estas regulaciones recién entrarían en vigencia a partir de Julio del 2020, hubo mucha incertidumbre en la comercialización de bicimotos, ya que también se prohibían los ensamblajes artesanales. En contraste, el MTC no ha publicado ningún reglamento a seguir para poder formalizar los negocios de estos comerciantes y aún existen incongruencias en cuanto a la clasificación de estos vehículos, aludiendo a vacíos legales. Cabe decir, que este tipo de modificaciones podrían afectar negativamente la venta de bicimotos, ya que su principal función es movilizarse mientras prevalece la economía y comodidad y al introducir documentación junto con tramites obligatorios; el costo final de adquisición aumentaría; volviendo el umbral de sustitución con una bicicleta más pequeño.

Existen dos tipos de bicimoto; con motor a gasolina y con motor eléctrico. La bicimoto con motor mecánico a gasolina de dos tiempos, puede ser de $49 \mathrm{cc} \mathrm{u} 80 \mathrm{cc}$, y el motor viene con todos los accesorios necesarios para poder adaptarlo a la bicicleta (kit de motor), estas partes incluyen: tanque de combustible, silenciador, carburador, cadena y clip de cadena, piñón de 44 dientes y 9 agujeros, bujía, CDI de encendido, mango de acelerador y embrague, cable del acelerador, manguera de combustible, sujetador, caño de escape, tornillos, tuercas y elementos varios. No existe ningún requisito para tener que adaptarlo a la bicicleta, solo que esta tenga 
el espacio suficiente en el marco o de otra manera, se deberá realizar una adaptación extra. El ensamblaje del motor, siempre se realiza en el centro del marco, verificando que se pueda conectar con ruedas y timón, que haya un espacio para el tanque si es que no viene incluido en el cuadro y que este nivelada. Por último, se verifica la correcta operatividad del motor y sus componentes (Revelo y Benavidez, 2016).

La ventaja principal de este tipo de bicimoto es que si en caso se agotara el combustible; funciona perfectamente pedaleando como una bicicleta tradicional, en el caso de las bicimotos eléctricas; no siempre es así, ya que no todas cuentan con pedales. Este tipo de bicimoto cuenta con un tanque de 1.9 galones de gasolina que rinde de $60 \mathrm{~km}$ a $70 \mathrm{~km}$, con una velocidad máxima de 45 a $50 \mathrm{~km} / \mathrm{h}$. La mezcla de combustible deberá ser por cada $500 \mathrm{ml}$ de gasolina agregarle $25 \mathrm{ml}$ de aceite de dos tiempos.

Según Gestión (2018), existen varios modelos de bicimotos, entre ellos; ross sport line (urbanas y off-roads), cruiser, chopper, motoped, gasbike, fatbike, bobber e indian boardtrack. La flexibilidad de los modelos dependerá mucho de la habilidad del mecánico para adaptar el motor a una bicicleta o construir un nuevo marco. Además, también los proveedores de los motores realizan venta de diseños novedosos y completos, con tanque de combustible incluido, llantas anchas, entre otras cosas más. Los colores a su vez son muy versátiles y pueden personalizarse a pedido del cliente. Sumado a esto, los marcos pueden ser los denominados "gas" que están hechos a base de aluminio, acero y combinaciones con aleaciones de cobre que ayudan para absorber la vibración del motor y el cual disminuye el $25 \%$ de su peso normal.

Los motores de bicicleta son únicamente importados desde China, ya que este fue el pionero en la fabricación de este tipo de motores debido a su gran población. Guangzhou; es 
una de las ciudades más industrializadas y productoras de bicicletas junto con Chang Chun (Matailo, 2016). De aquí, se derivan las importaciones hacía todos los comercializadores de bicimotos en Perú, puesto que en el país no somos productores de estos. Dos de los grandes distribuidores en China son: CDH International Company y Jilin Zeda Company. Aunque existen motores conocidos como "versión americana o USA", estos tan solo son nombres distintivos para las mejoras que se les va haciendo a los productos. En cuando a las bicimotos eléctricas, existen diferentes marcas reconocidas que las comercializan; como General Motors, Jeep, Monark y otros más, sin embargo, hay que recordar que todas estas son "Made in China".

Blas, L. (2018) dueño de Bicimotos Store, nos explica que los precios dependerán de la necesidad del cliente, ofreciendo precios desde los S/.1 000 hasta superar los S/.7 000. Sin embargo, esto también dependerá del lugar de la compra, ya que existen tiendas formalizadas que incrementan sus precios debido a costos conexos para ofrecer un mejor servicio; entre los precios más económicos se puede encontrar bicimotos de segunda mano a S/.650 y nuevas desde S/.750 en Bicimotos Pirata Bike, pero también encontramos muchos vendedores “en campo" que tienen precios más económicos; este tipo de comerciantes los podemos encontrar en Jirón de la Unión; Cercado de Lima donde se encuentran los mayoristas de las piezas de bicicletas y se exhiben bicimotos en las calles para atraer la atención. En cuando al conocimiento de los comerciantes; este podría ser muy variable, por lo que es importante que el cliente tenga alguna noción sobre las bicimotos para no ser víctima de engaños. 


\section{Diamante de Porter.}

De acuerdo con Consultores Ematris Offshore (2009) en un análisis del diamante de Porter para un estudio de mercado chileno, las barreras de entrada son altas por un tema legislativo de importación, pero esto no es replicable a Perú, ya que no existen restricciones para importar bicimotos o motores a gasolina, es más, se cuenta con un advalorem del $0 \%$ gracias al TLC con China; quien es proveedor único de estos insumos. El poder de negociación de los clientes es medio-alto, debido a que hoy en día existe más oferta, no solo de bicimotos, sino también de sustitutos bastante económicos, con una homologación y legislación clara. Se puede decir lo mismo del mercado peruano, ya que recientemente por la masificación de estos vehículos el MTC lanzó nuevas normas de regularización, pero que aún no son lo suficientemente claras para ejecutarse.

Por otro lado, los sustitutos de las bicimotos tienen un alto poder de negociación, ya que existe competencia indirecta como las bicicletas tradicionales y motocicletas, sin embargo, para optar por una motocicleta se deberá tener un mayor poder de compra, debido a que el precio es mayor, por otro lado, las bicicletas tradicionales alcanzan velocidades muy bajas y son más desgastantes al compararlas con la eficacia de las bicimotos. Los proveedores tienen un bajo poder de negociación, ya que, a pesar de ser el único país productor de los insumos necesarios para ensamblar una bicimoto, existen gran cantidad de productores que comercializan sus productos internacionalmente, aunque los proveedores de alta calidad que son reconocidos mundialmente tienen un alto poder de negociación debido a su nivel de preferencia del consumidor, como lo son marcas como Shimano, SRAM o Campagnolo. Por último, el mercado potencial de compradores de bicimotos, el transporte público urbano sería un sustituto que cumple el 
mismo fin, pero debido a la mala calidad de servicio, este pierde niveles de aceptación en el público. Finalmente, el análisis nos muestra que hay una baja rivalidad entre los competidores, pero como se mencionó anteriormente, hoy en día la demanda ha aumentado y ya existen numerosos comerciantes de bicimotos en Lima formales e informales.

\subsubsection{Bicicleta Eléctrica, Bicimoto Eléctrica o e-bike}

De acuerdo con Vaic (2016), la bicicleta eléctrica, bicimoto eléctrica o e-bike es un vehículo de dos ruedas muy ligero que puede tener o no pedales que complementa la movilización del vehículo mediante la electricidad generada por el motor. Tiene una autonomía de 5 a 6 horas con una carga de 3 horas y cuenta con motor desde los $250 \mathrm{kw}$. Motores por encima de los 1000w ya son considerados scooters eléctricos, hoy en día los motores más utilizados son los de litio, ya que son los más limpios, de tamaño reducido, poco peso y sin efecto memoria (Híbridos y Eléctricos, 2013). Las velocidades oscilan entre 25 a $35 \mathrm{~km} / \mathrm{h}$. Se pueden clasificar en bicicleta eléctrica pura o ciclomotores eléctricos, el cual se compone de un motor eléctrico dentro del marco de la bicicleta y se moviliza con la fuerza eléctrica solo con la rotación de la manija, y también existen la bicicleta de accionamiento mecánico o pedelec, que combina el movimiento humano con la fuerza eléctrica; es decir, tan solo ayuda con el pedaleo más no acciona por si sola (Abagnale, 2015). Además, debido a que solo se alimenta de carga eléctrica, no emite gases contaminantes por lo que se vuelve ecoeficiente (Mostafavi y Doherty, 2014).

Los componentes para la bicimoto eléctrica constan de: motor, batería, sensor de pedal, aro de llanta y mando de control. Para las instalaciones, se pueden hacer por medio de dos 
enfoques: con una ubicación del motor en el buje de la rueda, con un ensamblaje sencillo, bajos costos de mantenimiento y fabricación; siendo la técnica más utilizada. El otro enfoque es el motor instalado en el eje del pedalier; en donde la fuerza es conducida sobre el piñón y el correcto funcionamiento dependerá de la habilidad del ciclista para introducir los cambios de velocidades. Este sistema es utilizado por Yamaha y Panasonic, pero por lo mismo es un poco más complicado y costoso. (Medio Ambiente y Naturaleza, 2016).

\subsubsection{Productos Sustitutos}

Los productos sustitutos pueden no ser totalmente idénticos a los que produce cierta empresa; por lo que comprende una competencia indirecta que, si no se maneja, puede llegar a ser una verdadera amenaza, ya que se vuelve en una opción de compra atractiva para el potencial cliente que muchas veces puede ser más económica o eficiente (EAE Business School, 2018). Según Economipedia (2017), un bien sustituto cubre la misma necesidad que otro, aunque no cumpla con las mismas características o precio, también puede basarse en una tecnología diferente (Porter, 1997).

Los bienes sustitutos tienen demandas relacionadas entre sí, ya que se espera que un bien aumente de precio, su demanda baje y, por ende, la demanda del sustituto se incremente al reemplazar al anterior; esto se conoce en economía como elasticidad cruzada (Beltrán y Cueva, 2003). A pesar de esto, la aparición de productos sustitutos no es siempre evidente.

Algunos de los factores que incrementan la fortaleza de los productos sustitutos son:

- Disponibilidad del producto

- Precio

- Calidad 
- Rendimiento

- Desconocimiento de la ventaja diferencial

A su vez, existen grados de sustituibilidad yendo desde la sustituibilidad perfecta; que se da cuando el cliente no percibe diferencias entre ambos, hasta la sustituibilidad reducida e imperfecta, cuando se notan algunas diferencias. Por otro lado, Porter (1997) nos dice que existen dos ocasiones en donde los sustitutos se vuelven fuertes amenazas rápidamente cuando no se da algún cambio aparente en la competencia o precio, estos son: relacionados a una tendencia de mejora de desempeño y precio; como el caso de los vehículos de transporte alternativos como la motocicleta, bicimoto o vehículos eléctricos, o en el caso de productos de sectores industriales que tienen un alto rendimiento.

Este concepto es aplicable a lo que son los vehículos de transporte alternativo privado; un sustituto de vehículo común de transporte, que entrega ventajas como ahorro de dinero y tiempo, además, se contribuye con el medio ambiente. Es por mucho más económico que un auto, sin embargo, presenta una funcionalidad similar y comete el mismo objetivo: trasladarse.

De acuerdo a Cornejo (1994), la sustitución de productos perfecta solo puede darse cuando los productos son exactamente iguales, ya que, si no cumplieran con la misma necesidad o se cubriera parcialmente, no tendría por qué afectar sustancialmente la demanda del primero y como estos productos rompen con el concepto de un monopolio perfecto, puesto que, aunque no haya competencia directa, siempre habrá un sustituto en el mercado. Esto es aplicable a los vehículos de transporte alternativos, ya que cubren parcialmente la necesidad principal; que es trasladarse individualmente y con comodidad, pero hay factores conexos como la flexibilidad y espacio que no son completamente iguales. 


\subsubsection{Elasticidad Ingreso de la Demanda}

Este indicador mide el grado de variabilidad en cuanto al consumo de un bien, respecto a la variación de los niveles de ingreso o renta. También es conocido como "elasticidad renta" y uno de los ejemplos más comunes es; a más ingreso, más consumo de bienes y servicios (Fortún, M. 2020).

Bajo una ecuación, se busca entender el comportamiento del consumo:

$$
E_{I}=\frac{\text { Variación } \% \text { en la Cantidad Demandada }}{\text { Variación } \% \text { en el Ingreso }}=\frac{\frac{\Delta Q}{Q}}{\frac{\Delta I}{I}}
$$

De acuerdo al resultado, se divide a los bienes mediante una clasificación:

- Bienes Normales: Con valores positivos.

- Bienes de Lujo: Con valores mayores que uno.

- Bienes Inferiores: Con valores negativos.

- $\quad$ Bienes de Primera Necesidad: Con valores positivos, pero menores a uno.

De acuerdo a este concepto, BBVA Research (2010) nos indica en su análisis económico de la situación automotriz del Perú que, a mayor ingreso en las familias peruanas, hay una mayor demanda de vehículos que conlleva el aumento de actividad económica, clasificando así, a los automóviles como bienes de lujo al tener una elasticidad ingreso de 1.21 como podemos ver en la Tabla 1 y se comprueba en la ecuación mostrada. 
Tabla 1.

Elasticidad Ingreso de Automóviles en Perú

\begin{tabular}{cc}
\hline $\mathrm{N}^{\circ}$ Autos por Hogar & $\begin{array}{c}\text { Ingreso Bruto Promedio } \\
\text { Anual (S/.) }\end{array}$ \\
\hline 1 & 50183 \\
\hline 2 & 85302 \\
\hline
\end{tabular}

Fuente: BBVA Research (2010)

Elaboración: Propia

En donde se reemplazan valores y se obtiene:

$$
E_{I}=\frac{\frac{2-1}{2}}{\frac{85302-50183}{85302}}=\frac{0.5}{0.412}=1.213
$$

Lo que significa que la demanda de vehículos aumenta proporcionalmente más que el aumento de la renta. Por ejemplo, si la renta aumenta 1 por ciento, la demanda de vehículos aumenta es 1.213 por ciento. Los bienes cuya elasticidad ingreso es mayor a uno, se conocen como "bienes elásticos". 


\subsection{Objetivos e Hipótesis}

\subsubsection{Objetivos.}

\section{Objetivo General.}

Descubrir si existe una relación entre el parque automotor y la cantidad de vehículos alternativos.

\section{Objetivos Específicos.}

- Definir el tipo de relación que existe entre el parque automotor y la cantidad de vehículos alternativos en Lima, desde 2010 hasta 2018

- Identificar los factores que influyen en la relación entre el parque automotor y la cantidad de vehículos alternativos.

- Conocer los elementos que influyen en la cantidad de vehículos alternativos.

- Reconocer si existe una relación entre los problemas del parque automotor y su crecimiento.

- Comprobar si los vehículos alternativos son una posible solución ante los problemas del parque automotor.

\subsubsection{Hipótesis.}

\section{Hipótesis General.}

Existe una relación entre el parque automotor y la cantidad de vehículos alternativos en Lima, desde el 2010 al 2018. 


\section{Hipótesis Especificas.}

- La relación entre el parque automotor y la cantidad de vehículos alternativos en Lima es de tipo inverso.

- La congestión vehicular, contaminación e inseguridad influyen en la disminución del parque automotor y aumento de la cantidad de vehículos alternativos.

- El ahorro de tiempo y dinero junto con el encarecimiento de los precios influyen en la cantidad de vehículos alternativos.

- Los problemas del parque automotor han hecho que su crecimiento se detenga.

- Los vehículos alternativos son una solución viable para la congestión vehicular, contaminación e inseguridad de los conductores en Lima. 


\section{Capítulo 2}

\subsection{Método}

El método usado en esta investigación fue un enfoque cuantitativo, ya que se realizaron encuestas para contabilizar respuestas que permitieron consolidar información junto a investigaciones previas relacionadas al tema, que permitieron encontrar el grado de asociación y correlación entre las variables mencionadas para una muestra en específico para luego analizar la causa de ésta (Pita, S. \& Pértegas, S., 2002).

\subsubsection{Tipo de Investigación.}

El tipo de investigación utilizado fue correlacional-causal, debido a que, este tipo de investigación busca describir relaciones entre dos o más variables presentadas, analizando su tipo relación e identificando elementos causales que pueden correlacionarse entre sí desde el principio, todo esto en un contexto y rango de tiempo específico (Hernández y Baptista, 2014).

\subsubsection{Diseño de Investigación.}

El diseño de investigación utilizado fue no experimental debido a que se observan las variables en su propia naturaleza, y no se realiza ningún tipo de alteración sobre ellas para demostrar algo (Pallela y Martins, 2011) con enfoque transversal o transeccional, ya que se investiga en un determinado periodo de tiempo, bajo un mismo contexto (Hernández y Baptista, 2014). Además, no se busca realizar experimentos, ni manipular las variables, tampoco se quiere describir o explicar en detalle un fenómeno, si no correlacionar y encontrar el causal entre dichas variables. 


\title{
2.1.3. Variables.
}

\section{Variable X: Parque Automotor.}

El parque automotor es el número total de vehículos circulantes en un espacio determinado; clasificados por vehículos ligeros, de carga y de carga pesada (MTC, 2006). En esta investigación, se excluye a las motocicletas del parque automotor; y se las considera como vehículos alternativos. Además, solo se consideran datos de los vehículos livianos; es decir, automóviles de uso particular. El parque automotor presenta algunos factores de importancia.

\author{
X1: Congestión Vehicular \\ X2: Contaminación Ambiental \\ X3: Inversión de Compra \\ X4: Objetivo de Compra \\ X5: Características del Comprador
}

\section{Variable Y: Cantidad de Vehículos Alternativos.}

Es el total de vehículos motorizados a gasolina o eléctricos y no motorizados no mayores a dos ruedas para el uso privado de transporte. Como, por ejemplo: motocicleta, bicicleta, bicimoto, scooter eléctrico, patín eléctrico, entre otros. Comprende algunos factores de importancia:

\author{
Y1: Ahorro de Tiempo \\ Y2: Beneficios Físicos y Ambientales
}


Y3: Poder Adquisitivo de Compra

Y4: Objetivo de Compra

Y5: Características del Comprador

\subsubsection{Muestra.}

La muestra partió de los distritos de Barranco, Miraflores y Santiago de Surco de la Provincia de Lima para analizar los resultados. Estos distritos fueron escogidos debido a que la población que los habita conforma parte del nivel socioeconómico $\mathrm{AB}$ y $\mathrm{C}+$, que suele ser el público demandante de medios alternativos de transporte como bicimotos, scooters y patines eléctricos y tienen una mayor afluencia de estos. Se analizaron hombres y mujeres de 18 a 39 años; ya que es el rango de edad con mayor necesidad de movilización eficaz y económica hacía un centro de estudios o trabajo, y que por primera vez podrían comprar u obtener un vehículo propio.

Según CPI (2019), la población en Lima Provincia es de 9 millones 481 mil y nos indica la distribución por distritos escogidos de la siguiente manera. 
Tabla 2.

Población por Distritos 2019.

\begin{tabular}{lcc}
\hline & Distrito & Población \\
\hline Barranco & & 37500 \\
Miraflores & 107800 \\
Santiago de Surco & & 360400 \\
\hline & Total & 505700 \\
\hline
\end{tabular}

Fuente: CPI, 2019

Elaboración: Propia

De los cuales, $49.7 \%$ son hombres y $50.27 \%$ son mujeres, $12.8 \%$ tienen entre 18 a 24 años y $25.5 \%$ tiene entre 25 a 39 años. Además, $27.9 \%$ se encuentran dentro del NSE “AB” y $41.3 \%$ en el NSE “C”' (CPI, 2019). Disgregando, se obtuvo una población de 49763 personas.

Bajo estas características, se calculó la fórmula probabilística de población finita para poder hallar el número exacto de muestras a recolectar.

$$
n=\frac{N * Z^{2} * p * q}{e^{2} *(N-1)+\left(Z^{2} * p * q\right)}
$$

Donde "N" es el número total de la población encontrado siendo 49 763, “Z”; es el nivel de confianza del 95\%, siendo un valor de 1.96; “p”, es el grado de probabilidad de ocurrencia de la relación entre el parque automotor y la cantidad de vehículos alternativos de dos ruedas, en este caso; consideramos un $72 \%$ de probabilidad de ocurrencia basándonos en el porcentaje de limeños que terminan estresados a causa del tráfico por lo que estarían dispuestos a cambiar 
si método de transporte (Gestión, 2018), y para "q" que es la probabilidad de no ocurrencia, consideramos un $28 \%$. Finalmente, "e"; que es el grado de margen de error, fue de $5 \%$.

Se pudo obtener la siguiente ecuación, reemplazo los datos mencionados:

$$
n=\frac{49763 * 1.96^{2} * 0.72 * 0.28}{0.05^{2} *(49763-1)+\left(1.96^{2} * 0.72 * 0.28\right)}
$$

El resultado fue de 308 muestras a recolectar.

\subsubsection{Instrumentos de Investigación.}

Los instrumentos de investigación fueron cuestionarios, que nos permitieron hacer 16 preguntas con respecto al tema de investigación a los usuarios que se transportan diario a trabajar y/o estudiar por algún medio de transporte. Además, se realizaron observaciones en campo de las bicimotos y autos circulando. Por otro lado, se obtuvieron datos secundarios por medio de expertos importadores y comercializadores de bicimotos como Pirata Bike, Bicimotos Store y Retrobikes. Finalmente, se realizó un análisis de las estadísticas presentadas por la Asociación Automotriz del Perú, SUNAT, INEI para conocer data acumulada del comportamiento de importaciones de vehículos y vehículos alternativos.

\subsubsection{Procedimientos de Recolección de Datos.}

Las encuestas fueron desarrolladas virtualmente por distintos puntos de los distritos de Barranco, Miraflores y Santiago de Surco. La data estadística se obtuvo desde los portales 
web de SUNAT, AAP e INEI. Sumado a esto, se hicieron consultas mediante correo electrónico y visitas a los expertos en talleres y tiendas. También se pudo observar en horas pico dentro de los distritos mencionados el comportamiento de manejo, diferenciación y contabilización durante días se semana y fines de semana. 


\section{Capítulo 3}

\subsection{Plan de Análisis.}

En base a los datos recolectados de la SUNAT y APP (Asociación Peruana Automotriz), se pudo analizar el comportamiento de las importaciones de cuatro tipos de vehículos: automóviles livianos, motocicletas, bicimotos y vehículos eléctricos a dos ruedas. Los dos primeros medios de transporte fueron calculados por medio de las DUA registradas en Aduanas, se utilizaron netamente vehículos nuevos. El cálculo de las bicimotos se buscó con ayuda de las consultas fuera de línea que la página de la SUNAT ofrece bajo la subpartida arancelaria 8407320000 para luego ser utilizados solo los registros que cumplían con la naturaleza de "kit de motor" o "bicimoto" ya armada con motor mayor o igual a 50cc, pero menor a 250cc. En el caso de los vehículos eléctricos a dos ruedas, se analizó la subpartida arancelaria 8711600000 ya que todas las incluyentes tienen como mínimo un motor eléctrico a propulsión, los cuales pueden ser scooters, patines, motores eléctricos para bicicletas, bicicletas eléctricas armadas o bicicletas de pedaleo asistido. Se hizo la disgregación de la descripción de producto con "Scooter Eléctrico" o "Bicicleta Eléctrica". Además, se contabilizo solo los ítems dentro de la categoría L1, ya que es el equivalente a una bicimoto de baja potencia y velocidad en la que no existen restricciones a la fecha. Para el análisis de motocicletas, se utilizaron los resultados originales de la AAP.

Por otro lado, para el análisis cuantitativo, se realizaron 308 encuestas con las 16 preguntas mostradas en el Anexo 1; en donde se obtuvo data de preferencia de los usuarios que se transportan, perspectiva de viaje y opiniones en cuanto a las regulaciones del sistema de 
transporte, para probar el nivel de satisfacción y oportunidad de sustitución que están dispuestos a realizar.

\subsection{Resultados}

\subsubsection{Presentación de Resultados.}

Se recolectó data de SUNAT, y se combinó la información de las importaciones de bicimotos, vehículos eléctricos, registro de motocicletas (AAP) y el consumo aparente de las bicicletas que se halló con data del 2008 al 2014 de la producción menos la exportación de estas (Infantas, F. \& Mendoza, M., 2017), proyectando los siguientes años hasta el 2018 con un $\mathrm{R}^{2}$ de 0.73 , para así identificar el número presente en la población. Se puede notar en la Figura 1, como la evolución de estos vehículos se ha ido incrementando en los últimos diez años.

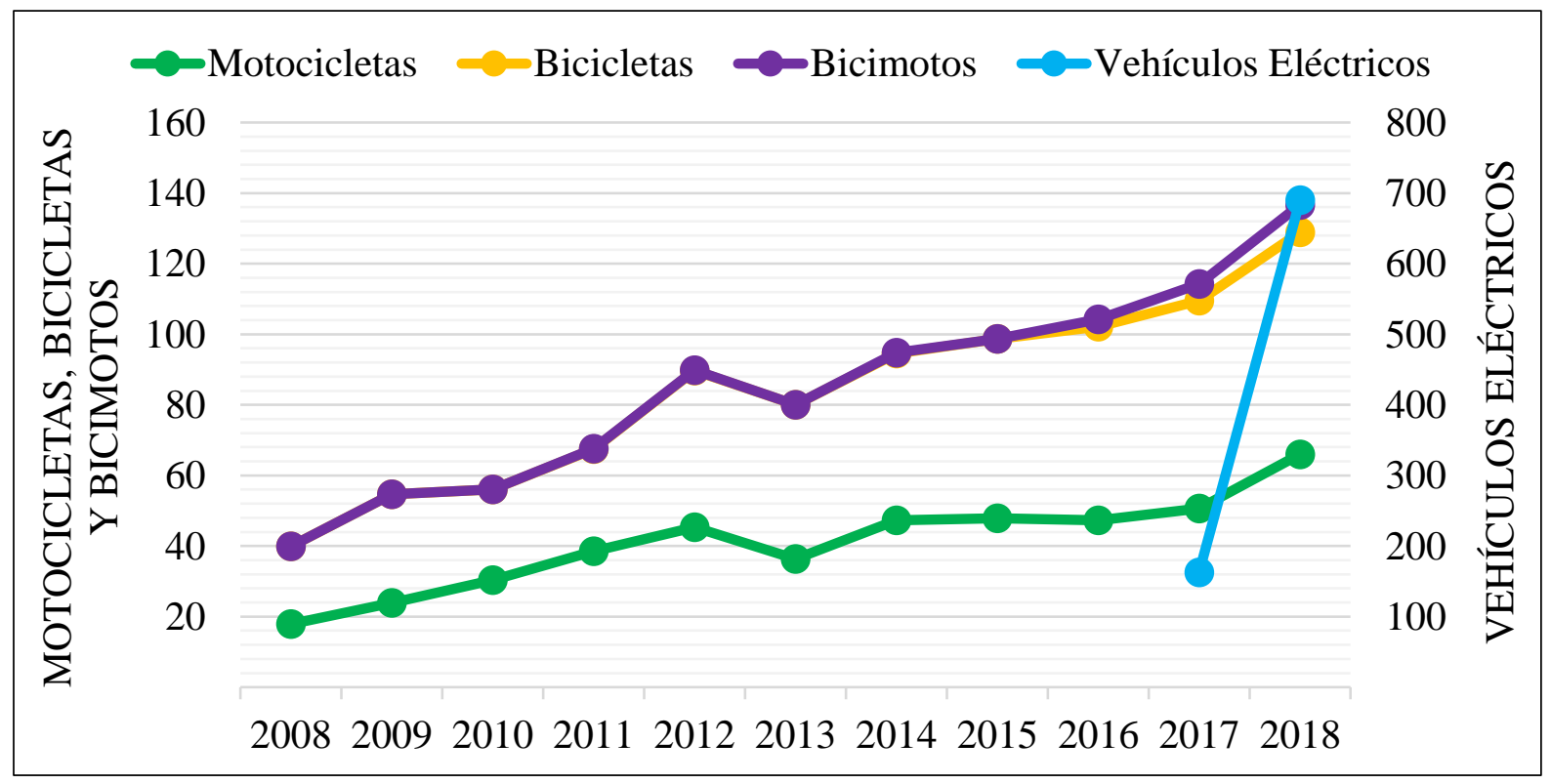

Figura 1. Evolución de los Medios de Transporte Alternativos (En Miles)

Fuente: SUNAT, AAP, Repositorio Universidad de Lima. 
Adicionalmente, se encontró por medio de SUNAT la cantidad de importaciones de bicimotos y vehículos eléctricos mensualizados, como se puede observar en la Figura 2, en donde ambos vehículos han tenido un constante crecimiento a lo largo de los años, aunque tienen periodos de importación bimestral o trimestralmente.

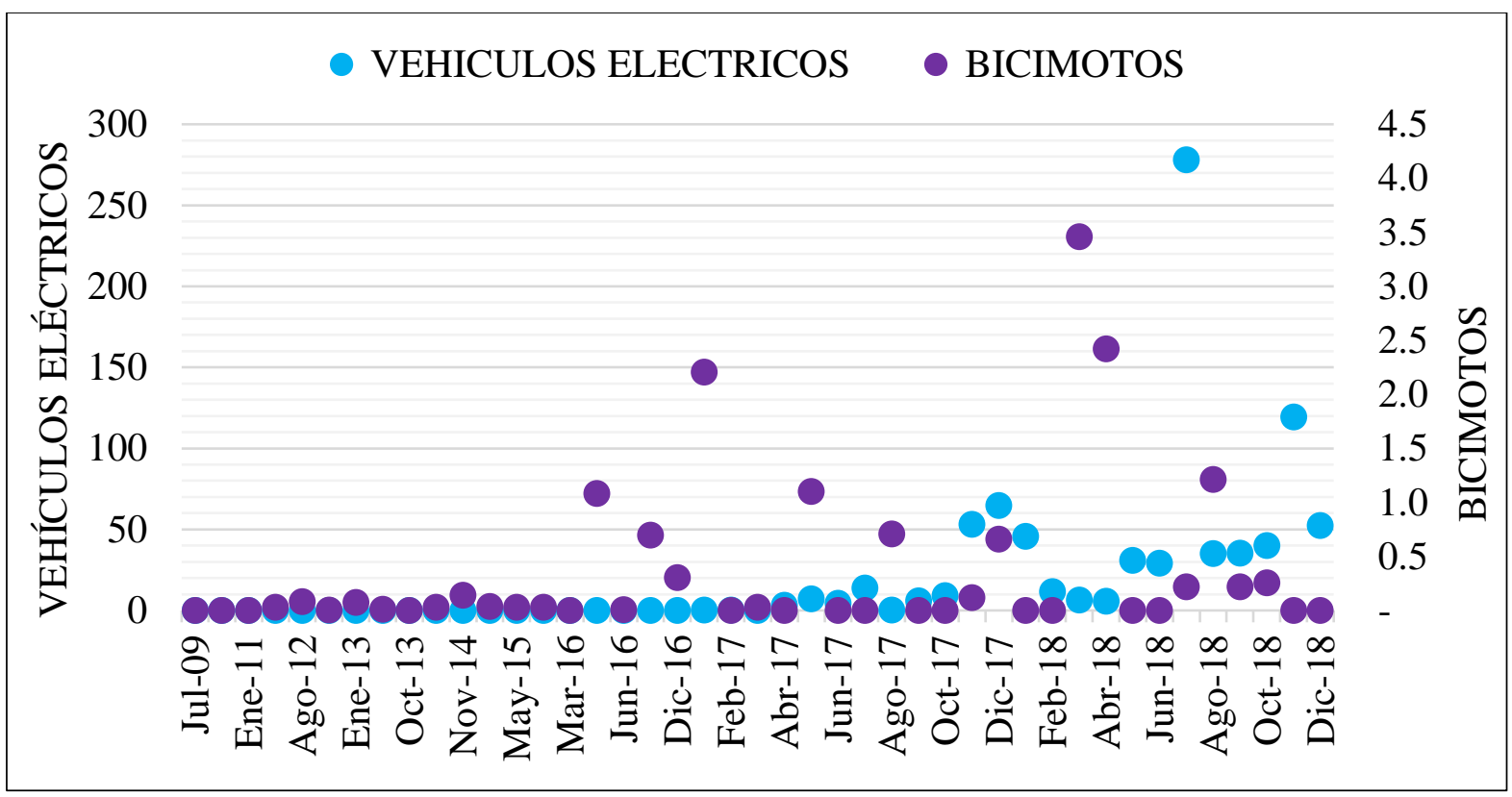

Figura 2. Evolución de las Importaciones de Bicimotos y Vehículos Eléctricos (En Miles)

Fuente: SUNAT

Después de completar el número de encuestas correspondientes, se pudieron obtener los siguientes resultados:

\section{¿Con qué motivo se moviliza con mayor frecuencia?}

El 92\% de la población encuestada se transporta con motivo de trabajos o estudios. En segundo lugar, con un 3\% tenemos el transporte por ocio; es decir para acudir a cualquier actividad por entretenimiento y para hacer compras. Finalmente, un $2 \%$ de la población se moviliza tan solo para llevar a un tercero; ya sea hijos, padres u otros como se muestra en la 
Figura 3. Por lo que se puede inferir, que la movilización individual hacía centros de trabajo y estudios es primordial para la población.

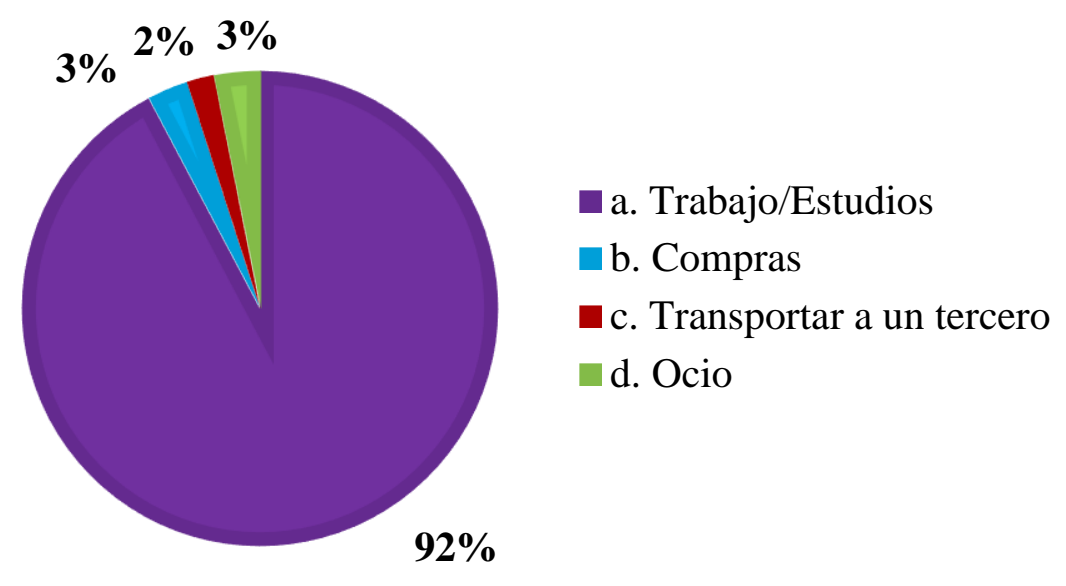

Figura 3. Motivo de Movilización (En Porcentajes)

\section{¿En qué medio de transporte se moviliza con mayor frecuencia?}

El 72\% de la población se moviliza en transporte público, ya sea buses, colectivos, trenes, metropolitanos, entre otros. En segundo lugar, tenemos con un $20 \%$ la movilización mediante automóvil propio y en tercer lugar con 3\% la movilización con bicicleta. Esto nos deja entender la aglomeración que puede existir en los medios de transporte públicos y en la congestión vehicular, ya que las personas viajan individualmente en ya sea un vehículo bastante poblado o, en un vehículo totalmente vacío solo para ellos congestionando las calles. Sumado a esto, existe un $1.9 \%$ que se moviliza a pie. Podemos observar esta información en la Figura 4. 


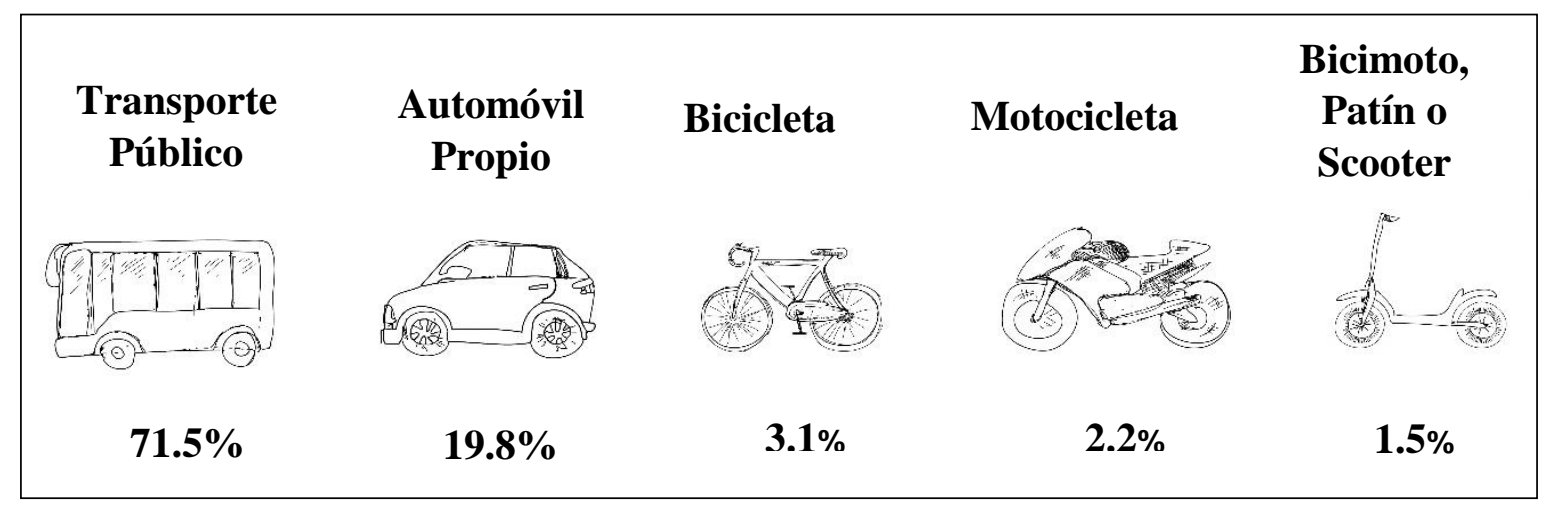

Figura 4. Distribución de Motivos de Movilización (En Porcentajes)

¿Cuántos días a la semana se moviliza generalmente?

La Figura 5, nos muestra que el 58\% de las personas encuestadas se movilizan de 6 a 7 días a la semana, $32 \%$ de 4 a 5 días a la semana y en tercer lugar, con $9 \%$ de 3 a 4 días a la semana. Ninguna reportó movilizarse tan solo una vez a la semana.

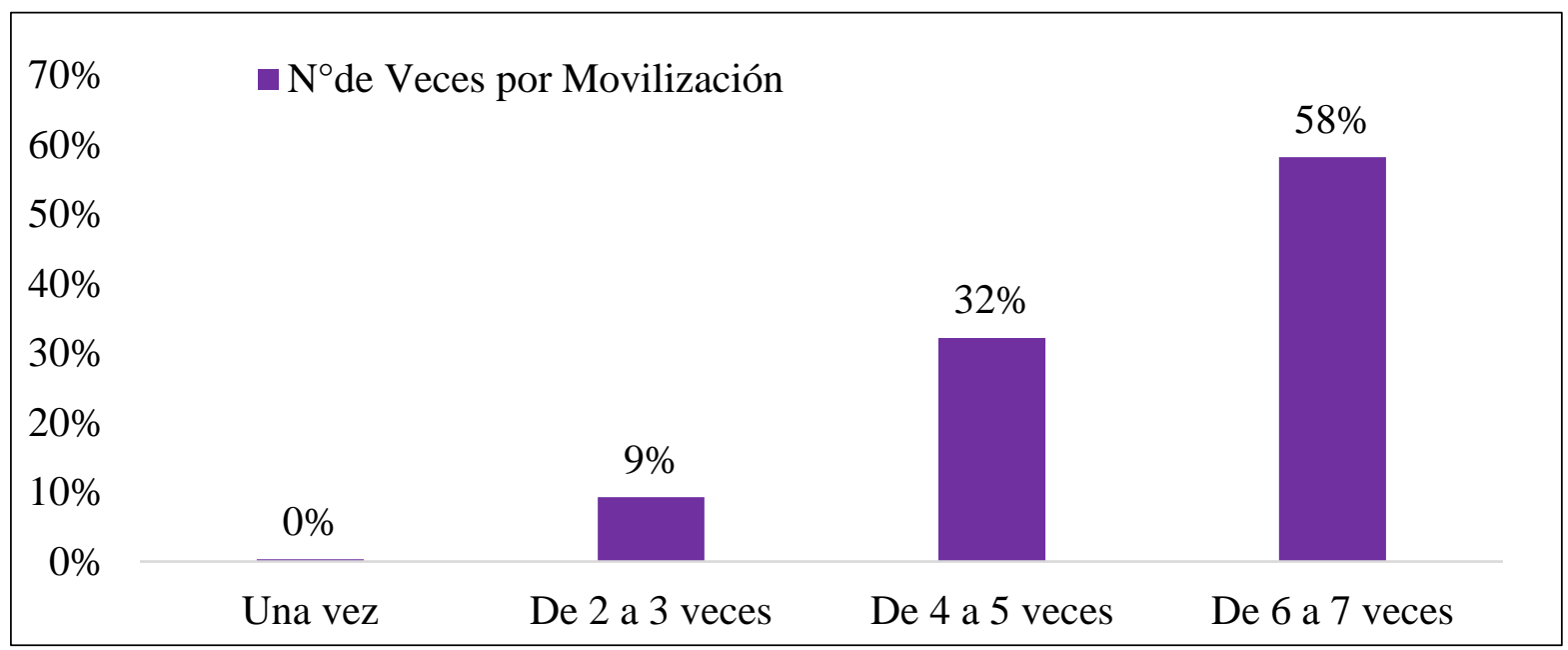

Figura 5. Frecuencia de Movilización (En Porcentajes) 


\section{¿Cuánto tiempo tarda en llegar a su destino?}

El $47 \%$ de los encuestados tarda de 30 minutos a una hora en llegar a su destino, el $24 \%$ tarda de 15 a 30 minutos en llegar a su destino y tan solo con un punto de diferencia con $23 \%$ se encuentran las personas que demoran más de una hora en movilizarse, esto se puede observar en la Figura 6.

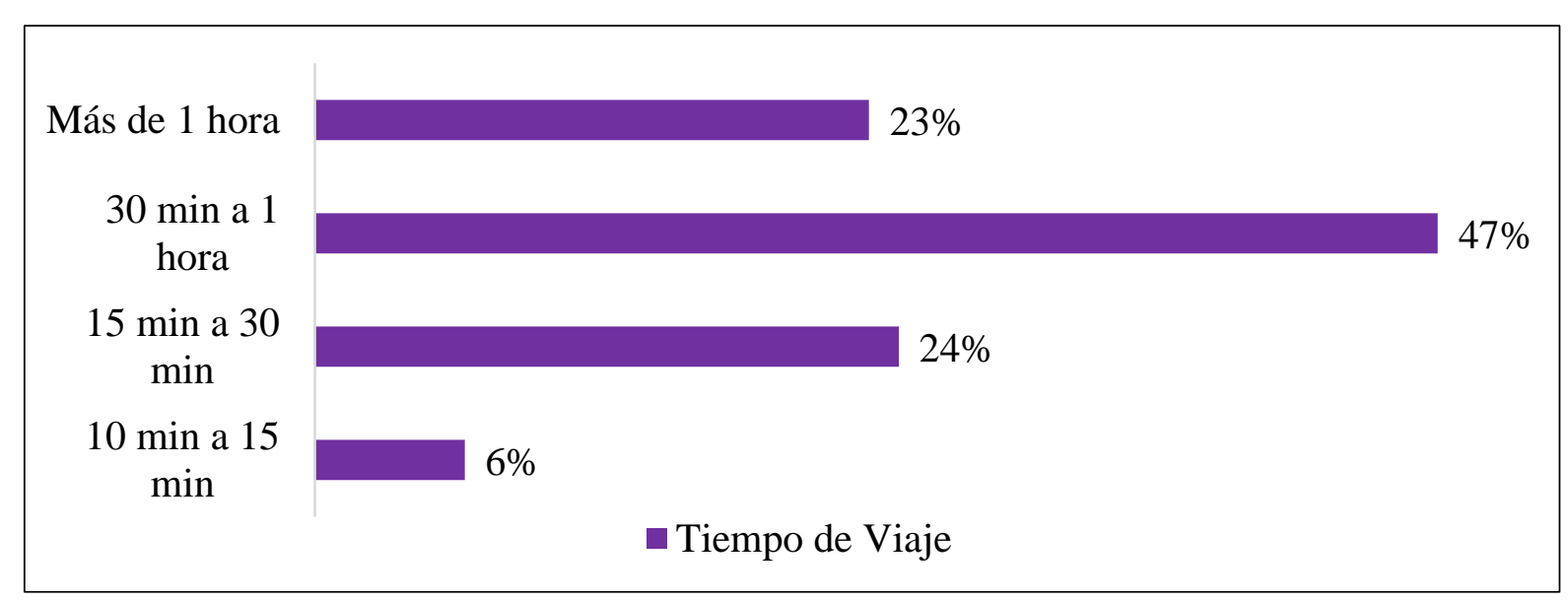

Figura 6. Tiempo de Recorrido (En Porcentajes)

\section{¿Qué es lo que valora más en un medio de transporte?}

En la siguiente pregunta, se dieron a escoger cuatro factores para que los encuestados contestaran el nivel de importancia de cada uno de ellos, desde muy importante hasta sin importancia. Esos factores fueron: rapidez, en términos del tiempo que toma trasladarse; comodidad, en función del nivel de confort durante el trayecto de transporte; economía, en cuanto a la relación precio-costo del medio de transporte utilizado y, funcionalidad, con relación a la practicidad en lograr su cometido de transporte y eficiencia en ésta. La rapidez, comodidad y funcionalidad fueron clasificadas como "Muy Importante" en todos los encuestados, obteniendo los mayores puntajes, con un $65 \%, 55 \%$ y $48 \%$ respectivamente, dejando a la economía en la clasificación de "Importante" con un 48\%. Con esto, podemos 
determinar que, en su mayoría, las personas dan prioridad a la eficiencia y valor del transporte en comparación a su costo. A pesar de esto, la calificación de estos atributos se encuentra entre "Muy Importante" e "Importante" lo que se debería considerar al momento de evaluar los atributos para seleccionar un medio de transporte. La clasificación de estos factores como "Nada Importante" fue menor al 1\% del total de los encuestados. El resultado se muestra en la Tabla 3 y Figura 7.

Tabla 3.

Valoración de Atributos (En Porcentajes)

\begin{tabular}{lcccc}
\hline \multicolumn{1}{c}{ Atributo } & Muy & Algo & Nada \\
& Importante & Importante & Importante & Importante \\
\hline Rapidez & 65 & 32 & 4 & 0 \\
\hline Comodidad & 55 & 35 & 9 & 1 \\
\hline Economía & 42 & 48 & 9 & 1 \\
\hline Funcionalidad & 48 & 39 & 11 & 1 \\
\hline
\end{tabular}

Fuente: Encuesta de Medios Alternativos de Transporte

Elaboración: Propia 


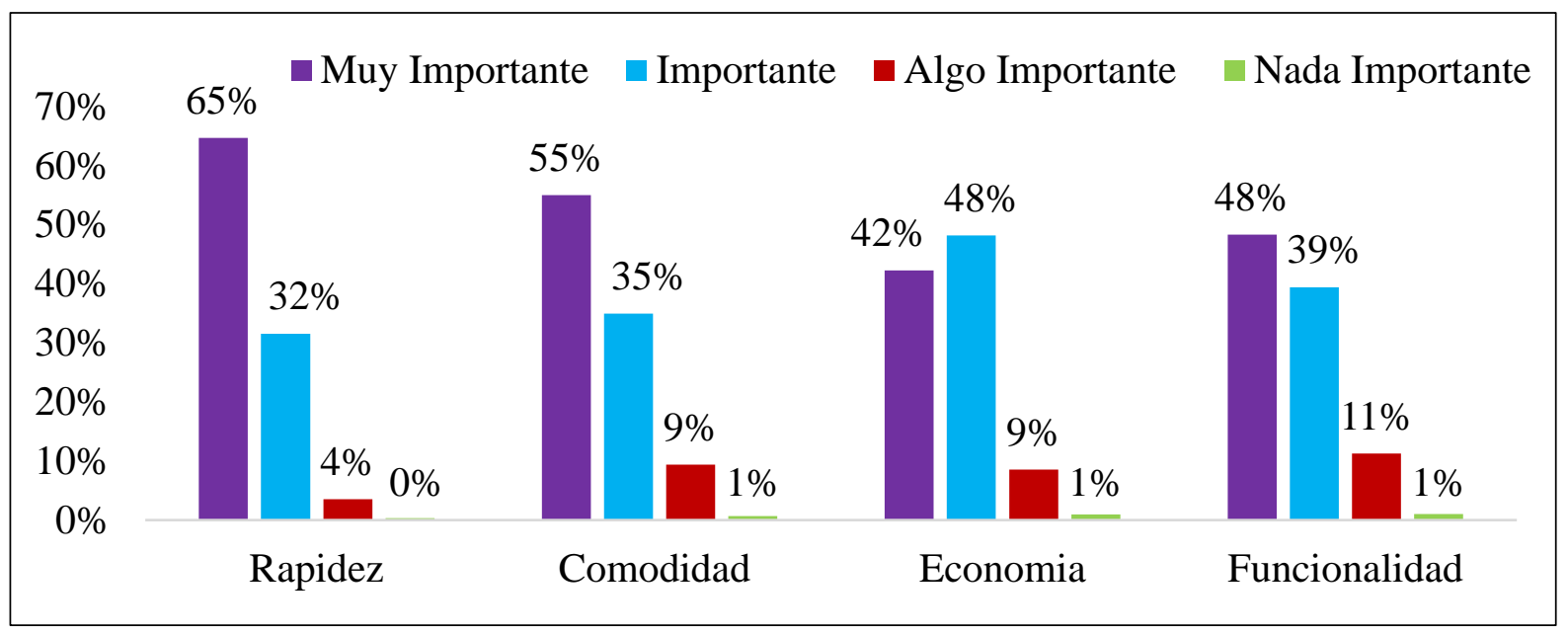

Figura 7. Niveles de Importancia de los Atributos de Transporte (En Porcentajes)

\section{En la escala del 1 al 5 calificar el nivel de insatisfacción o lo que más le incomoda de los} siguientes aspectos de movilizarse por las calles de Lima, donde 5 es muy insatisfactorio y 1 es poco insatisfactorio.

En esta pregunta se evaluó cuatro aspectos sobre la movilización en Lima: tráfico, seguridad, comodidad y contaminación, en donde se debía clasificar qué tan fuerte era el nivel de insatisfacción de cada uno de ellos. En la Tabla 4 y Figura 8, podemos observar que los mayores puntajes de insatisfacción son para el tráfico, seguridad y contaminación dentro de la clasificación de "Muy Insatisfactorios" obteniendo 66\%, 45\% y 44\% respectivamente. Tan solo el $25 \%$ piensa que la comodidad es "Insatisfactorio", lo que significa que, de todos estos factores, el factor incomodidad es el que más podrían tolerar si es que el transporte fuera eficiente. Esto concuerda con la calidad deficiente del servicio de transporte público en Lima y las aglomeraciones que aun así se forman en las colas de los trenes, corredores y Metropolitano ya que es un aspecto que, aunque cause insatisfacción están dispuestos a tolerar para poder transportarse. 
Tabla 4.

Insatisfacción hacía los Medios de Transporte Públicos

\begin{tabular}{lccccc}
\hline Aspecto de & 5 & 4 & 3 & 2 & 1 \\
Insatisfacción & & & & & \\
\hline Tráfico & 66 & 11 & 8 & 3 & 11 \\
\hline Seguridad & 45 & 25 & 13 & 8 & 9 \\
\hline Incomodidad & 28 & 23 & 30 & 12 & 7 \\
\hline Contaminación & 44 & 20 & 17 & 9 & 9
\end{tabular}

Fuente: Encuesta de Medios Alternativos de Transporte

Elaboración: Propia

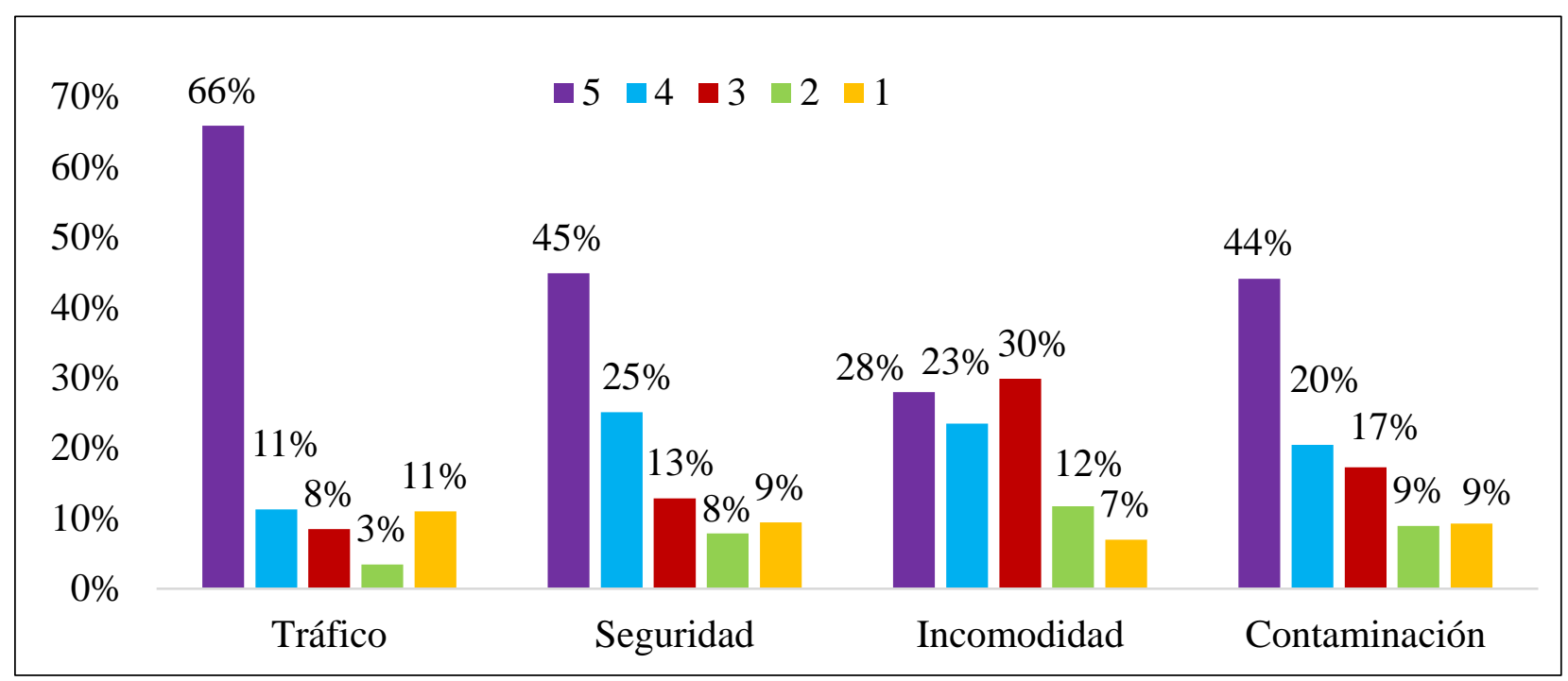

Figura 8. Niveles de Insatisfacción de acuerdo a los Aspectos de Movilización (En Porcentajes) 
¿Qué tan satisfecho se encuentra con el transporte público de Lima (Metropolitano, Tren

Eléctrico, Corredores Municipales, Microbuses, etc.)?

En cuanto a la satisfacción de las personas encuestadas con el transporte público, podemos observar en la Figura 9, que el 38\% se encuentra parcialmente satisfechos, seguido de un 23\% que están totalmente insatisfechos y $21 \%$ se encuentran algo insatisfechos, lo que significa que la mayoría de la población tiene una tendencia hacía la insatisfacción en general y que tan solo el 3\% se encuentra totalmente satisfecho.

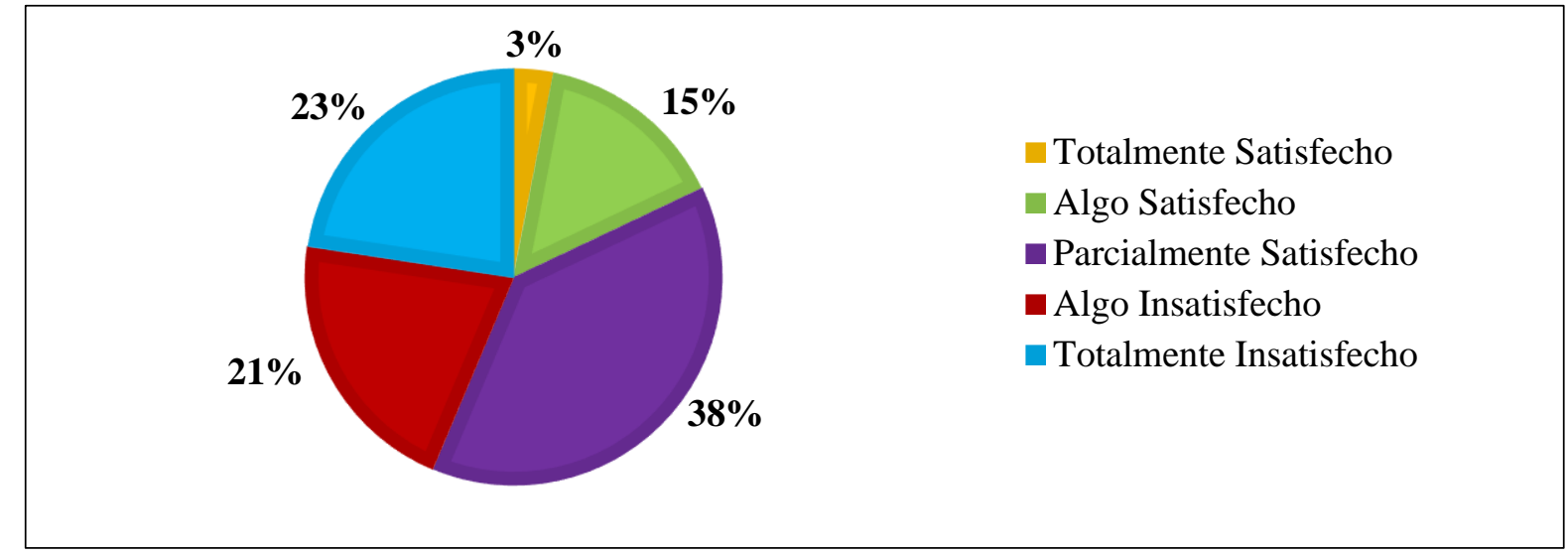

Figura 9. Nivel de Satisfacción con el Transporte Público

¿Cuánto gasta en transporte mensualmente? Sea en transporte público, taxi o en su propio vehículo (combustible más otros gastos)

El 42\% de los encuestados gasta de S/ 100 a S/ 200 en su medio de transporte mensualmente, el $23 \%$ gasta menos de S/ 100 y en tercer lugar con $20 \%$ se encuentran las personas que gastan de S/ 200 a S/ 300 en transporte. Tan solo el 2\% de los encuestados reporta no gastar dinero en su medio de transporte, los cuáles son los que se movilizan en 
bicicleta o van a pie. La media mayor va concorde al porcentaje de encuestados que viajan en transporte público como se observa en la Figura 10.

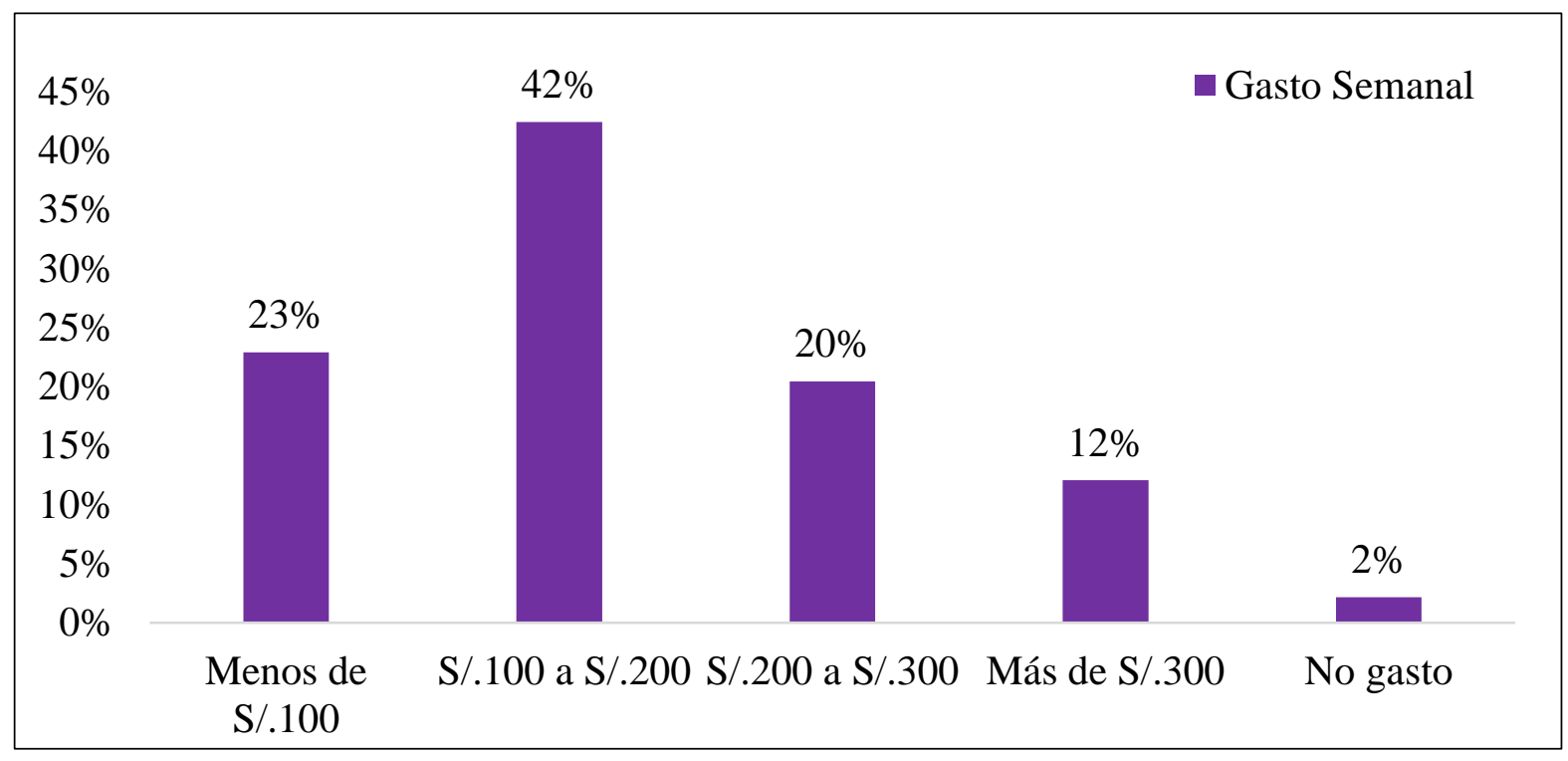

Figura 10. Gasto Promedio Semanal en Transporte (En Porcentajes) 
¿Conoce los medios de transporte alternativos (bicimoto, scooter, patín o bicicleta eléctrica)?

Como podemos observar en la Figura 11, el 91\% de los encuestados conoce los medios de transporte alternativos y solo el $9 \%$ reportó no conocerlos, aunque por medio de la encuesta realizada, ya tienen conocimiento de ellos.

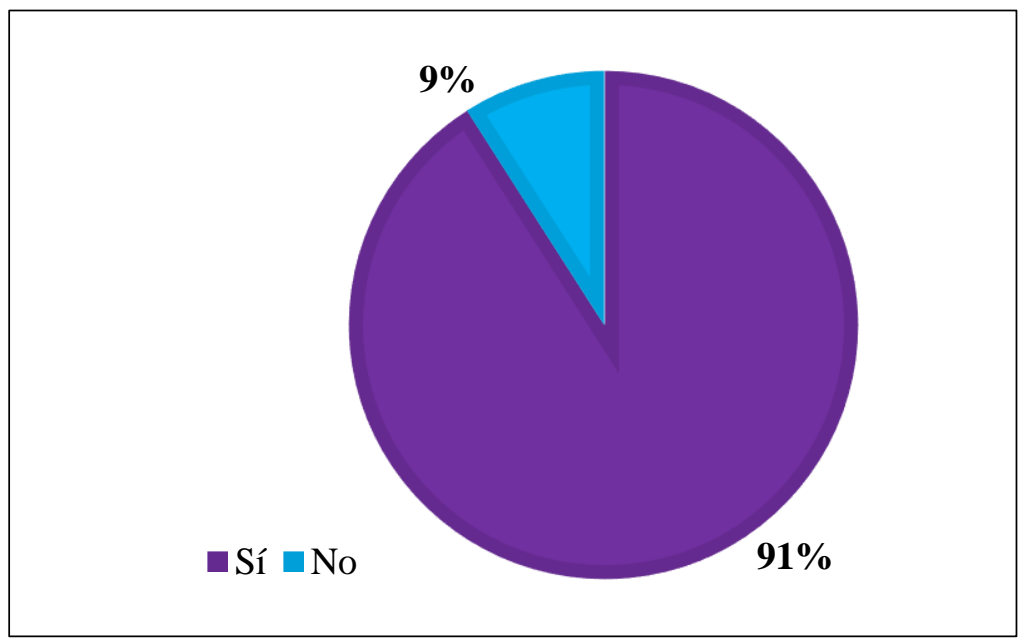

Figura 11. Proporción de Conocimiento de los Medios de Transporte Alternativos en la Población 


\section{¿Ha considerado sustituir su tipo de movilización actual a un medio de transporte alternativo?}

La Figura 12, nos muestra el $65 \%$ de los encuestados ha considerado sustituir su medio de transporte por uno alternativo; y $35 \%$ no lo ha hecho.

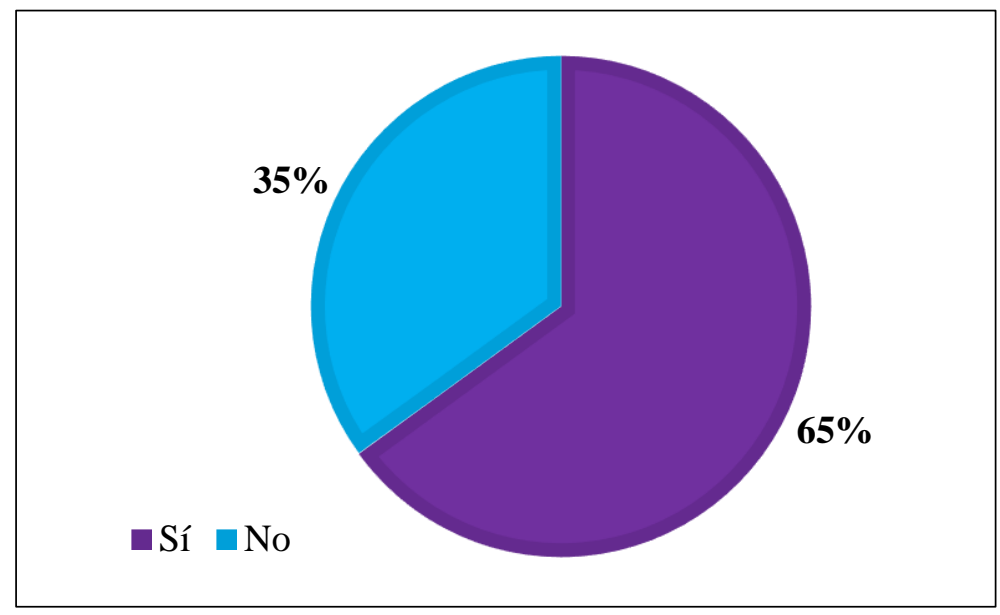

Figura 12. Proporción de la Consideración sobre Sustituir el Medio de Transporte Actual por un Vehículo Alternativo en la Población

\section{¿Qué factores lo incentivan a sustituir su medio de transporte por uno alternativo?}

Siguiendo con la pregunta anterior, observamos la Figura 13 en donde se le dieron a escoger a los encuestados diferentes motivos por lo cual sustituirían su medio de transporte, entre ellos: tráfico o congestión vehicular, precio y/o economizar, tiempo perdido en la movilización, inseguridad, contaminación y otros. El 37\% de los encuestados posicionó a la razón principal al tráfico o congestión vehicular que sufren con su medio de transporte actual, la segunda razón con un $25 \%$ sería el tiempo perdido en movilizarse y, por último, con un $23 \%$ el precio y/o economizar de su medio de transporte actual. Aunque, si bien solo con un $1 \%$, los encuestados concordaron dentro del campo de "otros factores" a la comodidad. 


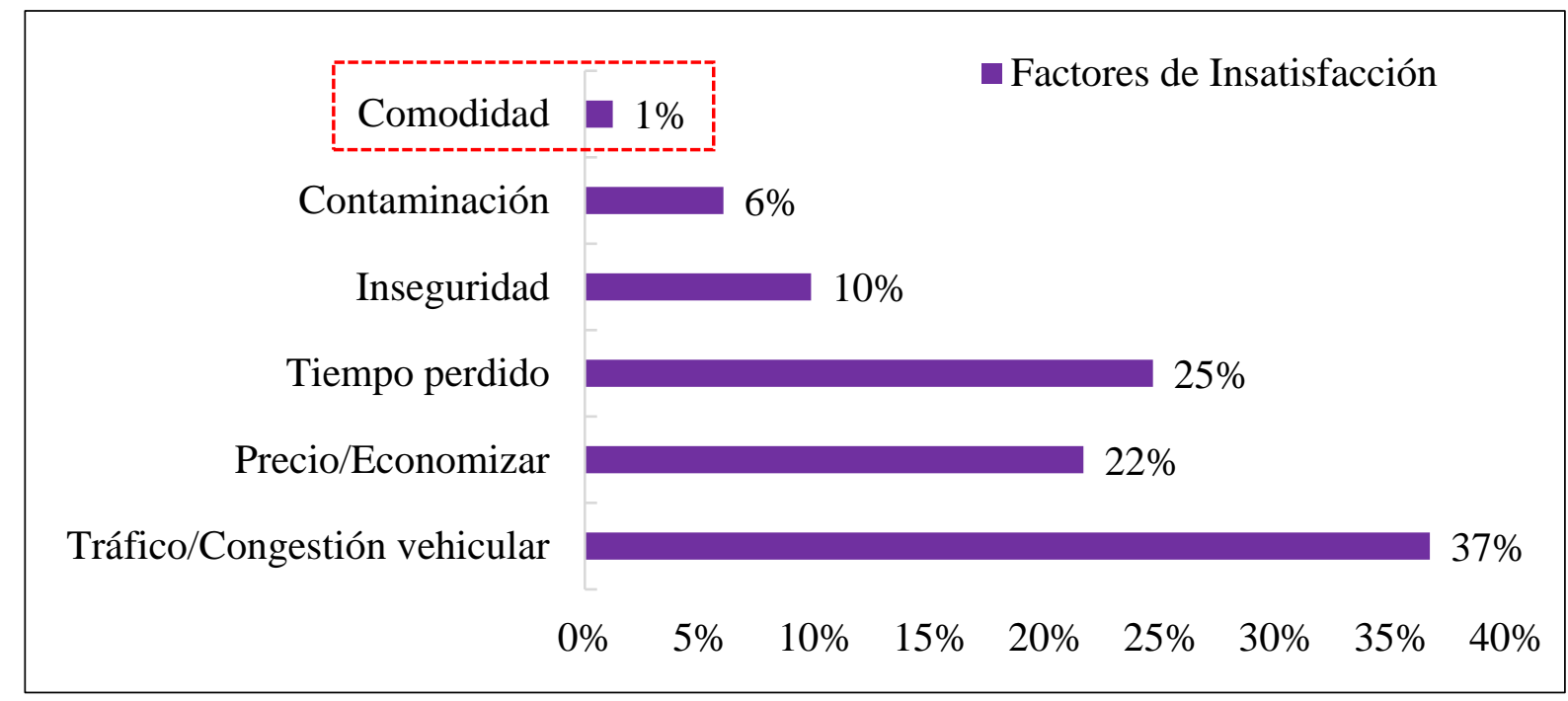

Figura 13. Incentivos para Sustituir El Medio de Transporte Actual por uno Alternativo (En Porcentajes)

\section{¿Qué le desalienta de pasarse a un medio de transporte alternativo?}

En cuanto a las trabas que frenan a los encuestados a cambiarse de medio de transporte, se dieron a escoger las siguientes alternativas: falta de ciclovías o vías especializadas para estos medios de transporte, cultura vial de conductores y/o peatones, falta de definición en el reglamento peruano en cuanto a la regulación de estos vehículos, precio o accidentes. Un 33\% de los encuestados determinó que la falta de ciclovías o vías especializadas sería la razón principal por la que no se cambiarían de medio de transporte, la cultura vial y de peatones ocupa un $26 \%$ ubicándolo en el segundo lugar y la tercera razón con un $18 \%$ sería la falta de regulación por parte del Estado para los medios alternativos de transporte. Tan solo un $7 \%$ considera que la razón principal sería el precio; reafirmando así el valor y eficacia del medio de transporte sobre su precio. Estos resultados los podemos observar en la Figura 14. 


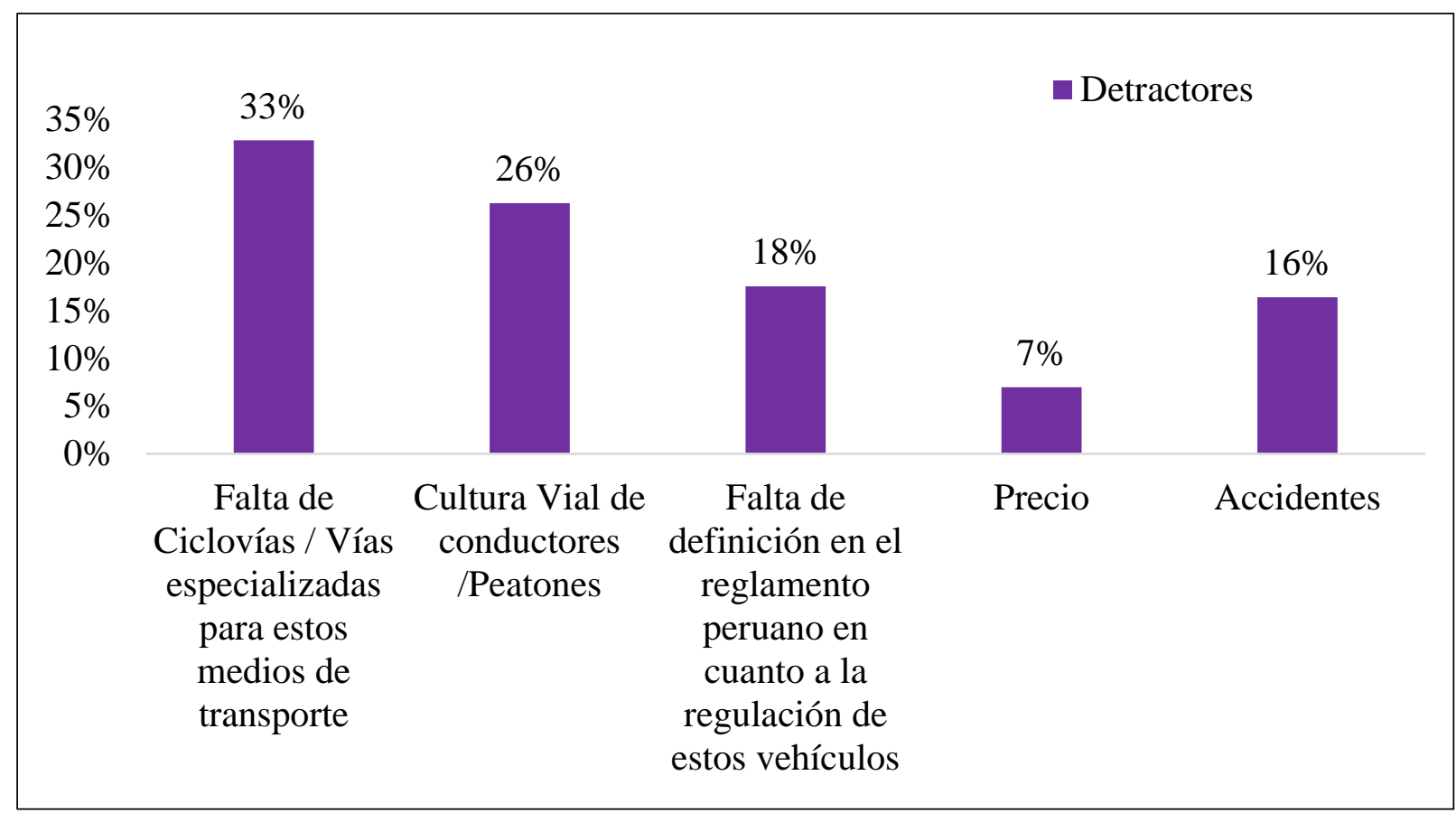

Figura 14. Detractores para la Sustitución de un Medio de Transporte Tradicional a un Transporte Alternativo (En Porcentajes)

¿Considera que alguno de los medios de transporte alternativo sería una solución para el tráfico vehicular?

El 39\% de los encuestados considera que los medios de transporte alternativos podrían solucionar parcialmente el tráfico vehicular. En segundo lugar, un 35\% está totalmente de acuerdo con que los medios de transporte alternativos serían una solución y el 19\% solo estaría de acuerdo. En esta pregunta podemos confirmar que más del $90 \%$ considera a estos medios de transporte como una solución viable al tráfico. 


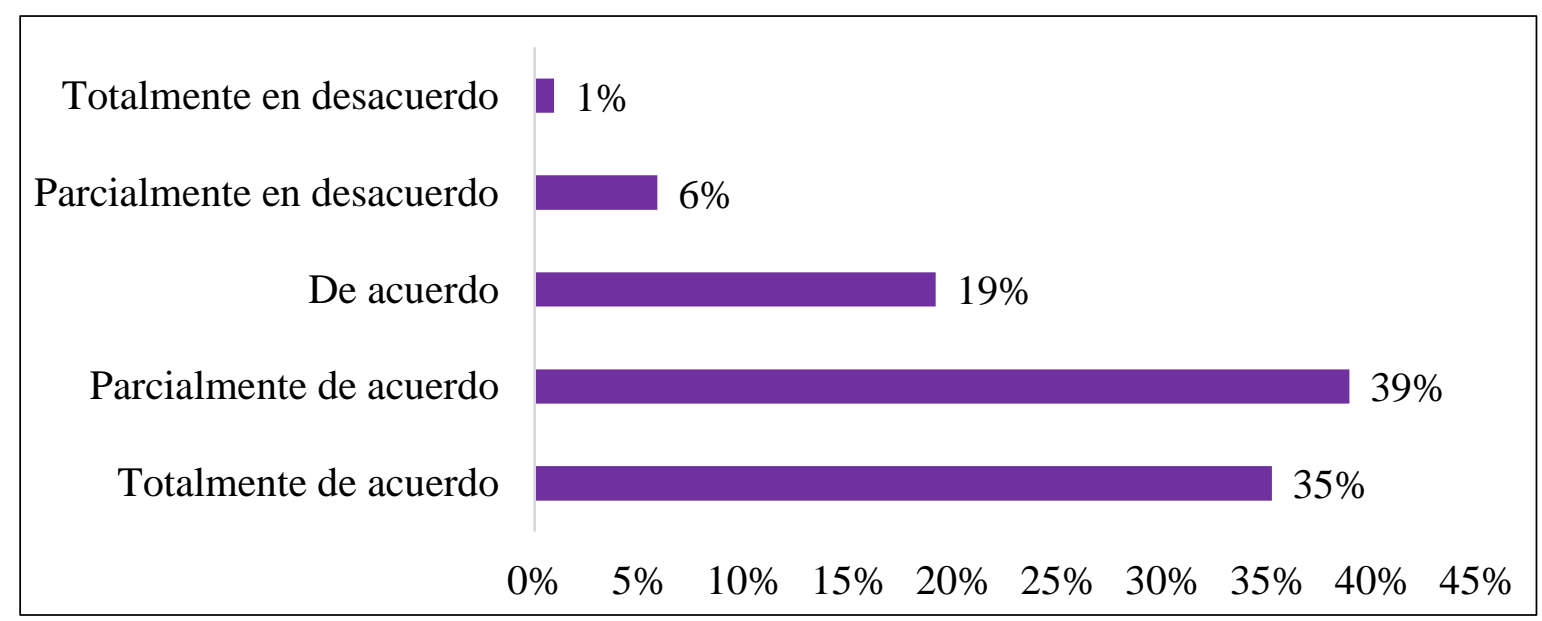

Figura 15. Niveles de Conformidad en Cuanto a la Propuesta de Medios de Transporte Alternativos como Sustitutos de los Medios Transporte Convencionales

¿Considera Ud. que El Estado peruano propone soluciones para los problemas del tráfico en Lima?

La Figura 16 nos muestra el 80\% considera que El Estado peruano no propone soluciones para los problemas del tráfico en Lima, el 20\% considera que sí.

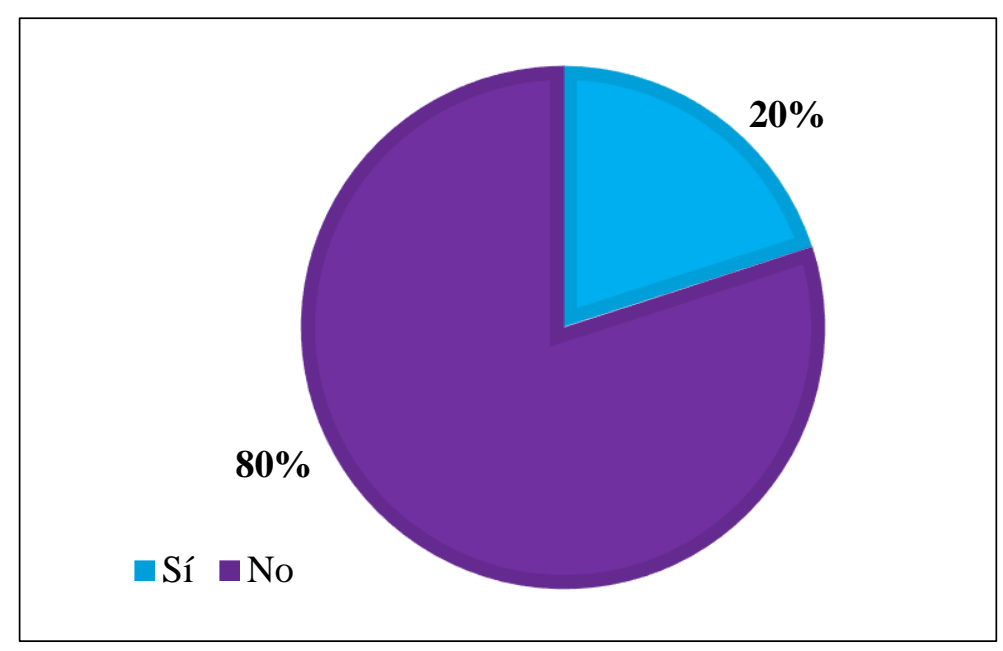

Figura 16. Proporción de las Consideraciones de la Población sobre las Soluciones que El Estado Propone para los Problemas del Tráfico Vehicular (En Porcentajes) 
De acuerdo a las recientes regulaciones para el uso de bicimotos y scooters eléctricos: Registro de placa, brevete, SOAT, entre otros no establecidos, ¿opina que esto es parte de una solución para el orden del tráfico o que influye negativamente ante posibles soluciones a este?

Como se puede observar en la Figura 17, el 73\% de los encuestados piensa que las últimas regulaciones del Estado son necesarias para ordenar el tráfico en Lima, el 27\% considera que estas regulaciones son innecesarias. Por otro lado, en la Figura 18, observamos que el 63\% considera que las regulaciones van por encima de lo necesario para estos medios de transporte alternativos y afectan las posibles soluciones de transporte, y el $36 \%$ considera que las regulaciones van de acuerdo a lo necesario para estos tipos de vehículo y no afecta las posibles soluciones de transporte.

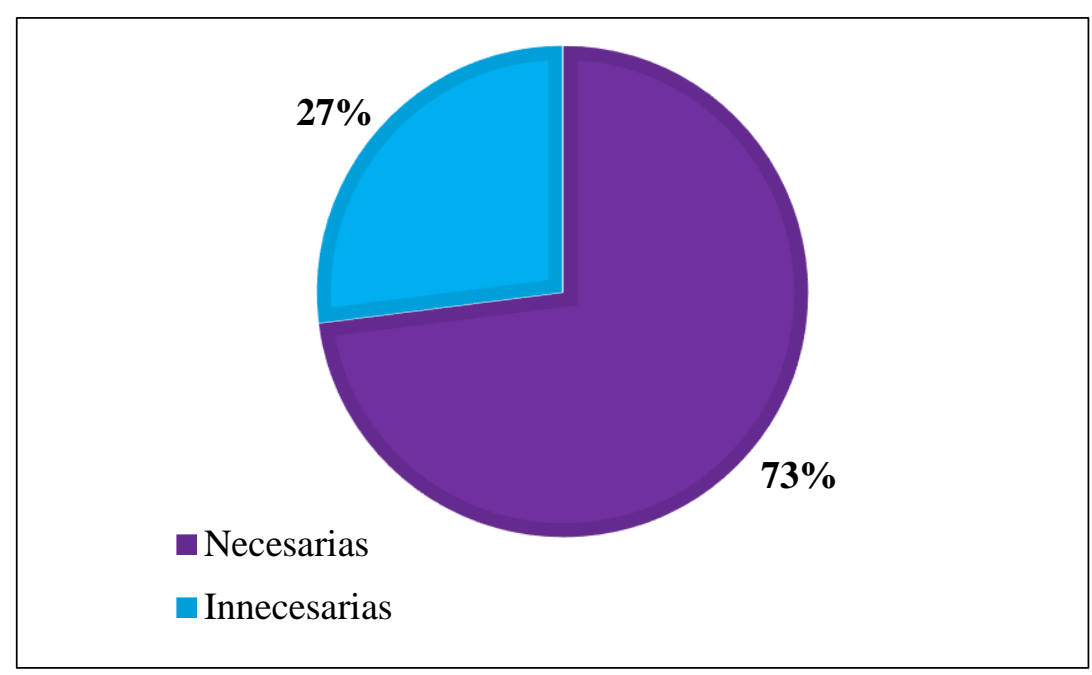

Figura 17. Proporción de la Conformidad con la Necesidad de las Nuevas Medidas Restrictivas del Estado para el Transporte 


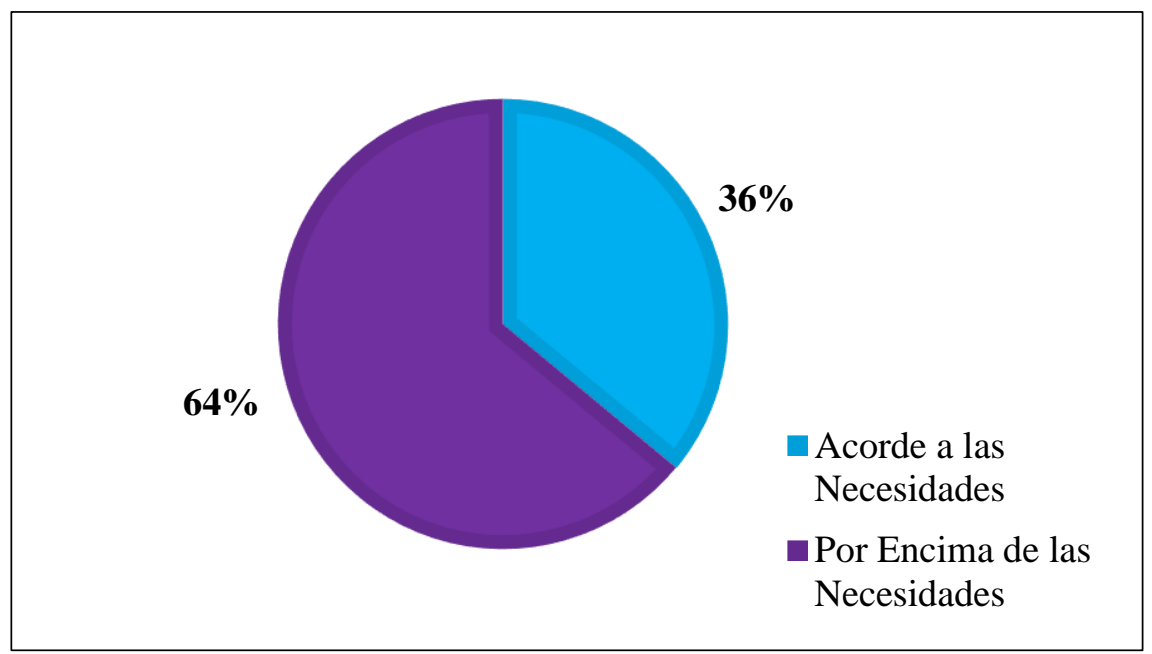

Figura 18. Proporción de la Consideración sobre el Nivel de

Concordancia y Necesidades hacía las Nuevas Medidas Restrictivas del Estado para el Transporte

¿Cuál es su opinión en cuanto a las últimas restricciones vehiculares establecidas? (Pico Placa, Velocidad a 60kh/m en Costa Verde, Restricción de Tránsito en carril izquierdo de la Panamericana en ciertos tramos para vehículos pesados y camiones)

En la Figura 19, se muestra que el 50\% de los encuestados está parcialmente de acuerdo con que estas últimas restricciones son algo necesarias, sumado a esto el $24 \%$ de los encuestados están totalmente de acuerdo con que estas medidas son necesarias y, en contraparte un $12 \%$ se encuentra parcialmente en desacuerdo, ya que piensa que son algo innecesarias. Podemos afirmar así, que la mayoría de los ciudadanos están conscientes sobre que las regulaciones son necesarias para ordenar la congestión vehicular, pero no están de acuerdo en cuanto a que sean las mejores soluciones disponibles. 


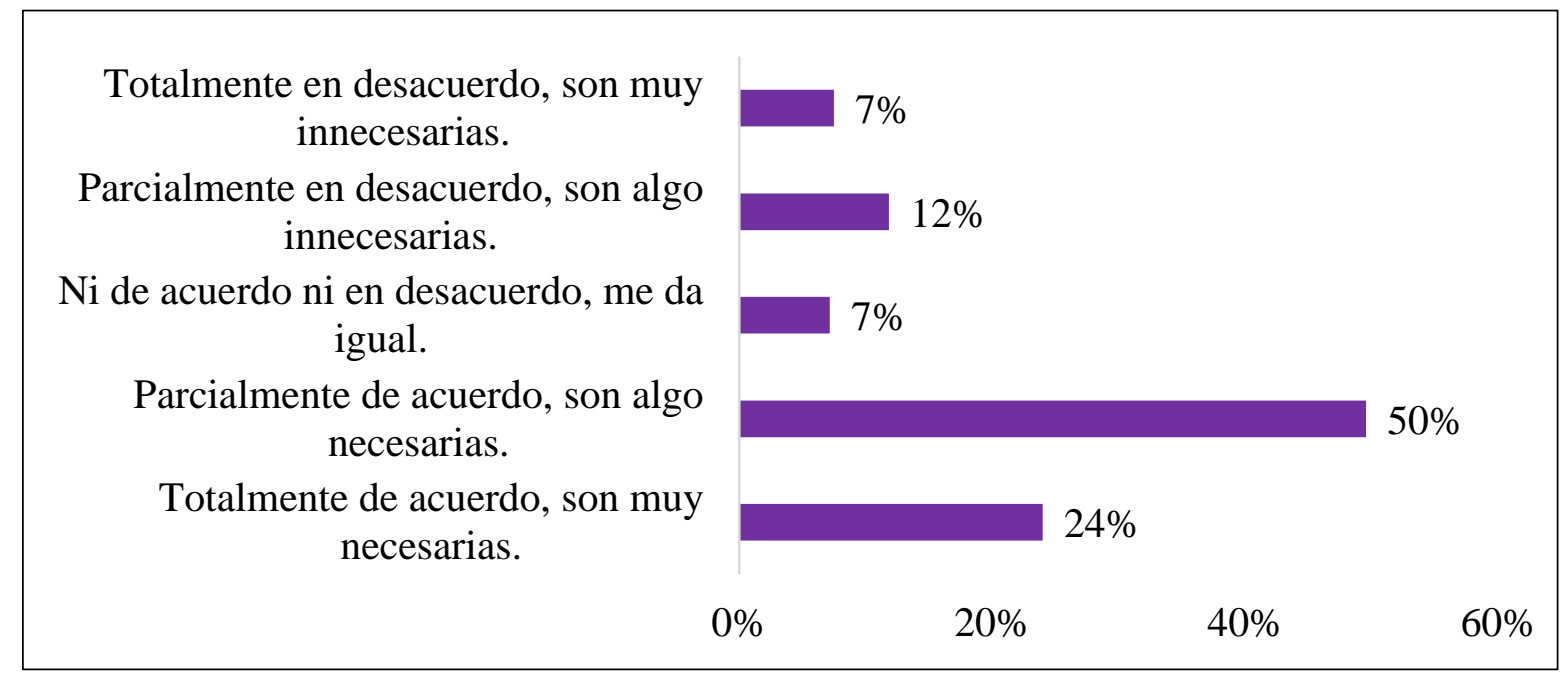

Figura 19. Opinión de los Encuestados en cuanto a las Restricciones Vehiculares

En síntesis, se puede confirmar que la mayoría de las personas se movilizan por trabajo y/o estudios casi diariamente por medio de transporte público y automóviles particulares, y que mayoritariamente no están conformes con los medios de transporte por la congestión vehicular, inseguridad y contaminación que estos generan, obteniendo tan solo un $3 \%$ de satisfacción total en la población.

El $91 \%$ de la población conoce los medios de transporte alternativos y el $65 \%$ estaría dispuesto a sustituir su medio de transporte actual debido al tráfico y congestión vehicular, preferentemente si este medio de transporte alternativo cumple con la rapidez, comodidad y funcionalidad esperados. Los encuestados buscan mantenerse en los parámetros de gasto de entre S/ 100 a S/200 o menor, y que ocupen como máximo de 30 minutos a 1 hora de viaje.

Uno de los principales motivos para evitar la sustitución de medio de transporte a uno alternativo sería la falta de vías especializadas para este tipo de vehículos y la falta de cultura vial por parte de peatones y conductores. A pesar de esto, un $37 \%$ piensa que los medios de transporte alternativos son una solución parcial al tráfico de Lima y considera que, aunque El 
Estado ha impuesto regulaciones necesarias para ordenar el tráfico, estas van por encima de lo necesario y no son congruentes con cada tipo de vehículo presente hoy en día.

Con esto se puede decir que, los limeños buscan un medio de transporte rápido y eficiente, que les dé facilidad al transportarse sin perder la comodidad y seguridad, sumado a esto se afirma que están dispuestos a invertir un poco más de dinero a cambio de obtenerlo. Además, están conscientes de los puntos débiles por parte de ellos y del Estado peruano en cuanto a aplicar nuevas posibles soluciones ante el caos vehicular. Un medio alternativo de transporte cumple con las expectativas de las personas que se transportan en Lima y una buena regulación de estos sería lo que hace falta para poder llevarlo a cabo, y comenzar el cambio.

\subsubsection{Discusión.}

Existe una relación de tipo inverso entre el parque automotor y la cantidad de vehículos alternativos en Lima, desde el 2010 al 2018. Esto se demuestra en principio con base en las importaciones de automóviles, motocicletas, bicimotos y vehículos eléctricos. En la Tabla 5 podemos observar que entre el 2017 y el 2018 las importaciones de bicimotos se incrementaron de 4846 a 7787 unidades, mientras que las importaciones de automóviles caen de 164 mil a 142 mil unidades, además, las importaciones de motocicletas se incrementan de 247 mil a 260 mil junto con un aumento de 67789 a 191215 unidades de vehículos eléctricos de dos ruedas dentro de la categoría L1, siendo el mayor aumento entre todos los tipos de vehículo analizados. Es decir, que existe una relación inversa y es consistente. 
Tabla 5 .

Importaciones por Tipo de Vehículo (En Miles de Unidades)

\begin{tabular}{ccccc}
\hline Tipo de Vehículo & 2015 & 2016 & 2017 & 2018 \\
\hline Automóviles Ligeros & 146 & 138 & 164 & 142 \\
Motocicletas & 231 & 226 & 247 & 260 \\
Bicimotos & 2 & 5 & 8 \\
Vehículos Eléctricos & & 68 & 191 \\
\hline Total & 377 & 366 & 484 & 601 \\
\hline
\end{tabular}

Fuente: Asociación Peruana Automotriz, SUNAT.

Elaboración: Propia

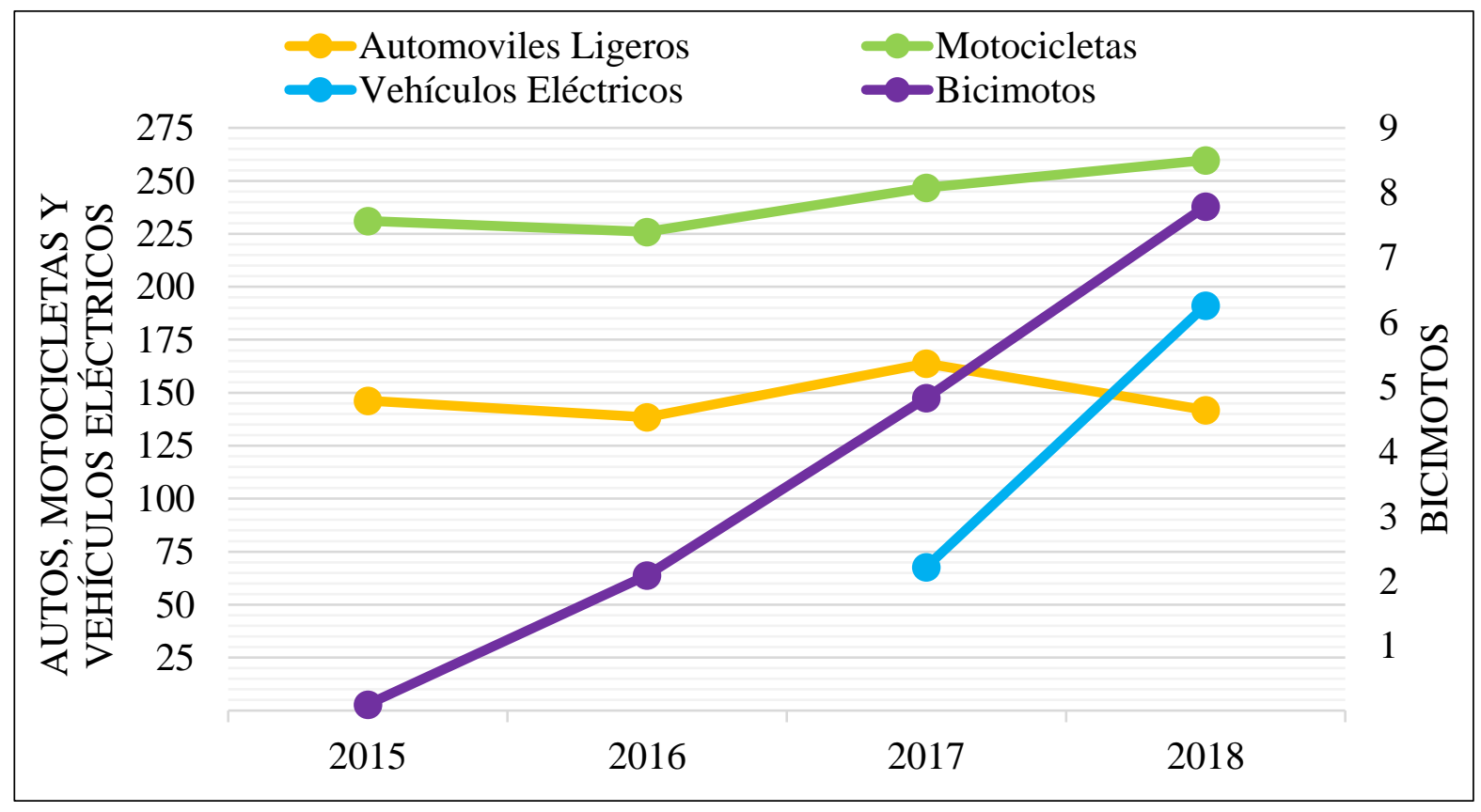

Figura 20. Comportamiento de las Importaciones por Tipo de Vehículo (En Miles de Unidades)

Fuente: Asociación Peruana Automotriz, SUNAT. 
Cabe recalcar que, la aparición de las bicimotos en el país comenzó aproximadamente hace 11 años con fines de recreación volviéndose un medio de transporte muy usado hoy en día. En 2009, se registraron tan solo dos unidades de importación de kits de motores que se volvieron 7787 unidades en el 2018, con un crecimiento de más del 3000\% en 10 años, podemos observar su evolución en la Figura 21.

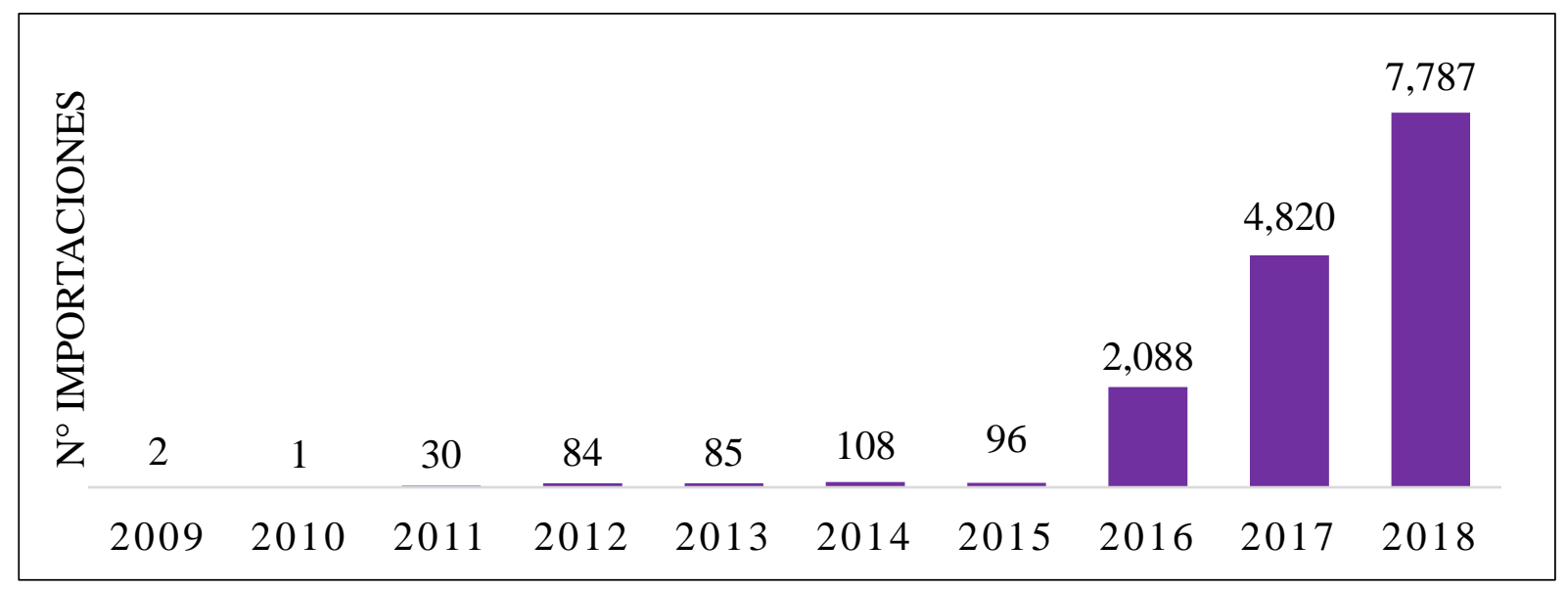

Figura 21. Evolución de las Importaciones de Kits de Bicimotos.

Fuente: SUNAT

Por otro lado, en los resultados obtenidos de la encuesta, podemos determinar que el $65 \%$ de la población encuestada optaría por sustituir su vehículo convencional por un vehículo alternativo en Lima, reforzando así la hipótesis principal. Esto se puede ver en la Tabla 6. 
Tabla 6.

¿Ha considerado sustituir su tipo de movilización actual a un medio de transporte alternativo?

\begin{tabular}{ccc}
\hline Respuesta & Frecuencia & Porcentaje \\
\hline Sí & 200 & $65 \%$ \\
No & 108 & $35 \%$ \\
\hline Total & 308 & $100 \%$ \\
\hline
\end{tabular}

Elaboración: Propia

La congestión vehicular, contaminación e inseguridad influyen en la disminución del parque automotor y aumento en la cantidad de vehículos alternativos. Según Santos De La Cruz, E. (2007), las personas consideran que los vehículos son los que generan la mayor contaminación sonora en Lima. Además, el $85 \%$ de los encuestados se encuentra muy insatisfechos con el tráfico vehicular, contaminación y seguridad, volviéndolos principales factores de sustitución de su medio de transporte ya sea privado o público afectando en la cantidad de automóviles circulantes en el parque automotor. Esto, se reafirma con el 37\% que considera como principal motivo de sustitución a la congestión vehicular, un 10\% a la inseguridad y un $6 \%$ a la contaminación como se puede ver en la Tabla 7. 
Tabla 7.

¿Qué factores lo incentivan a sustituir su medio de transporte por uno alternativo?

\begin{tabular}{|c|c|c|}
\hline Opción & Frecuencia & Porcentaje \\
\hline Tráfico/Congestión vehicular & 113 & $37 \%$ \\
\hline Precio/Economizar & 67 & $22 \%$ \\
\hline Tiempo perdido & 76 & $25 \%$ \\
\hline Inseguridad & 30 & $10 \%$ \\
\hline Contaminación & 19 & $6 \%$ \\
\hline Comodidad & 4 & $1 \%$ \\
\hline Total & 308 & $100 \%$ \\
\hline
\end{tabular}

Elaboración: Propia

Adicionalmente, IPSOS (2020) nos muestra los resultados de sus encuestas donde el 80\% de los limeños afirma que usaría su bicicleta para ir al centro de estudios o trabajo de tener ciclovías adecuadas. En este contexto, el 22 de noviembre del 2018 El Estado promulgo la Ley $\mathrm{N}^{\circ} 30936$ en donde se establece que los gobiernos regionales y locales deben proveer a los ciudadanos de las infraestructuras necesarias y adecuadas para un uso seguro de la bicicleta, para así promover su uso, disminuir el parque automotor y congestión vehicular.

Bello, E. (2002) en su estudio de generación de alternativas viables para desincentivar del uso del vehículo privado en Bogotá, nos trata de convencer sobre los efectos de la contaminación y sus efectos en la salud pública y ambiente junto con las repercusiones en los aspectos económicos de carácter urbano y ambiental, concluyendo que deberían 
implementarse controles en los indicadores de contaminación y posesión de parque automotor para poder supervisar los efectos negativos. Algunas de estas medidas fueron tomadas en Singapur, Vietnam, China, y otros países más, teniendo efectos positivos. Un ejemplo también sería Lima, Perú con las recientes restricciones de "Pico-Placa" en donde solo circulan por vías principales los vehículos con terminaciones en la placa de ciertos números; pero esta restricción solo aplica a vehículos privados y no se toma en cuenta que el mayor desorden vehicular se debe al transporte público y falta de reglas de transito junto con la ausencia de cultural vial. Un $49 \%$ de la población desaprueba esta medida y considera que solo se ha pensado en un sector que implica a vías principales y sin un sistema integrado y ordenado de transporte, por lo que solo se estaría trasladando el tráfico a otras calles (IPSOS, 2019). Alberto Flores; presidente de Transitemos nos comenta que esta medida podría ser contraproducente, ya que podría haber un aumento del parque automotor como consecuencia de compra de otros vehículos usados a fin de poder salir los días de restricción (El Comercio, 2019). Esto obliga a los usuarios a tomar transporte público u optar por otros medios alternativos generando incomodidad ya que los tiempos de viaje se incrementan en los días que hay restricciones vehiculares.

En cuanto a la inseguridad, INEI (2019) nos comenta que tres de cada diez limeños han sufrido algún tipo de acto delictivo y que la inseguridad ha aumentado un $150 \%$ respecto al 2018. Esto no escapa del transporte, donde hay 10 asaltos diarios en transporte público (El Correo, 2018) instaurando el miedo en la población para no usar estos medios de transporte. Además, en promedio siete autos son robados diariamente (Diprove, 2017) lo cual también influye en la decisión de la ciudadanía al momento de optar por un auto nuevo, ya que esto 
implica una gran inversión, pero tan solo uno de cada 5 vehículos cuenta con seguros antirrobos debido al precio adicional que conlleva encareciendo su mantenimiento (Aspeseg, 2018).

El ahorro de tiempo y dinero junto con el encarecimiento de los precios influyen en la cantidad de vehículos alternativos privados. Otros factores relevantes encontrados en la encuesta son; el ahorro de tiempo con un $25 \%$ de influencia y al precio y economía con un $22 \%$ de influencia en la sustitución de forma de transporte para los ciudadanos.

La Tabla 8 nos dice que el 42\% de los encuestados gasta en promedio de S/100 a S/200 en transporte mensualmente, por lo que sus expectativas están como mínimo en el mismo rango, pero con mayor comodidad esperada; es así que ellos no tendrían problema para sustituir su medio de transporte, ya que una motocicleta gasta en promedio S/ 40 soles semanales en un recorrido de $200 \mathrm{~km}$ aproximadamente, una bicimoto a motor de gasolina los haría gastar de S/.4.50 a S/.5.00 por un recorrido de $70 \mathrm{~km}$ aproximadamente y un vehículo eléctrico tendría un gasto hundido en los gastos de energía del hogar, por lo que se ahorraría el $100 \%$ de combustible, lo que equivale a una suma menor a la que ellos esperan gastar. 
Tabla 8.

¿Cuánto gasta en transporte mensualmente? Sea en transporte público, taxi o en su propio vehículo (combustible más otros gastos en su vehículo)

\begin{tabular}{lcc}
\hline Opción & Frecuencia & Porcentaje \\
\hline Menos de S/.100 & 71 & $23 \%$ \\
De S/.100 a S/.200 & 129 & $42 \%$ \\
De S/.200 a S/.300 & 65 & $21 \%$ \\
Más de S/.300 & 37 & $12 \%$ \\
No gasto & 6 & $2 \%$ \\
\hline Total & 308 & $100 \%$ \\
\hline
\end{tabular}

Elaboración: Propia

Neoauto (2019), nos afirma que el $90 \%$ de los encuestados estarían dispuestos a comprar un vehículo eléctrico por el ahorro que este conlleva y que existe una exoneración de Impuesto Selectivo al Consumo (ISC) a diferencia de los automóviles tradicionales para disminuir el costo de adquisición e incentivar la venta de los primeros.

Adicionalmente, La Prensa (2018) nos comenta que el 91\% de los millenials que comprenden la edad entre los 18 a 29 años, no poseen un vehículo propio privado, por lo que se transportan en transporte público como buses, microbuses y Metropolitano, y por lo que tienen una gran preocupación; la cual es la seguridad, a pesar de esto, ellos optan por no comprar un vehículo propio por cuestiones de ahorro. Por otro lado, la Tabla 9 en base a los 
encuestados nos muestra un $47 \%$ pierde diariamente de 30 minutos a 1 hora y, un $23 \%$ más de 1 hora por trayecto para desplazarse a su centro de trabajo y/o estudios. Con el uso de un transporte alternativo privado, al ser más pequeño evita quedarse atascado en el tráfico y así maximizar la eficiencia de viaje aun así teniendo menor velocidad que un automóvil.

Tabla 9.

¿Cuánto tiempo tarda en llegar a su destino?

\begin{tabular}{lcc}
\hline Opción & Frecuencia & Porcentaje \\
\hline 10 min a 15 min & 19 & $6 \%$ \\
15 min a 30 min & 74 & $24 \%$ \\
30 min a 1 hora & 144 & $47 \%$ \\
Más de 1 hora & 71 & $23 \%$ \\
\hline Total & 308 & $100 \%$ \\
\hline
\end{tabular}

Elaboración: Propia

Los problemas del parque automotor han hecho que su crecimiento se detenga. Los problemas conexos al aumento del parque automotor a parte del tráfico vehicular, contaminación e inseguridad ha ocasionado que las ventas vayan disminuyendo como por ejemplo un alza en los precios directos e indirectos y niveles de endeudamiento. Podemos observar en la Tabla 10 que en los últimos tres años la variación promedio de la venta de autos es negativa siendo $-2 \%$ mientras que las motocicletas tuvieron una variación promedio positiva de $2 \%$ lo cual es consistente con nuestra hipótesis. 
Tabla 10 .

Evolución de Ventas de Automóviles y Motocicletas (En Miles de Unidades)

\begin{tabular}{ccccc}
\hline Año & Motocicletas & Autos & Autos & Motocicletas \\
& & & Var $\%$ & Var \% \\
2015 & 267 & 157 & & \\
2016 & 268 & 154 & $-2 \%$ & $0 \%$ \\
2017 & 277 & 164 & $6 \%$ & $3 \%$ \\
\hline Promedio & 285 & 148 & $-9 \%$ & $3 \%$ \\
\hline
\end{tabular}

Fuente: Asociación Automotriz de Vehículos

Elaboración: Propia

Gestión (2019) nos señala que la disminución en las ventas de automóviles fue uno de los más altos de la región con un $6.3 \%$ debido al aumento del ISC y a la volatilidad de la moneda por las tensiones comerciales entre Estados Unidos y China. Asimismo, el ISC se incrementó como medida restrictiva del gobierno para desincentivar la venta de los vehículos debido a la alta densidad del parque automotor y los problemas que estos conllevan actualmente. Sumado a esto, podemos observar en la Tabla 11, el comportamiento del uso de los diferentes medios de transporte, en donde comparando el automóvil, motocicleta y bicicleta, podemos observar que el automóvil tiene un menor crecimiento a comparación de las otras dos opciones; esto debido a las desventajas y problemas que han surgido con los vehículos privados. 
Tabla 11.

Evolución del Uso de Tipo de Transporte (En Porcentajes)

\begin{tabular}{cccccccccc}
\hline Crecimiento & 2011 & 2012 & 2013 & 2014 & 2015 & 2016 & 2017 & 2018 & Promedio \\
\hline Autos & 2 & 0 & 88 & -42 & -3 & 1 & 11 & 4 & 8 \\
Motocicleta & 120 & 27 & 7 & -33 & -30 & 43 & 70 & -12 & 24 \\
Bicicletas & -9 & -10 & -11 & 0 & 13 & -67 & 167 & 38 & 15 \\
\hline
\end{tabular}

Fuente: Lima Cómo Vamos

Elaboración: Propia

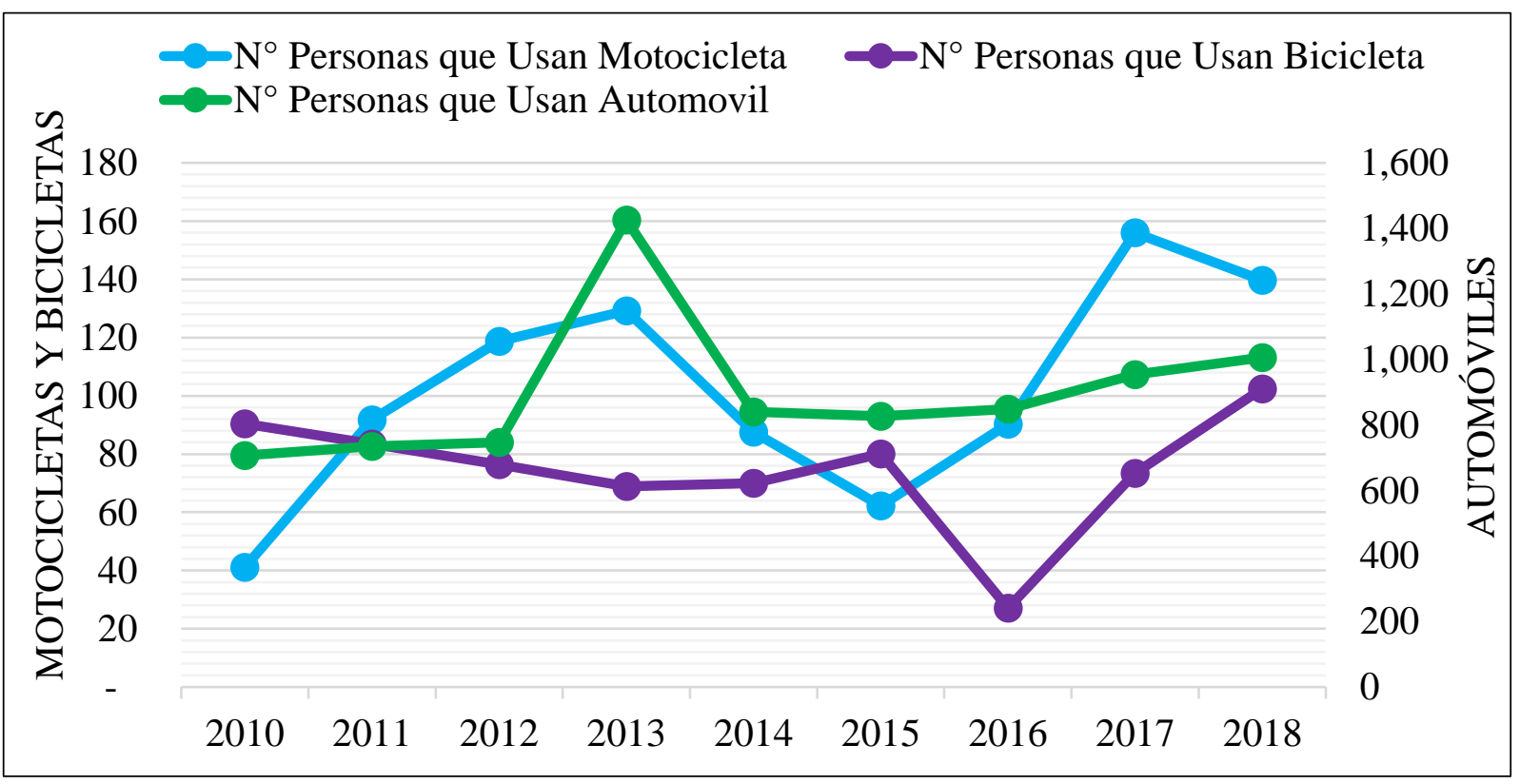

Figura 22. Uso de Tipos de Vehículos como Medios de Transporte (En Miles)

Fuente: Lima Cómo Vamos

En cuanto al nivel de endeudamiento y facilidades para obtener un vehículo de cuatro ruedas, tan solo el $20 \%$ de los automóviles adquiridos son por medio de créditos vehiculares (Asbanc, 2018) y el 50\% es al contado; es decir que, aunque un limeño quiera adquirir un 
auto, tratará de ahorrar por lo menos de 3 a 5 años para poder adquirir un vehículo de cuatro ruedas, y de querer acceder a un crédito deberán tener un salario o ingreso mensual mínimo de S/1 500 junto a un buen y conocido historial crediticio (Banco de Crédito del Perú, 2018) esto conlleva a buscar la mejor alternativa para transportarse de la manera más eficiente y económica.

Los vehículos alternativos privados son una solución viable para la congestión vehicular, contaminación e inseguridad de los conductores en Lima. Un 35\% de los encuestados está totalmente de acuerdo con que los medios de transporte alternativos privados sean una solución ante el caos vehicular, esto debido a que estos últimos ocupan menos esfuerzo económico y de espacio volviéndolo más sostenible en el tiempo, esto se ve en la Tabla 12. 
Tabla 12.

¿Considera que alguno de los medios de transporte alternativo sería una solución para el tráfico vehicular?

\begin{tabular}{lcc}
\hline Opción & Frecuencia & Porcentaje \\
\hline Totalmente de acuerdo & 109 & $35 \%$ \\
Parcialmente de acuerdo & 119 & $39 \%$ \\
De acuerdo & 59 & $19 \%$ \\
Parcialmente en desacuerdo & 18 & $6 \%$ \\
Totalmente en desacuerdo & 3 & $1 \%$ \\
\hline Total & 308 & $100 \%$ \\
\hline
\end{tabular}

Elaboración: Propia

Si bien es cierto, existe la Ley $\mathrm{N}^{\circ} 30936$ para promover el uso de la bicicleta, muy aparte de tener que construir y unir las ciclovías ya existentes en Lima, un $21 \%$ de limeños demoran de dos a tres horas en llegar a su centro de trabajo o estudios y un $12.1 \%$ más de cuatro horas (Marketwin, 2017), esto nos lleva a que un 59\% de los trabajadores considera que no se desempeñan al $100 \%$ en su labor debido al estrés que les causa transportarse de su casa al trabajo y el tiempo que conlleva (CENTRUM, 2017) por lo que no sería prudente pedirles que se transporten en bicicleta lo que involucraría manejarla por 45 minutos a 1 hora o más, haciendo referencia a que no todos guardan las mismas condiciones físicas para poder realizar esta actividad. Además, involucraría el tener que portar una muda extra de ropa para cambiarse y/o que existiesen duchas y esté permitido su uso en el centro de trabajo o estudios. Sumado 
a esto, hay que considerar la baja cultura vial que se tiene en Lima y la falta de respeto para con los vehículos menores. Rivera, J. (2015) nos proporciona en su estudio "El Uso de La Bicicleta como Alternativa de Transporte Sostenible e Inclusivo para Lima Metropolitana: Recomendaciones Desde Un Enfoque De Movilidad”, que es necesario cambiar la resistencia para modificar la infraestructura vehicular predominante y tomar en consideración los altos costos económico, sociales y medioambientales, para que así existan más medidas y se lleven a cabo priorizando la salud y comodidad del ciudadano.

Sin embargo, El Estado ha puesto trabas para detener la propagación de los medios de transporte alternativos con muchas restricciones de por medio. Ante esto, el $73 \%$ de la población considera a las restricciones necesarias, pero en contraparte el $64 \%$ considera que están parametrizadas por encima de las necesidades, dificultando el transporte y empeorando la congestión vehicular en vez de ofrecer posibles soluciones, esto se puede ver en las Tabla 13 y 14. Como es el caso del Decreto Supremo N019-2018-MTC donde se prohíbe el ensamblaje, comercialización y transporte por medio de las bicimotos, y donde para el manejo de scooters y otros vehículos eléctricos sería necesario el SOAT, brevete B-II, registro de placa e inmatriculación. Además, el uso de patines eléctricos solo podría ser para fines de recreación y no de transporte. Esta ley fue promulgada, sin embargo, no se publicaron los procesos o medidas a tomar para la formalización de los productores y comerciantes ni mucho menos para realizar los procesos de regulación de estos vehículos alternativos ya en circulación. No tomando en cuenta que dicha normatividad podría afectar no solo a miles de peruanos que se transportan en ellos diariamente, sino también a los que lo usan como medio 
de trabajo, obligándolos así a recurrir a medios que son inaccesibles o no convenientes para la población limeña.

Tabla 13.

¿Considera a las regulaciones necesarias o innecesarias para la congestión vehicular?

Opción $\quad$ Frecuencia $\quad$ Porcentaje

Considero las regulaciones necesarias para

ordenar el tráfico

$225 \quad 73 \%$

Considero las regulaciones innecesarias para

3

$27 \%$

ordenar el tráfico

Total

308

$100 \%$

Elaboración: Propia 
Tabla 14.

¿Considera que las regulaciones van concordes o por encima de lo necesario de acuerdo al tipo de vehículo?

\begin{tabular}{lcc}
\hline Opción & Frecuencia & Porcentaje \\
\hline Considero que las regulaciones van por & & \\
encima de lo necesario para estos tipos de & 197 & $64 \%$ \\
vehículo y afectan las posibles soluciones & & $36 \%$ \\
de transporte & & \\
Considero que las regulaciones van de & & \\
acuerdo a lo necesario para estos tipos de & & 111 \\
vehículo y no afecta las posibles soluciones & 308 & \\
de transporte & & \\
\hline Total
\end{tabular}

Elaboración: Propia

Finalmente, se procedió a calcular el coeficiente de correlación de Pearson, que mide la relación estadística entre dos variables continuas lineales.

Según Pearson, la relación puede estar dentro del rango de valores de +1 a -1 , en donde 0 significa que no hay asociación entre variables, un valor mayor a 0 indica una asociación positiva y un valor menor a 0 indica una asociación negativa; es decir, inversa. Los valores de 1 o -1 indican una asociación perfecta, ya sea positiva o negativa respectivamente. 
Para realizar este análisis, se tomó como base las ventas y registros de automóviles (AAP) como primera variable y la suma de las importaciones de bicimotos y vehículos eléctricos (SUNAT) bajo la clasificación de vehículos alternativos para obtener la segunda variable, cada una de ellas con 36 datos.

A continuación, se muestra la formula del coeficiente de correlación de Pearson:

$$
r_{x y}=\frac{\sum_{i=1}^{n}\left(x_{i}-\bar{x}\right)\left(y_{i}-\bar{y}\right)}{\sqrt{\sum_{i=1}^{n}\left(x_{i}-\bar{x}\right)^{2} \sum_{i=1}^{n}\left(y_{i}-\bar{y}\right)^{2}}}
$$

Se aplicó la formula a los datos mostrados en la Tabla 15, y se obtuvo un coeficiente de correlación de Pearson de -0.33 que demuestra que existe una relación estadística inversa y un nivel de sustitución entre el uso de automóviles y el mercado incipiente de los vehículos alternativos. A lo largo del intervalo de tiempo estudiado y aún con importaciones de vehículos alternativos que no son continuas, se ha logrado demostrar que existió un impacto negativo en el número de ventas y registros de automóviles, reafirmando así la relación inversa entre estos dos tipos de vehículos, en donde ya existe un nivel de sustitución. 
Tabla 15 .

Ventas de Automóviles vs. Importaciones de Vehículos Alternativos

\begin{tabular}{|c|c|c|}
\hline Período & Autos & $\begin{array}{l}\text { Vehículos } \\
\text { Alternativos }\end{array}$ \\
\hline Ene-13 & 17691 & 75 \\
\hline Mar-13 & 12856 & 10 \\
\hline Feb-14 & 12994 & 30 \\
\hline Nov-14 & 11816 & 141 \\
\hline Ene-15 & 15255 & 36 \\
\hline Мay-15 & 13064 & 30 \\
\hline Set-15 & 12561 & 30 \\
\hline Mar-16 & 13466 & 1 \\
\hline May-16 & 12904 & 1082 \\
\hline Jun-16 & 12354 & 7 \\
\hline Ago-16 & 12495 & 695 \\
\hline Dic-16 & 13714 & 303 \\
\hline Ene-17 & 14498 & 2519 \\
\hline Feb-17 & 13114 & 146 \\
\hline Mar-17 & 14449 & 151 \\
\hline Abr-17 & 11485 & 3223 \\
\hline Мay-17 & 14470 & 8360 \\
\hline Jun-17 & 13117 & 4342 \\
\hline
\end{tabular}




\begin{tabular}{|c|c|c|}
\hline Jul-17 & 12245 & 13755 \\
\hline Ago-17 & 15441 & 928 \\
\hline Set-17 & 13340 & 5995 \\
\hline Oct-17 & 12792 & 9253 \\
\hline Nov-17 & 14134 & 53232 \\
\hline Dic-17 & 14643 & 65398 \\
\hline Ene-18 & 13435 & 45783 \\
\hline Feb-18 & 12709 & 11539 \\
\hline Mar-18 & 12813 & 9788 \\
\hline Abr-18 & 14950 & 8108 \\
\hline Мay-18 & 14873 & 30982 \\
\hline Jun-18 & 11906 & 29246 \\
\hline Jul-18 & 11254 & 278283 \\
\hline Ago-18 & 11804 & 36232 \\
\hline Set-18 & 11216 & 35603 \\
\hline Oct-18 & 11708 & 40417 \\
\hline Nov-18 & 11506 & 119301 \\
\hline Dic-18 & 10236 & 52424 \\
\hline
\end{tabular}

Fuente: AAP, SUNAT. 


\subsubsection{Conclusiones.}

Se puede concluir que, en base a los resultados de la encuesta realizada a la muestra de la población, junto a la información obtenida de diferentes fuentes y realidades culturales de otros países y continentes, existe una relación entre el parque automotor y la cantidad de vehículos alternativos en Lima de tipo inverso. Se ha notado un aumento progresivo a lo largo de los años de los vehículos alternativos en el mercado, mientras existe una leve disminución de en las importaciones y ventas, por ende, el parque automotor circulante. El $80 \%$ considera como aspectos decisivos para un medio de transporte eficiente a la rapidez, funcionalidad y comodidad que este le brinde, y $65 \%$ de los ciudadanos estarían dispuestos a sustituir a su vehículo particular por un medio de transporte alternativo siempre que tenga las características anteriores.

La congestión vehicular, es el principal factor por el cual las personas buscan un medio de transporte más efectivo; ocupando el 37\% de las razones por lo que no están satisfechos con el transporte en Lima, debido a que un $70 \%$ pierde de 30 min a más de una hora de su tiempo al día trasladándose de su casa a centro de trabajo o estudios seguidos del gasto de adquisición y mantención. El cuarto factor, es la inseguridad con un $10 \%$ debido a la alta frecuencia de robos que existen diariamente y, en quinto lugar, la contaminación con un $6 \%$, aunque se nota una cultura mucho más consiente en cuanto a la necesidad de un medio ambiente saludable para preservar la calidad de vida y salud.

El ahorro de tiempo está directamente relacionado a la insatisfacción con la congestión vehicular en Lima, por lo que se busca acortar el tiempo perdido. Los medios de transporte alternativo ahorrarían el tiempo de traslado, debido a su tamaño y versatilidad, evitando los 
atascos en el tráfico. Por otro lado, el precio accesible de estos medios de transporte va concorde a las posibilidades de los trabajadores amateurs que no poseen un gran poder adquisitivo y no pueden acceder a créditos vehiculares en un $80 \%$.

Aunque el principal motivo de sustitución de un medio de transporte es la congestión vehicular, existen otras trabas que no permiten que este siga creciendo, como lo es el encarecimiento de los precios de los automóviles debido a una saturación en el mercado y aumento de impuestos sobre ellos; además, de un retraso de la economía junto a un crecimiento en el desempleo que llevan a las personas a no querer endeudarse. Sumado a esto, existe un aumento en la concientización sobre la funcionalidad que se busca en un medio de transporte, prevaleciendo el tiempo, costo, comodidad y seguridad.

Las motocicletas, bicimotos, scooters, patines y bicicletas eléctricas; son soluciones viables para un mejor sistema de transporte y está considerado como tal en un $90 \%$ de la población, principalmente porque evitarían la congestión del tráfico y permitirían un mayor ahorro en los nuevos adquisidores de estos. Emiten menos contaminación y consumen menos combustible, por lo que aun en tiempo de crisis son más fáciles de mantener económicamente, ocupan menos territorio en las vías públicas e incluso consumen energía renovable; como la electricidad. 


\subsubsection{Recomendaciones.}

La principal recomendación es incentivar al uso de vehículos alternativos de transporte bajo políticas estructuradas y coherentes con la naturaleza de estos vehículos, el $64 \%$ de la población considera que las medidas adoptadas por El Estado van por encima de lo necesario y es que, las medidas tomadas a la fecha imponen la restricción de estos vehículos o restringen su comercialización con normas no parametrizadas. Se tiene que considerar la seguridad de peatones y conductores si es que se busca difundir el uso de estos vehículos; y un 73\% está consciente de ello, pero debe ir ligado al principal motivo de adquisición de estos; los cuales son la eficiencia y economía. Podemos observar, como en Europa o Asia, no existen más restricciones a parte del uso de accesorios de seguridad y una licencia para conducir de automóvil, esto debido a que se espera que el conductor de automóvil tenga un espectro más amplio sobre las normas de tránsito.

Por lo que, también se debe buscar mejorar la cultura vial existente, para que así, exista un respeto entre todos los medios de transporte circulantes; comenzando por la imputación de sanciones reales cuando exista una falta de tránsito y una restructuración en la ética de quienes las regulan. Se recomienda aumentar por medio de campañas la concientización de la población, sean conductores o no, para respetar las reglas de tránsito y así evitar accidentes y congestión vehicular. Sumado a esto, se deberá educar a los conductores sobre el correcto uso y mantenimiento de sus vehículos; independientemente de cuál sea, para evitar fallas mecánicas que puedan propiciar un accidente y contaminación.

En segundo lugar, se tendría que reevaluar el propio sistema inteligente de transporte, es decir; los semáforos que actualmente en un $68 \%$ son arbitrarios, se propone buscar una 
automatización para que ayuden a descongestionar la congestión vehicular y así, usar otros recursos valiosos en la cadena reglamentaria de transporte, como los policías de tránsito, para que realmente ocupen su tiempo haciendo regir el cumplimiento de las normas.

Además, se tendría que aplicar medidas que desincentiven el uso del vehículo pero que tengan buena aceptación con la población conductora, esto no aplica al "Pico y placa"; ya que un $49 \%$ percibe que esto simplemente traslada la congestión vehicular de un lugar a otro y de no tener vías alternas de acceso hacía su punto de destino, significa que un día llegarían temprano, y el otro, llegarían tarde. El ISC, ha tenido efecto positivo en la disminución de las ventas en $6.3 \%$ de vehículos en 2019 , por lo que se recomienda mantenerlo y a su vez, dar beneficios en otro tipo de impuestos por usar medios alternativos de transporte.

Finalmente, para una próxima investigación sobre vehículos alternativos, y si se quiere regularizar dentro de las políticas de transporte, es necesario que se comience a construir data publica sobre las estadísticas de importación, uso y venta para que haya una correcta lectura dentro de los supervisores del medio de transporte y se puedan crear medidas regulatorias de forma transparente. 


\section{Referencias Bibliográficas}

Andina Agencia Peruana de Medios. (2017) Uno de cada tres autos vendidos en 2017 fue mediante financiamiento. Recuperado el 25 de Junio, 2020 en: https://andina.pe/agencia/noticia-unocada-tres-autos-vendidos-2017-fue-mediante-financiamiento-699885.aspx

Alternativas Económicas (2014) Trasporte // La Bici se Impone en Todo el Mundo. Medios de Transporte Alternativos. Recuperado el 18 de Agosto, 2020 en: https://alternativaseconomicas.coop/medios-de-transporte-alternativos

Beltrán, A. \& Cueva, H. (2007) Evaluación Privada de Proyectos (2da Edición). Lima: Universidad del Pacifico Centro de Investigación.

Benza, P. (2019) Scooters eléctricos: el modelo de negocio de las apps de moda qgue ingresan a Lima. Semana Económica. Recuperado en http://semanaeconomica.com/article/sectoresy-empresas/servicios/339204-scooters-electricos-el-modelo-de-negocio-de-las-apps-demoda-que-ingresan-a-

Birgit, H., Berntsen, S., Velde, S., Fyhri, A., Deforche, B., Andersen, L.\& Bere, E. (2019) From cars to bikes - The effect of an intervention providing access to different bike types: A randomized controlled trial. University of British Columbia, Canada. Recuperado el 28 de junio, 2020 en: https://doi.org/10.1371/journal.pone.0219304

Blackman, A. (2012) The increased popularity of mopeds and motor scooters: Exploring usage patterns and safety outcomes. Queesland University of Techonology. Recuperado el 05 de julio, 2020 en https://eprints.qut.edu.au/52685/1/Ross_Blackman_Thesis.pdf

BBVA Research (2019) Perú Situación Automotriz. Análisis Económico BBVA Research Latam. Recuperado el 03 de agosto en: https://www.bbvaresearch.com/wpcontent/uploads/mult/peru_automotriz_2010_tcm346-274709.pdf 
Cano, L. (2007) Importación de componentes electrónicos para el Instituto Nacional de Astrofísica Óptica y Electrónica (Tesis de Licenciatura). Recuperada en http://catarina.udlap.mx/u_dl_a/tales/documentos/lni/cano_a_fl/capitulo2.pdf

Céspedes, E., Pérez, A. \& Ruano, A. (2014) Madrid sobre ruedas: transportes alternativos. Periódico Universitario UCEM en la Web 2.0. Recuperado el 18 de agosto, 2020 en: http://generaciondospuntocero.com/madrid-sobre-ruedas-transportes-alternativos/

Compañía Peruana de Estudios de Mercado y Opinión Pública (2018) Perú: Población 2018. Market Report. Recuperado el 30 de marzo, 2019 de http://www.cpi.pe/images/upload/paginaweb/archivo/26/mr_poblacional_peru_201805.p df

Cohen, K. (2020) Human Behavior and New Mobility Trends in the United States, Europe, and China. Fondazione Eni Enrico Mattei (FEEM). Recuperado el 05 de agosto, 2020 en: https://www.jstor.org/stable/resrep21774

El Peruano (2002) Disponen fusión por Absorción por de la Superintendencia Nacional de Administración Tributaria - SUNAT con la Superintendencia Nacional de Aduanas. Decreto Supremo $\mathrm{N}^{\circ}$ 061-2002-PCM. Recuperado el 30 de marzo, 2019 de http://www.sunat.gob.pe/legislacion/sunat/ds061-2002-PCM.pdf

El Peruano (2018) Decreto Supremo que modifica el Reglamento Nacional de Vehículos, el Texto Único Ordenado del Reglamento Nacional de Tránsito - Código de Tránsito y dicta otras disposiciones. Decreto Supremo No 019-2018-MTC. Recuperado en https://busquedas.elperuano.pe/normaslegales/decreto-supremo-que-modifica-elreglamento-nacional-de-vehic-decreto-supremo-n-019-2018-mtc-1721540-2/

Fernández, J. (2018) Análisis del crecimiento económico en el Perú y su relación con las importaciones de autos asiáticos en el periodo 2010 al 2015 (Tesis para Bachiller) Recuperado 
http://repositorio.utp.edu.pe/bitstream/UTP/1145/1/Julio\%20Fernandez_Trabajo\%20de\% 20Investigacion_Bachillerato_2018.pdf

Fortún, M. (2020) Elasticidad Ingreso de la Demanda. Economipedia. Recuperado el 03 de Agosto del 2020 en https://economipedia.com/definiciones/elasticidad-ingreso-de-lademanda.html.

Gestión (2016) Flujo vehicular por unidades de peaje aumentó 12.8\% en julio del 2016. Sección: Actualidad. Recuperado el 24 de marzo, 2019 de https://gestion.pe/economia/flujovehicular-unidades-peaje-aumento-12-8-julio-2016-147935

Gestión (2018) Lima ocupa el séptimo lugar entre las ciudades con tráfico más lento de la región. Sección: Actualidad. Recuperado el 24 de marzo, 2019 de https://gestion.pe/peru/limaocupa-septimo-lugar-ciudades-trafico-lento-region-226029

Gestión. (2019) Lima entre las ciudades con el peor congestionamiento vehicular: ¿Qué lugar ocupa en el ranking? Sección: Tendencias. Recuperado el 03 de Julio, 2020 en: https://gestion.pe/tendencias/lima-ciudades-peor-trafico-269483-noticia/

Gestión (2018) Más allá de los autos: categorías, diseño y tecnología de las bicimotos. Recuperado el 30 de marzo, 2019 de https://gestion.pe/tendencias/alla-autos-categorias-disenotecnologia-bicimotos-224384

Gob.pe (2019) Obtener la Tarjeta de Identificación Vehicular (TIV). Recuperado el 30 de marzo, 2019 de https://www.gob.pe/306-obtener-la-tarjeta-de-identificacion-vehicular-tiv

Haworth, Narelle L. \& Nielson, Angela L. (2007) Motor scooters and mopeds: A growing attraction for young people. Paper presented at Australasian College of Road Safet. Recuperado el 05 de julio, 2020 en https://eprints.qut.edu.au/13023/1/13023.pdf 
Hernández, R., Fernández, C. \& Baptista, L. (2017) Metodología de la Investigación (6ta Edición). México: Interamericana Editores S.A.

Hsu, T., Tsai, C. \& Lin, Y. (2007) Comparative Analysis of Household Car and Motorcycle Ownership Characteristics. Journal of the Easter Asia Society for Transportation Studies, Vol 7. Recuperado el 07 de Julio, 2020 en: https://www.jstage.jst.go.jp/article/easts/7/0/7_0_105/_pdf/-char/ja

Infantas, F. \& Mendoza, M. (2017) Estudio de Pre-Factibilidad para La Instalación de Una Planta Ensambladora de Bici Motos Eléctricas en Lima Metropolitana. Recuperado el 09 de Julio, 2020

en: http://repositorio.ulima.edu.pe/bitstream/handle/ulima/5675/Infantas_Recharte_Francisco .pdf?sequence $=1$ \&isAllowed $=\mathrm{y}$

Instituto Nacional de Estadística e Informática (2018) Resultados Definitivos de los Censos Nacionales 2017. Tomo I. Recuperado el 30 de marzo, 2019 de https://www.inei.gob.pe/media/MenuRecursivo/publicaciones_digitales/Est/Lib1583/

La República (2018) Limeños pierden 60 horas en el tráfico al mes, según estudio. Sección: Actualidad. Recuperado el 24 de marzo, 2019 de https://larepublica.pe/sociedad/1321015lima-limenos-pierden-60-horas-trafico-mes-estudio-universidad-piura

Lee, M., Chow, J., Yoon, G. \& He, B. (2019) Forecasting e-scooter competition with direct and access trips by mode and distance in New York City. Cornell University. Recuperado el 30 de Julio, 2020 en: https://arxiv.org/abs/1908.08127

León, A. (2017). Cada hora ocurren 10 accidentes viales en las pistas del Perú | \#NoTePases. El Comercio. Sección: Transporte. Recuperado el 08 de Julio, 2020 en: https://elcomercio.pe/lima/transporte/hora-ocurren-10-accidentes-viales-pistas-perunotepases-ecpm-noticia-678682-noticia/ 
Lima Cómo Vamos (2016) VII Informe de Percepción sobre Calidad de Vida. Recuperado el 25 de Febrero, $2020 \quad$ en: http://www.limacomovamos.org/cm/wpcontent/uploads/2017/04/EncuestaLimaC\%C3\%B3moVamos_2016.pdf

Méndez, J. (2017) Parque automotor y contaminación ambiental en el Centro Histórico de Lima (Tesis de Licenciatura) en http://cybertesis.unmsm.edu.pe/bitstream/handle/cybertesis/6200/Mendez_mj.pdf?sequen ce $=1 \&$ is Allowed $=\mathrm{y}$

Ministerio de Transportes y Comunicaciones (2006) Clasificación Vehicular y Estandarización de Características Registrables Vehiculares. Resolución Directoral N4848-2006-MTC/15. $\begin{array}{llllll}\text { Recuperado el } & 30 & \text { de }\end{array}$ http://transparencia.mtc.gob.pe/idm_docs/directivas/1_0_1743_.pdf

Ministerio de Transportes y Comunicaciones (2014) Anuario Estadístico [versión electrónica]. Recuperado en file:///C:/Users/Clarita/Downloads/4422.pdf

Moreno, A. (2011) Análisis de alternativas de movilidad urbana sostenible en la zona metropolitana de San Luis de Potosí: El caso de la Bicicleta. Universidad Autónoma de San Luis de Potosí. Recuperado el 05 de Julio, 2020 en: http://ninive.uaslp.mx/xmlui/bitstream/handle/i/3543/MCA1MJC201101.pdf?sequence=3 \&isAllowed $=\mathrm{y}$

Ng, W., Schipper, L. \& Chen, Y. (2010) China Motorization Trends: New Directions for Crowded Cities. Journal of Transport and Land Use. Recuperado el 23 de Julio, 2020 en: http://www.jstor.com/stable/26189158

Ordoñez, S. (2016) Evaluación de una bicicleta eléctrica como Alternativa de Movilidad en la Ciudad de Cuenca (Trabajo de Investigación). Recuperado en http://dspace.uazuay.edu.ec/bitstream/datos/6339/1/12509.pdf 
Perú 21 (2018) El 79\% de peruanos compraría su auto a crédito. Sección: Economía. Recuperado el 30 de marzo, 2019 de https://peru21.pe/economia/neoauto-79-peruanos-compraria-autocredito-nndc-430948

Perú 21. (2018) El 79\% de peruanos compraría su auto a crédito. Sección: Economía. Recuperado el 20 de Junio, 2020 en: https://peru21.pe/economia/neoauto-79-peruanos-compraria-autocredito-nndc-430948-noticia/

Perú 21 (2019) Bicimotos y motos eléctricas, ¿la alternativa para huir del caos? Recuperado el 30 de marzo, 2019 de https://peru21.pe/lima/bicimotos-motos-electricas-alternativa-huircaos- 457513

Pita, S.\& Pértegas, S. (2002) Investigación Cuantitativa y Cualitativa. Unidad de Epidemiología Clínica y Bioestadística. Recuperado el 14 de Agosto, 2020 en: http://www.fisterra.com/gestor/upload/guias/cuanti_cuali2.pdf

Porter, M. (1997): Estrategia Competitiva. México: Editorial Continental, S.A. de C.V.

Posada, C. (2018) Aumento Continuo del Parque Automotor, un Problema que Urge Solucionar. Cámara de Comercio de Lima, Sección: Comercio Exterior. Recuperado el 25 de marzo, 2019

de https://www.camaralima.org.pe/repositorioaps/0/0/par/r816_3/comercio\%20exterior.pdf

Pongthanaisawanab, J. \& Sorapipatanaab, C. (2010) Relationship between level of economic development and motorcycle and car ownerships and their impacts on fuel consumption and greenhouse gas emission in Thailand. Renewable and Sustainable Energy Reviews. Volume 14, Issue 9, Pages 2966-2975. Recuperado el 07 de Julio, 2020 en: https://www.sciencedirect.com/science/article/abs/pii/S1364032110002145 
Publimetro (2017) ¿Cuánto dinero y tiempo gastan los limeños en movilizarse? Sección: Actualidad. Recuperado el 18 de Diciembre, 2020 en: https://publimetro.pe/actualidad/cuanto-dineroy-tiempo-gastan-limenos-movilizarse-63827-noticia/

PromPerú (2013) Regímenes Aduaneros. Recuperado el 30 de marzo, 2019 de http://export.promperu.gob.pe/Miercoles/Portal/MME/descargar.aspx?archivo=F7D6880 2-E27A-4B9C-B2E0-9544590C17D7.PDF

RRP Noticias (2017) ¿Cuánto dinero gastan los limeños para movilizarse debido al tráfico? Sección: Economía. Recuperado el 24 de marzo, 2019 de https://rpp.pe/economia/economia/quemedios-de-transporte-utilizan-los-limenos-para-movilizarse-en-lima-noticia-1070944

Rodríguez, D. A., Santana, M., \& Pardo, C. F. (2015). La motocicleta en América Latina: caracterización de su uso e impactos en la movilidad en cinco ciudades de la región. Bogotá: CAF. Recuperado el 20 de Agosto, 2020 en: http://scioteca.caf.com/handle/123456789/754

Superintendencia Nacional de Aduanas y Administración Tributaria (2008) Ley General de Aduanas. Decreto Legislativo $N^{\circ}$ 1053. Recuperado el 30 de marzo, 2019 de http://www.sunat.gob.pe/legislacion/procedim/normasadua/gja-03.htm

Superintendencia Nacional de Aduanas y Administración Tributaria (2019) Institucional: ¿Qué es la SUNAT? Recuperado el 30 de marzo, 2019 de http://www.sunat.gob.pe/institucional/quienessomos/index.html

Thomson, I. (1997) ¿Por qué las inversiones en el transporte público no reducen la congestión de tránsito urbano? Revista de la CEPAL, N 61, página 107. Recuperado el 05 de Julio, 2020 en: https://repositorio.cepal.org/bitstream/handle/11362/12049/061107118_es.pdf?sequence= 1\&isAllowed=y 
Todomotos (2013) Amigo motero: ¿Conoces a qué categoría pertenece tu moto? Sección: Papeletas y Normas de Transito. Recuperado el 08 de Julio, 2020 en: http://www.todomotos.pe/seguridad-vial/2369-moto-documentos-categoria-lima

Tuan, A. (2011) Dynamic Interactions between Private Passenger Car and Motorcycle Ownership in Asia: A Cross-country Analysis. Institute for Transport Policy Studies. Recuperado el 19 de Junio, 2020 en: https://www.jstage.jst.go.jp/article/easts/9/0/9_0_541/_article/char/en

Van, H., Fuji, S. \& Schmöcker,J. (2009) Upgrading from motorbikes to cars: Simulation of current and future traffic conditions in Ho Chi Minh City. Journals of the Eastern Asia Society for Transportation Studies. Tokio. Recuperado el 15 de Julio, 2020 en: https://www.jstage.jst.go.jp/article/eastpro/2009/0/2009_0_335/_article

Velandia, P. (2014) Criterios Metodológicos para Involucrar el Factor Moto en los Estudios de Tránsito en Bogotá. Universidad Nacional de Colombia. Recuperado el 04 de Julio, 2020 dehttps://repositorio.unal.edu.co/bitstream/handle/unal/21853/300454.2014.pdf?sequence $=1$ \&isAllowed $=\mathrm{y}$

Villalobos, J. (2016) La Bicicleta como Medio para La Disminución de Contaminación Ambiental, Accidentes de Trabajo y Enfermedades Laborales en Las Organizaciones. Universidad Militar Nueva Granada. Recuperado el 05 de Julio, 2020 en: https://repository.unimilitar.edu.co/bitstream/handle/10654/15511/VillalobosRamirezJuli anDavid2016.pdf?sequence $=1$ \&isAllowed $=\mathrm{y}$

Winslott, L. \& Svenssona, A. (2014) Could the increased use of e-bikes (pedelecs) in Sweden contribute to a more sustainable transport system?. Lund University. Recuperado el 26 de Julio, 2020 en: http://enviro.vgtu.lt/

Yannis, G., Golias, J. \& Spyropoulou, I. (2007) Mobility Patterns of Motorcycle and Moped Riders in Greece. Transportation Research Record: Journal of the Transpotation Research Board. 
Sage Journals. Recuperado el 06 de Julio, 2020 en: https://journals.sagepub.com/doi/10.3141/2031-09 


\begin{abstract}
Anexos
ANEXO 1 - Instrumento de Investigación

Estimado Señor(a):

Gracias por su tiempo. Mi nombre es Brenda Martinez Esquén, egresada de la Facultad de Ciencias Empresariales, de la carrera de International Business, de la Universidad San Ignacio de Loyola. Me encuentro elaborando mi Tesis para optar el Título Profesional de Licenciada en International Business que trata acerca de la relación entre el parque automotor y las importaciones de vehículos alternativos en Lima en el período que va entre el 2010 al 2018.

Me he propuesto evaluar el efecto de las formas alternativas de transporte urbano tales como las bicimotos, scooters y patines eléctricos en los últimos años y medir, en la medida de lo posible, la existencia de algún "efecto sustitución" de los autos usados intensivamente en nuestra ciudad.

Por tal motivo, los datos brindados serán utilizados únicamente con fines académicos y no serán publicados sino en forma agregada mostrando la tendencia promedio de las cifras. Agradezco su valioso tiempo y atención dedicado a contestar la encuesta que he elaborado para tal fin.
\end{abstract}

\title{
ENCUESTA DE MEDIOS DE TRANSPORTE ALTERNATIVOS
}

- Nombres:

- Apellidos:

- Edad:

- Distrito de Residencia:

1. ¿Con qué motivo se moviliza con mayor frecuencia?
a. Trabajo/Estudios
b. Compras
c. Transportar a un tercero (hijos, sobrinos, primos, padres, etc.)
d. Ocio

2. ¿En qué medio de trasporte se moviliza con mayor frecuencia?
a. Automóvil Propio
b. Motocicleta
c. Bicimoto
d. Scooter / Patín Eléctrico
e. Bicicleta
f. Transporte Público (Metropolitano, Buses, Trenes)
g. A Pie 
3. ¿Cuántos días a la semana se moviliza generalmente?
a. Una vez a la semana
b. De 2 a 3 veces por semana
c. De 4 a 5 veces por semana
d. De 6 a 7 veces por semana

4. ¿Cuánto tiempo tarda en llegar a su destino?
a. $10 \mathrm{~min}$ a $15 \mathrm{~min}$
b. $15 \mathrm{~min}$ a $30 \mathrm{~min}$
c. 30 min a 1 hora
d. Más de 1 hora

5. ¿Qué es lo que valora más en un medio de transporte? (Marcar según nivel que corresponda)

\begin{tabular}{|l|l|l|l|l|}
\hline Niveles/Factores & Rapidez & Comodidad & Economía & Funcionalidad \\
\hline Muy Importante & & & & \\
\hline Importante & & & & \\
\hline Algo Importante & & & & \\
\hline Sin Importancia & & & & \\
\hline
\end{tabular}

6. En la escala del 1 al 5 calificar el nivel de insatisfacción o lo que más le incomoda de los siguientes aspectos de movilizarse por las calles de Lima, donde 5 es muy insatisfactorio y 1 es poco insatisfactorio.

\begin{tabular}{|l|l|}
\hline Tráfico & \\
\hline Seguridad & \\
\hline Incomodidad & \\
\hline Contaminación & \\
\hline
\end{tabular}

7. ¿Qué tan satisfecho se encuentra con el transporte público de Lima (Metropolitano, Tren Eléctrico, Corredores Municipales, Microbuses, etc.)?
a. Totalmente Satisfecho
b. Algo Satisfecho
c. Parcialmente Satisfecho
d. Algo Insatisfecho
e. Totalmente Insatisfecho 
8. ¿Cuánto gasta en transporte mensualmente? Sea en transporte público, taxi o en su propio vehículo (combustible más otros gastos en su vehículo)
a. Menos de $5 / .100$
b. De $S / .100$ a $S / .200$
c. De $5 / .200$ a $5 / .300$
d. Más de $5 / 300$
e. No gasto

9. ¿Conoce los medios de transporte alternativos (bicimoto, scooter, patín o bicicleta eléctrica)?
a. Sí
b. No

10. ¿Ha considerado sustituir su tipo de movilización actual a un medio de transporte alternativo?
a. Sí
b. No

11. ¿Qué factores lo incentivan a sustituir su medio de transporte por uno alternativo? (Puede marcar más de una opción)
a. Tráfico/Congestión vehicular
b. Precio/Economizar
c. Tiempo perdido
d. Inseguridad
e. Contaminación
f. Otros:

12. ¿Qué le desalienta de pasarse a un medio de transporte alternativo? (Puede marcar más de una opción)
a. Falta de Ciclovías / Vías especializadas para estos medios de transporte
b. Cultura Vial de conductores / Peatones
c. Falta de definición en el reglamento peruano en cuanto a la regulación de estos vehículos
d. Precio
e. Accidentes 
13. ¿Considera que alguno de los medios de transporte alternativo sería una solución para el tráfico vehicular?
a. Totalmente de acuerdo
b. Parcialmente de acuerdo
c. De acuerdo
d. Parcialmente en desacuerdo
e. Totalmente en desacuerdo

14. ¿Considera Ud. que el Estado peruano propone soluciones para los problemas del tráfico en Lima?
a. Sí: ¿Cuáles?
b. No

15. De acuerdo a las recientes regulaciones para el uso de bicimotos y scooters eléctricos: Registro de placa, brevete, SOAT, entre otros no establecidos, copina que esto es parte de una solución para el orden del tráfico o que influye negativamente ante posibles soluciones a este? (Puede marcar más de una opción)

a. Considero las regulaciones necesarias para ordenar el tráfico

b. Considero que las regulaciones van por encima de lo necesario para estos tipos de vehículo y afectan las posibles soluciones de transporte

c. Considero las regulaciones innecesarias para ordenar el tráfico

d. Considero que las regulaciones van de acuerdo a lo necesario para estos tipos de vehículo y no afecta las posibles soluciones de transporte

16. ¿Cuál es su opinión en cuanto a las últimas restricciones vehiculares establecidas? (Pico Placa, Velocidad a $60 \mathrm{kh} / \mathrm{m}$ en Costa Verde, Restricción de Transito en carril izquierdo de la Panamericana en ciertos tramos para vehículos pesados y camiones)
a. Totalmente de acuerdo, son muy necesarias.
b. Parcialmente de acuerdo, son algo necesarias.
c. Ni de acuerdo ni en desacuerdo, me da igual.
d. Parcialmente en desacuerdo, son algo innecesarias.
e. Totalmente en desacuerdo, son muy innecesarias. 


\section{ANEXO 2 - Elasticidad Ingreso de los Automóviles En Perú}

Gráfico 12

Ingreso familiar y compras de vehículos familiares nuevos

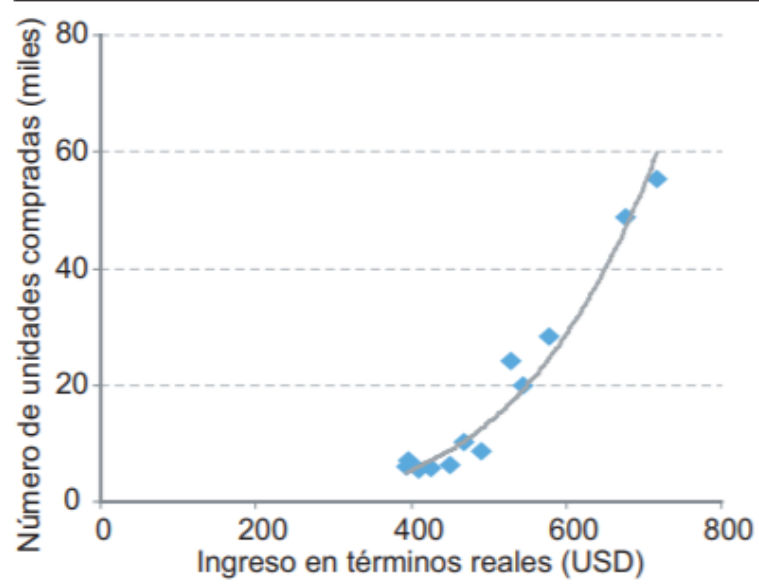

Fuente: Apoyo Opinión y Mercado, ARAPER
Gráfico 13

Estructura de la población por nivel socioeconómico (\% de la población)

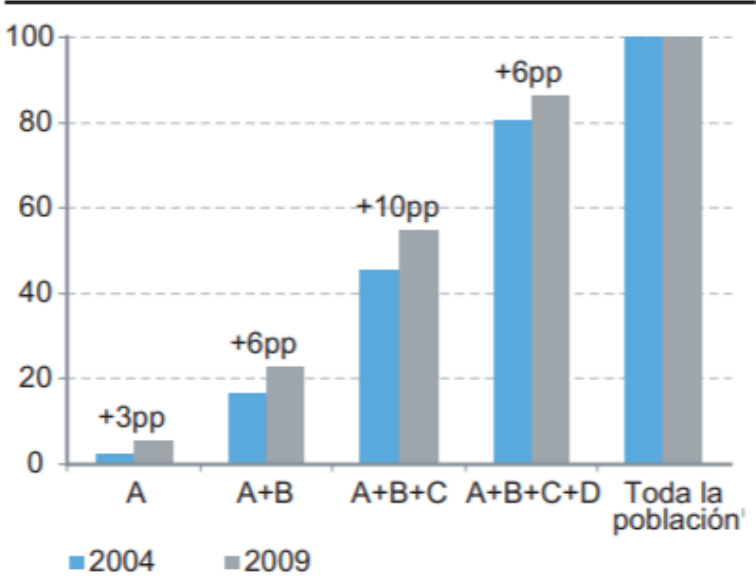

* El nivel socioeconómico A corresponde al de mayores ingresos Fuente: Ipsos Apoyo.

Tabla 4

Tenencia de Autos de Hogares

\begin{tabular}{lrrr}
\hline Autos por Hogar & Ingreso bruto (promedio) & Hogares & \% Hogares \\
\hline 0 & 17.139 & 6.483 .636 & 90,5 \\
1 & 50.183 & 594.221 & 8,3 \\
2 & 85.302 & 67.714 & 0,9 \\
3 & 135.295 & 11.196 & 0,2 \\
4 & 194.588 & 2.738 & 0,0 \\
5 & 211.668 & 558 & 0,0 \\
8 & 92.619 & 587 & 0,0 \\
Total & 20.800 & $\mathbf{7 . 1 6 0 . 6 4 9}$ & 100,0
\end{tabular}

Fuente: BBVA Research Perú a partir de la Encuesta Nacional de Hogares, 2009 


\section{ANEXO 3 - Cambio en el Comportamiento de Viaje}

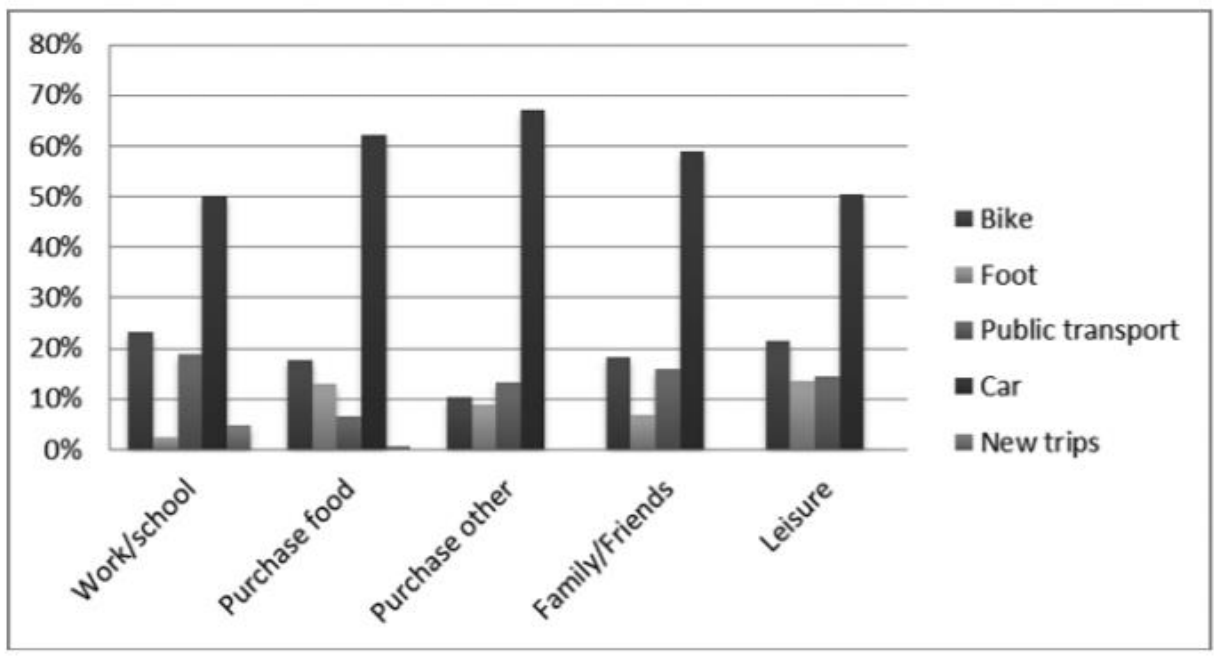

Fig. 1: Percentages distribution of the total number of e-bike journeys according to errand and transport mode

Fuente: Winslott, L. \& Svenssona, A., 2014.

\section{ANEXO 4 - Dinámica de Sustitución entre Automóviles y Motocicletas en Asia}

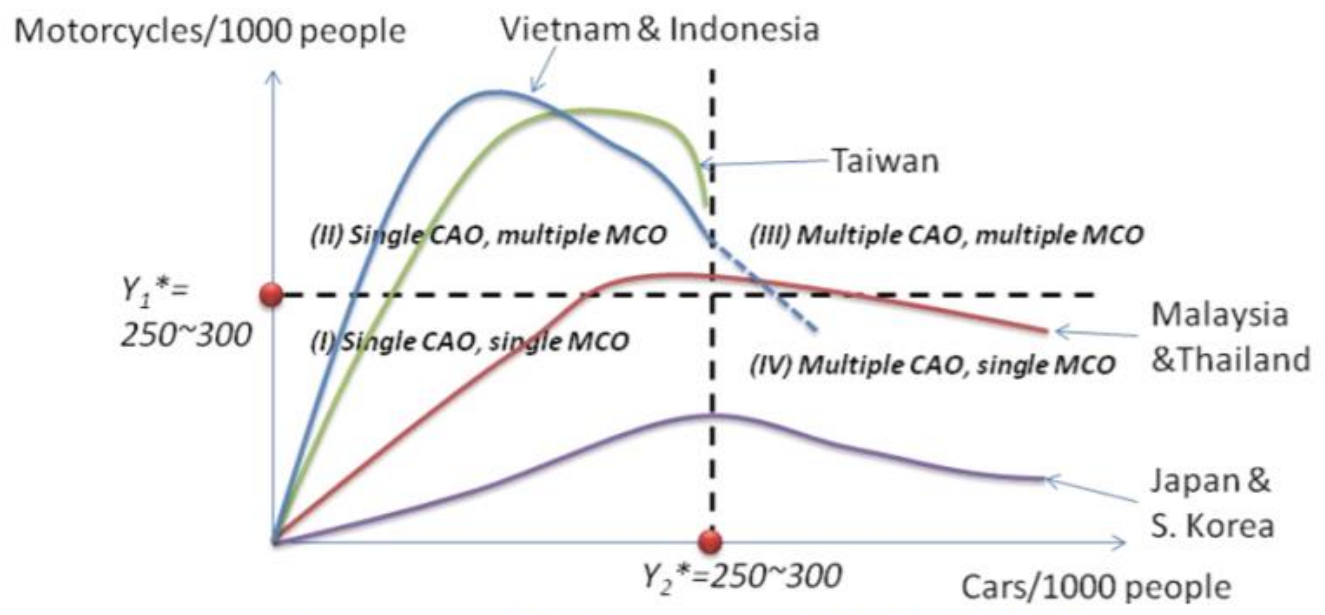

Figure 9 Scenarios of the dynamics of CAO and MCO in Asia

Fuente: Tuan, A., 2011. 


\section{ANEXO 5 - Modelo de Demanda y Factor de Viaje}

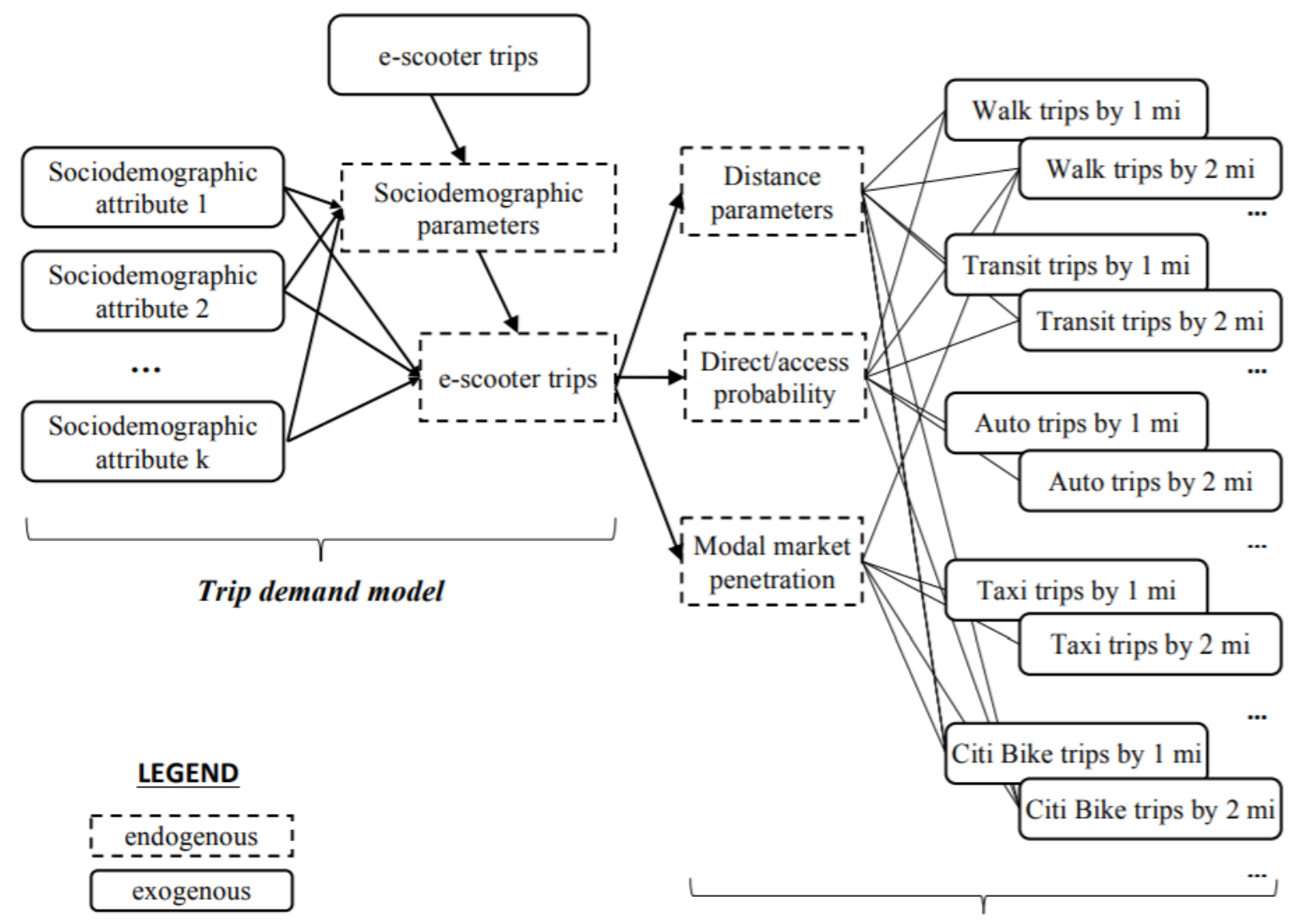

Trip factor model

FIGURE 1. Framework for research design.

Fuente: Lee, M., Chow, J., Yoon, G. \& He, B., 2019. 
ANEXO 6 - Cambio en la Velocidad Promedio si Existiera un Cambio de Motocicletas por Automóviles.

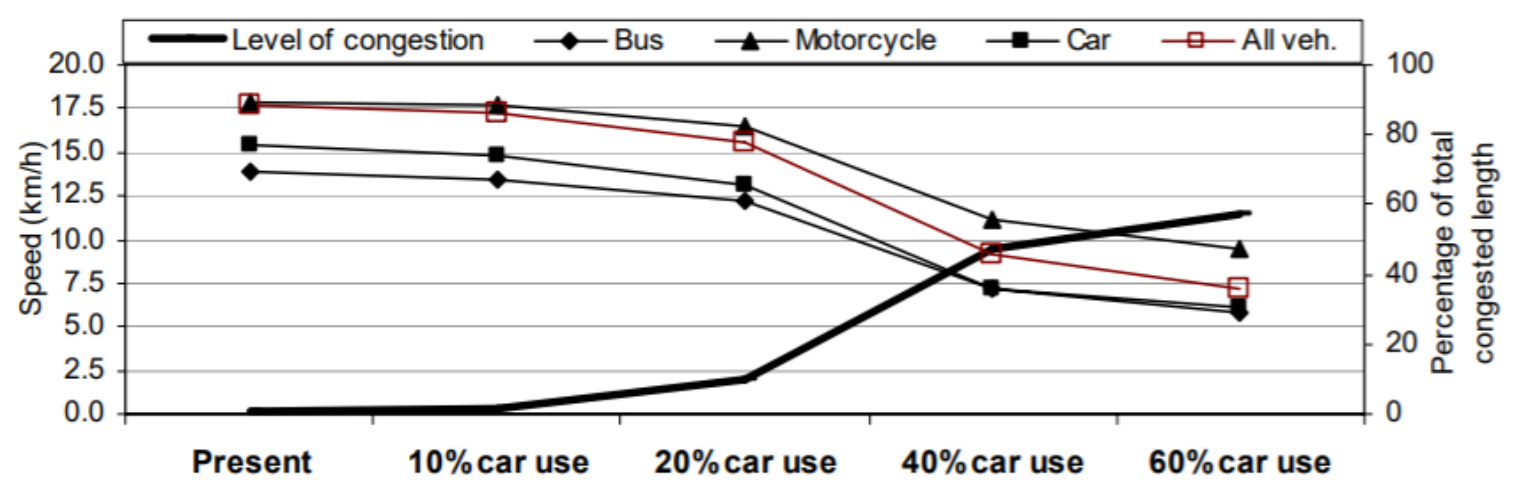

Figure 4 Average travel speed and percentage of congested part if motorcycle users shift to car use.

Fuente: Van, H., Fuji, S. \& Schmöcker,J., 2009. 


\section{ANEXO 7 - Matriz de Consistencia}

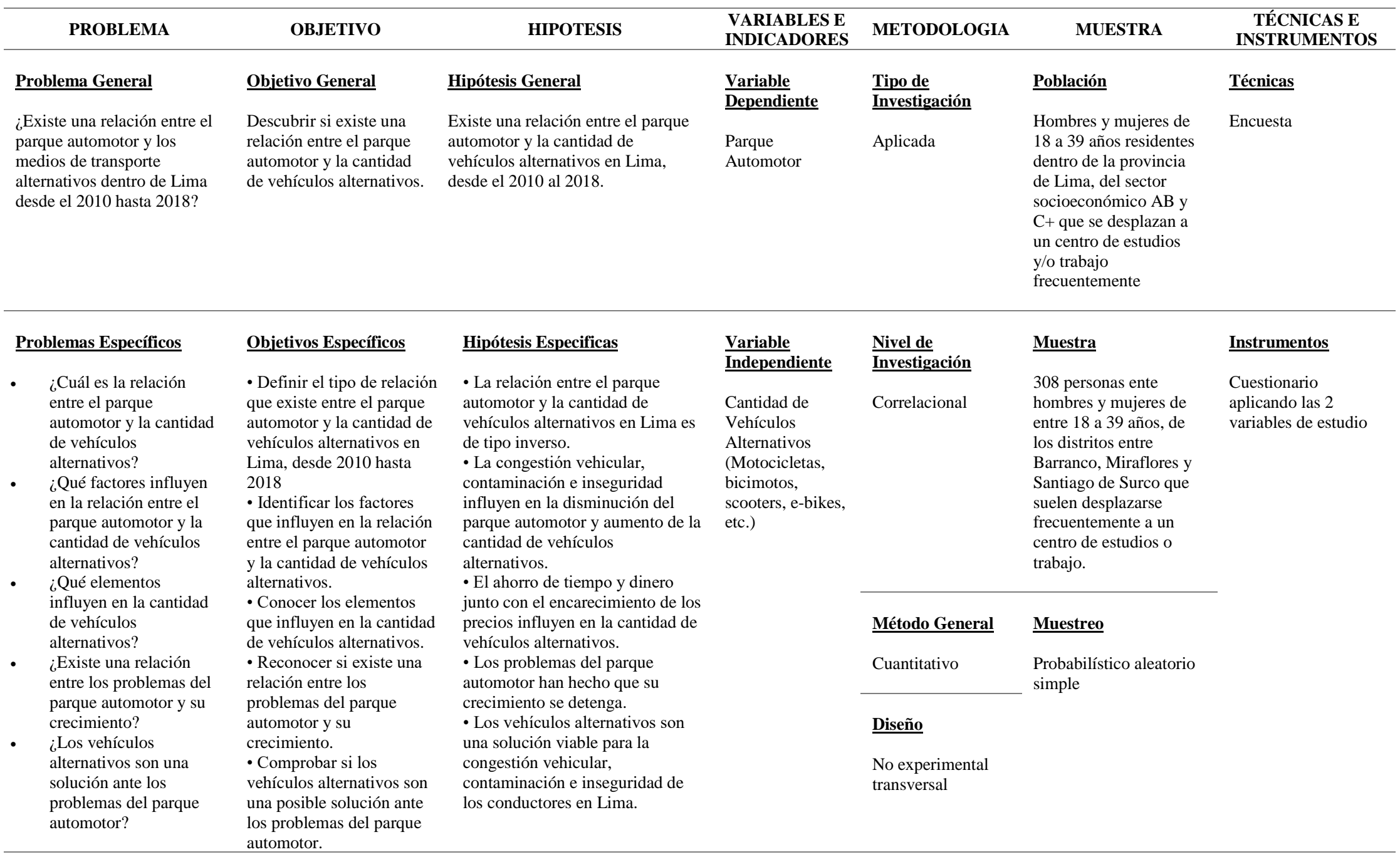

